NISTIR 7282

\title{
Estimates of Thermal Properties for Fire Fighters' Protective Clothing Materials
}

J. Randall Lawson

William D. Walton

Nelson P. Bryner

Francine K. Amon
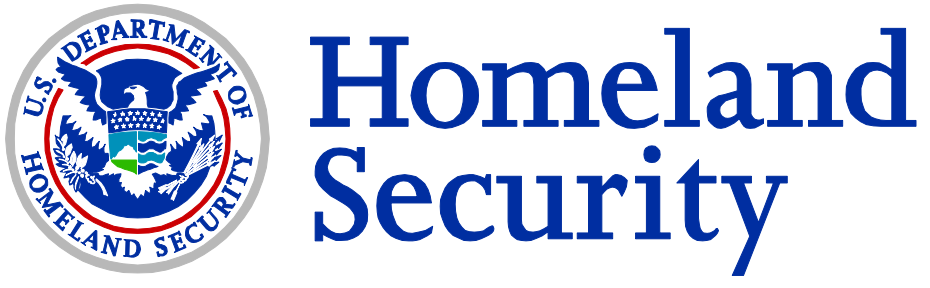

NIT

National Institute of Standards and Technology Technology Administration, U.S. Department of Commerce 
NISTIR 7282

\title{
Estimates of Thermal Properties for Fire Fighters' Protective Clothing Materials
}

Prepared for

U.S. Department of Commerce Building and Fire Research Laboratory National Institute of Standards and Technology Gaithersburg, MD 20899-8661

J. Randall Lawson William D. Walton Nelson P. Bryner Francine K. Amon

June 2005
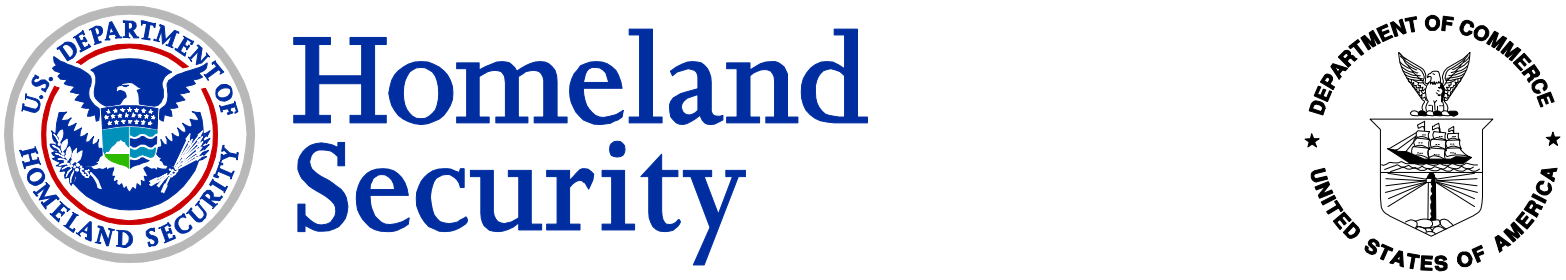

Department of Homeland Security

Michael Chertoff, Secretary

U.S. Fire Administration

R. David Paulison, Administrator

\author{
U.S. Department of Commerce \\ Carlos M. Gutierrez, Secretary \\ Technology Administration \\ Michelle O'Neill, Acting Under Secretary \\ of Commerce for Technology \\ National Institute of Standards and Technology \\ William Jeffrey, Director
}




\section{Table of Contents}

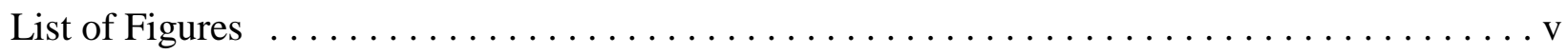

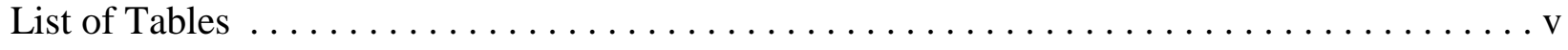

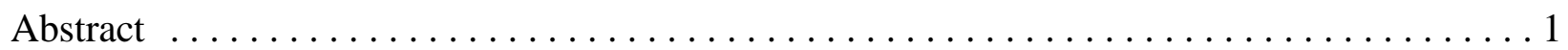

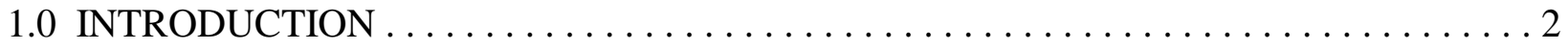

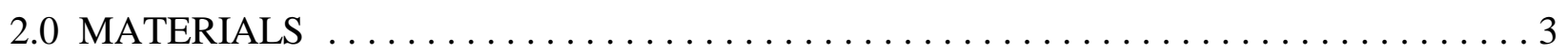

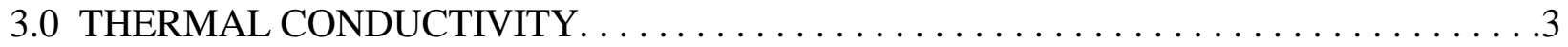

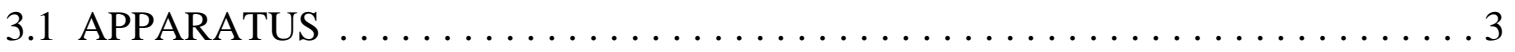

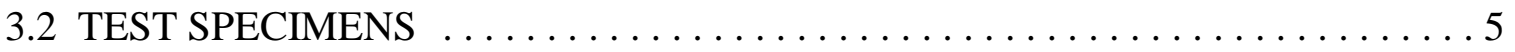

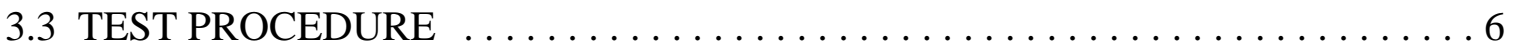

4.0 SPECIFIC HEAT $\ldots \ldots \ldots \ldots \ldots \ldots \ldots \ldots \ldots \ldots \ldots \ldots \ldots \ldots \ldots \ldots \ldots \ldots$

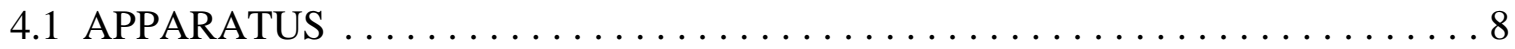

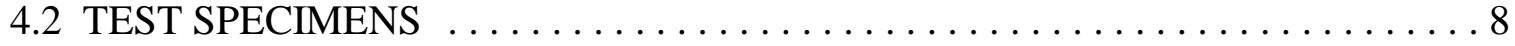

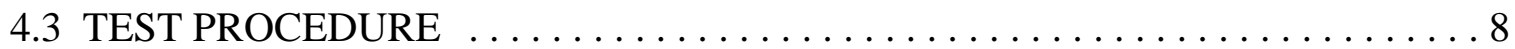

5.0 THERMO-OPTICAL PROPERTIES $\ldots \ldots \ldots \ldots \ldots \ldots \ldots \ldots \ldots \ldots \ldots \ldots$

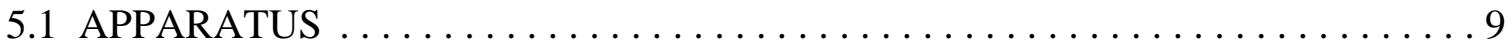

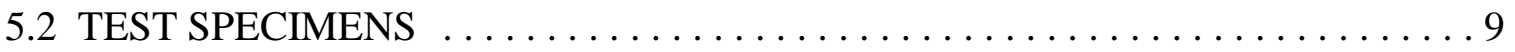

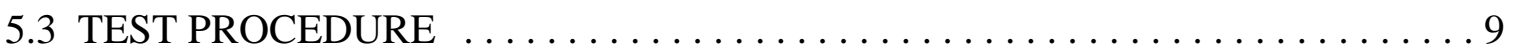

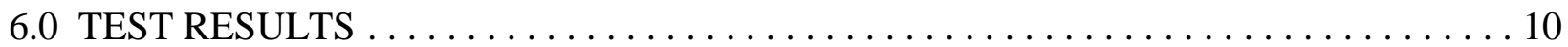

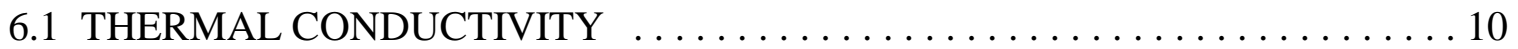

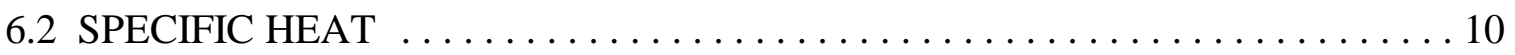

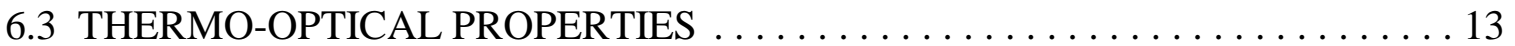

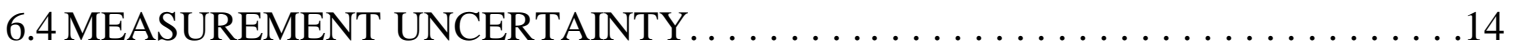

6.4.1 THERMAL CONDUCTIVITY TEST UNCERTAINTY . . . . . . . . . 15

6.4.2 SPECIFIC HEAT TEST UNCERTAINTY . . . . . . . . . . . . . . 15

6.4.3 THERMO-OPTICAL PROPERTIES UNCERTAINTY . . . . . . . . . . . . 16

6.4.4 MATERIAL PROPERTIES UNCERTAINTY . . . . . . . . . . . . . . . . 17

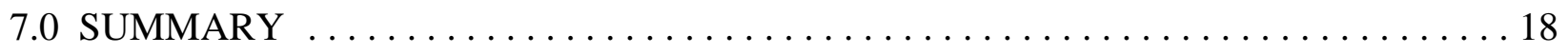

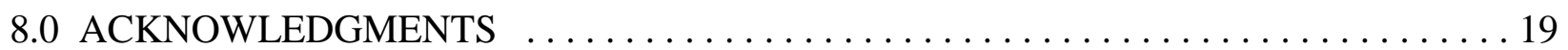

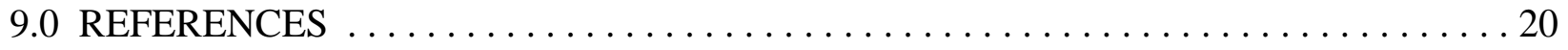




\section{Table of Contents}

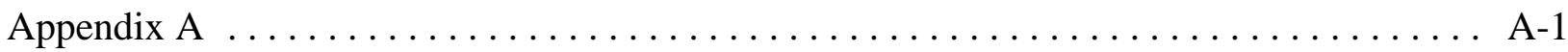

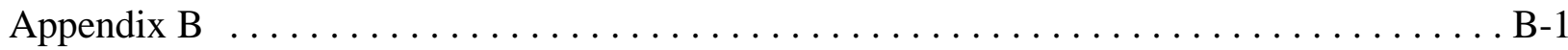

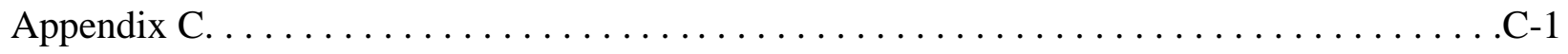




\section{List of Figures}

Figure 1 Rapid-k thermal conductivity test apparatus and computer system. . . . . . . . 5

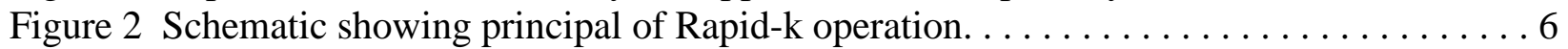

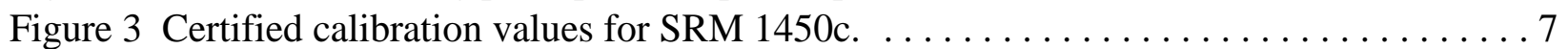

Figure 4 Estimated thermal conductivity for Aralite ${ }^{\circledR}$ and Cotton Duck. . . . . . . . . . 11

Figure 5 Estimated thermal conductivity for Breath Tex ${ }^{\circledR}$ and Neo-Guard ${ }^{\circledR} \ldots \ldots \ldots \ldots \ldots 11$

Figure 6 Estimated thermal conductivity for Breath Tex ${ }^{\circledR}$ Plus and Nomex ${ }^{\circledR}$ IIIA-Defender ${ }^{\mathrm{TM}}$.

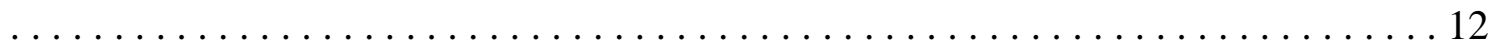

Figure 7 Estimated thermal conductivity for Nomex ${ }^{\circledR}$ E89 Crosstech ${ }^{\circledR}$ and

PBITM $^{\mathrm{TM}}{ }_{\text {Kevlar}}^{\circledR}$ Kombat $^{\mathrm{TM}}$.

Figure 8 Estimated thermal conductivity for Scotchlite ${ }^{\circledR}$ and Nomex ${ }^{\circledR}$ IIIA $\ldots \ldots \ldots \ldots 13$

\section{List of Tables}

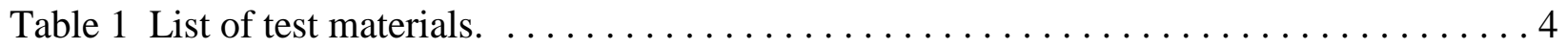

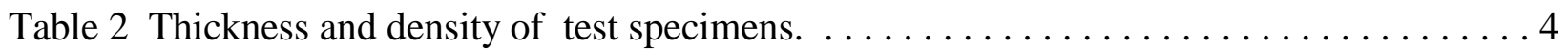

Table 3 Thermal conductivity results from $20{ }^{\circ} \mathrm{C}$ to $70{ }^{\circ} \mathrm{C} \ldots \ldots \ldots \ldots \ldots \ldots \ldots \ldots$

Table 4. Specific heat results, polynomial fit $(\mathrm{J} / \mathrm{gAC}) \ldots \ldots \ldots \ldots \ldots \ldots \ldots \ldots \ldots \ldots$ 


\title{
Estimates of Thermal Properties \\ for \\ Fire Fighters' Protective Clothing Materials
}

by

\author{
J. Randall Lawson, William D. Walton, Nelson Bryner, and Francine Amon
}

\begin{abstract}
A series of measurements has been carried out to quantify the thermal properties of materials used to fabricate fire fighters' thermal protective clothing. The thermal property measurements chosen have direct application for use in heat transfer model computations that may be used to predict the thermal performance of fire fighters' protective clothing. The thermal properties are: thermal conductivity, specific heat, and the thermo-optical properties of absorptivity, reflectivity, and transmissivity. In addition, the physical property of density was also measured. Since thermal properties vary with ambient temperature conditions, thermal conductivity measurements were made over a range of temperatures, $20^{\circ} \mathrm{C}$ to $100{ }^{\circ} \mathrm{C}$. Specific heat was measured over a range of $0^{\circ} \mathrm{C}$ to $100{ }^{\circ} \mathrm{C}$. The maximum temperature of $100^{\circ} \mathrm{C}$ was selected because it is below the temperature where material's thermal degradation occurs, and the temperature range used covers the temperatures where burn injuries occur in human skin. The thermo-optical properties data were generated only at room temperature, approximately $23^{\circ} \mathrm{C}$, since the test apparatus was not designed to operate at higher temperatures.
\end{abstract}

KEY WORDS: Absorptivity, Absorptance, fire fighters, fires, heat transfer, protective clothing, reflectivity, reflectance, specific heat, thermal conductivity, thermal properties, transmissivity, transmittance 


\subsection{INTRODUCTION}

The thermal performance of fire fighters' protective clothing is primarily based on the thermophysical properties of the materials that are used to construct the clothing and the insulating air space that is provided by the garment as a result of its design. Computer modeling and prediction of protective clothing thermal performance requires the use of numerical values of thermo-physical properties for all materials used in garment construction. Currently, little information is available for making detailed studies of protective clothing thermal performance. The work discussed in this paper describes an initial attempt to develop thermo-physical data on materials used in the construction of fire fighters' protective clothing. The physical properties used for thermal analysis and predictions are: thermal conductivity, specific heat, density, and the thermal spectral properties of emissivity, transmissivity and reflectivity [1].

Thermal conductivity $(\mathrm{k})$ of a material relates to the rate of heat transfer through the material [2]. Heat flow by this mechanism is based on the transfer of energy through motion between adjacent molecules. Therefore, insulating materials are typically lower density, lower thermal conductivity materials that have fewer numbers of molecular interfaces per unit volume. Thermal conductivity is moderately temperature dependent and therefore will vary with the amount of heat to which a material is exposed. Thermal conductivity will change for materials as the thermal exposure changes. In addition, the thermal conductivity of protective clothing systems will also significantly change when they become saturated with water or perspiration.

Specific heat of a material is a measure of how much energy the material can absorb per unit mass, per degree of rise in temperature. Examples of specific heat at work are shown by comparing the heating and cooling rates of two objects made from different materials but having the same mass. Examples: Compare a block of lead and a block of steel of the same mass heated at the same time by the same amount of energy. At the end of the heating period, the lead becomes warmer than the same mass of steel. Lead has a much lower specific heat than steel, $126 \mathrm{~J} / \mathrm{kg}$ AK as compared to $460 \mathrm{~J} / \mathrm{kg}$ AK [3]. When observing the cooling process of these two metals, it will be seen that steel with the higher specific heat will cool slower than the lead. In fire fighting, fire fighters' protective clothing typically becomes wet with water and perspiration. Water has a high specific heat, $4184 \mathrm{~J} / \mathrm{kg}$ AK [3]. As a result, it takes much more heat to cause a change in the water temperature. However, when the protective clothing gets wet the high specific heat of water causes the garment to retain its heat, and it cools at a very slow rate as compared to the air it displaced in the garment.

The radiative properties of materials relate to how the materials respond to and transmit electromagnetic energy. Emissivity is closely related to the property of absorptivity and is measured as a comparison to the emissive power of a black body at the same temperature. Therefore, emissivity of a material's surface is the ratio of its emissive power to that of a black body at the same temperature [2]. Emissivity, like absorptivity, is high for most nonmetallic materials and is low for polished metal surfaces. In addition, emissivity and absorptivity vary with spectral wavelength. Transmissivity is simply the fraction of incident radiant energy transmitted through a material and reflectivity is the 
fraction of energy reflected from a material. Infrared transparent substances like some gases and some liquids will transmit most incident thermal radiation through the substance, and polished solid surfaces, particularly those made from metals, will have high reflectivities [2].

The thermal properties measurements generated for the protective clothing materials in this study were developed over a range of temperatures below that where visible physical changes occur to the material surface. Observed physical changes in materials would indicate that the materials are beginning to degrade. As a result, the steady state measurement of material's performance would be compromised.

\subsection{MATERIALS}

Ten different materials were measured in these studies. See Table 1. Each of these material types except one, cotton duck, has been used in the fabrication of fire fighters' protective clothing. Some early fire fighter coats were made from a cotton duck material similar to the one in this study; however, the cotton duck on the early coats was usually coated with rubber to repel water. That construction would be similar to the one exhibited by Neo-Guard ${ }^{\circledR}{ }^{1}$. Of the materials tested, five were moisture barriers, three were outer shell fabrics, one was a thermal liner, and one represented retroreflective trim used on fire fighters' protective clothing. Even though this group of materials does not cover all of the materials currently used to fabricate fire fighters' protective clothing, it does represent a significant fraction of the materials that have been used. All fabric materials tested were received from the manufacturer rolled as bolts.

\subsection{THERMAL CONDUCTIVITY}

Reference [4] contains the thermal conductivity measurement details for each of the ten materials addressed in the document. The following summarizes information for this research study [4].

\subsection{APPARATUS}

The test equipment used to obtain thermal conductivity data reported in this document was constructed to operate in accordance with ASTM C 518, Standard Test Method for Steady-State Thermal Transmission Properties by Means of Heat Flow Meter Apparatus [5]. Thermal conductivity measurements were made using a commercially manufactured test apparatus. The apparatus used was a Holometrix, Rapid-k, Model VT400-A with computer control and data logging. Figure 1 shows a photograph of the test apparatus. The apparatus was calibrated using NIST Standard Reference Material (SRM) 1450c, a fibrous glass board insulation. The ASTM C 518 standard is a comparative method for measuring thermal conductivity that is based on apparatus calibrations obtained from the

\footnotetext{
${ }^{1}$ Certain commercial equipment, instruments, or materials are identified in this paper in order to adequately specify the experimental procedure. Such identification does not imply recommendation or endorsement by the National Institute of Standards and Technology, nor does it imply that the materials or equipment identified are necessarily the best available for the purpose.
} 
Table 1 List of test materials.

\begin{tabular}{|c|c|c|}
\hline MATERIAL* & MANUFACTURER & USE \\
\hline Aralite $\AA$ & Southern Mills & Thermal Liner \\
\hline Breathe-Tex ${ }^{\circledR}$ & Alden Industries & Moisture Barrier \\
\hline Breathe-Tex®Plus & Alden Industries & Moisture Barrier \\
\hline Cotton Duck & Not Available & Outer Shell \\
\hline Nomex ${ }^{\circledR}$ E-89 Crosstech $®$ & W.L. Gore \& Associates & Moisture Barrier \\
\hline Neo-Guard $\AA$ & Alden Industries & Moisture Barrier \\
\hline Nomex@ III- Defender ${ }^{\mathrm{TM}}$ & Southern Mills & Outer Shell \\
\hline Nomex® IIIA Pajama Check-Crosstech® & W.L. Gore \& Associates & Moisture Barrier \\
\hline PBI $^{\mathrm{TM}}$ Kevlar® Kombat ${ }^{\mathrm{TM}}$ & Southern Mills & Outer Shell \\
\hline Scotchlite $\AA$ & $3 \mathrm{M}$ & Trim \\
\hline
\end{tabular}

* Aralite ${ }^{\circledR}$, Defender ${ }^{\mathrm{TM}}$, and Kombat ${ }^{\mathrm{TM}}$ are registered trademarks of Southern Mills. Breathe-Tex®, and Neo-Guard®are registered trademarks of Alden Industries.

Nomex ${ }^{\circledR}$, and Kevlar® are registered trademarks of E.I. Du Pont.

Crosstech ${ }^{\circledR}$ is a registered trademark of W.L. Gore \& Associates.

$\mathrm{PBI}^{\mathrm{TM}}$ is a registered trademark of the Celanese Corporation.

Scotchlite ${ }^{\circledR}$ is a registered trademark of $3 \mathrm{M}$, Minnesota Mining and Manufacturing Company.

Table 2 Thickness and density of test specimens.

\begin{tabular}{|c|c|c|}
\hline Material & $\begin{array}{c}\text { Thickness } \\
(\mathrm{mm})\end{array}$ & $\begin{array}{r}\text { Density } \\
\left(\mathrm{kg} / \mathrm{m}^{3}\right) \\
\end{array}$ \\
\hline Aralite $®$ & 3.59 & 74.2 \\
\hline Breathe-Tex $®$ & 1.22 & 120.7 \\
\hline Breathe-Tex®Plus & 1.12 & 179.4 \\
\hline Cotton Duck & 1.32 & 518.9 \\
\hline Nomex $\AA$ E-89 Crosstech $®$ & 0.96 & 143.1 \\
\hline Neo-Guard® & 0.55 & 597.4 \\
\hline Nomex $®$ III- Defender $\square$ & 0.82 & 316.9 \\
\hline $\begin{array}{c}\text { Nomex } ® \text { IIIA Pajama Check } ® \\
\text { Crosstech® } \\
\end{array}$ & 0.52 & 316.8 \\
\hline PBI $^{\mathrm{TM}}$ Kevlar® Kombat $\square$ & 0.80 & 321.8 \\
\hline Scotchlite $\AA$ & 0.75 & 81.6 \\
\hline
\end{tabular}




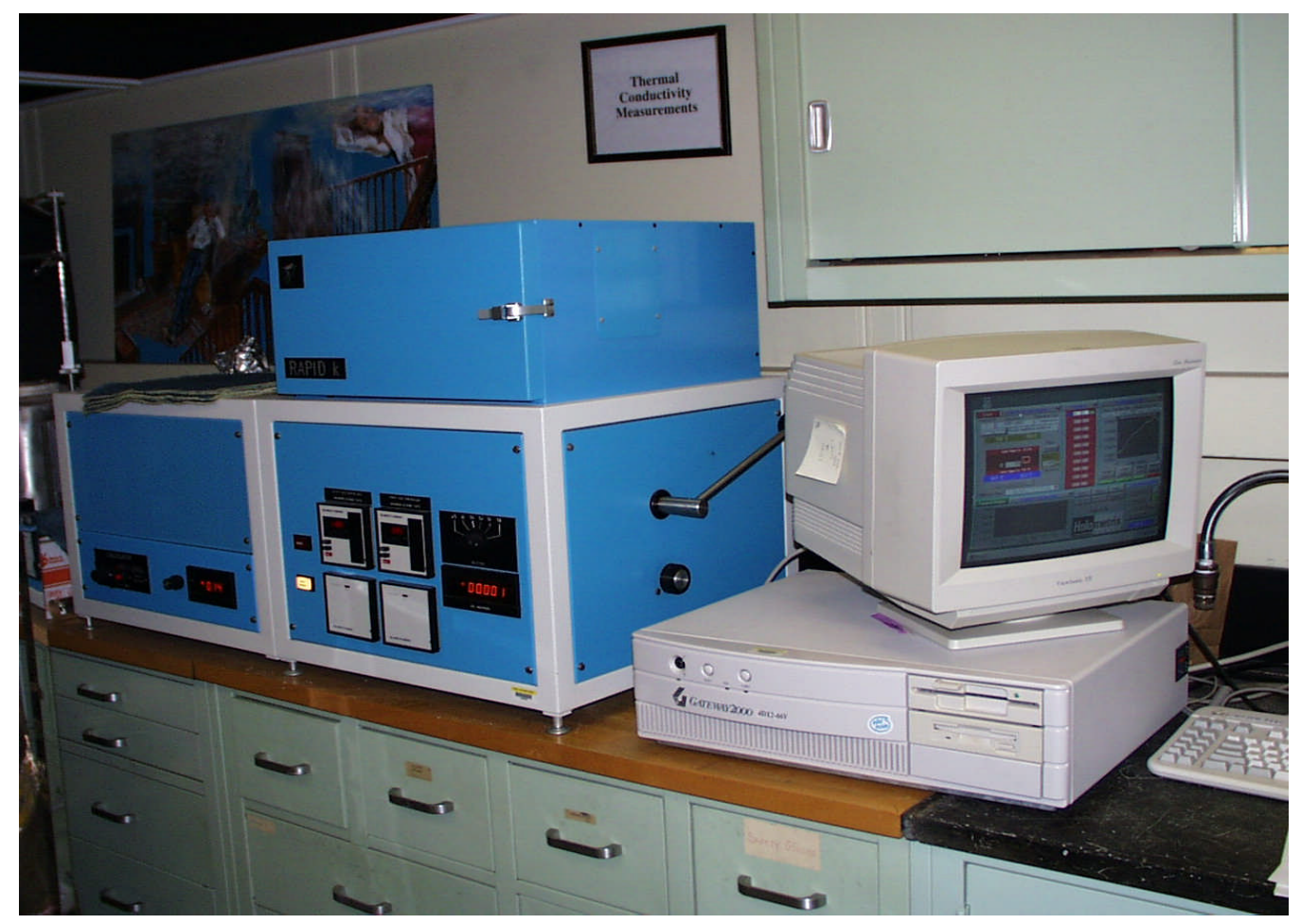

Figure 1 Rapid-k thermal conductivity test apparatus and computer system.

SRM. The heat flow meter apparatus establishes a steady state one-dimensional heat flux through the test specimen that is located between two parallel plates that are controlled at constant but different temperatures (Figure 2). Fourier's law of heat conduction is used to calculate thermal conductivity. Computer software used for calculating thermal conductivity is based on ASTM C 1045, Practice for Calculating Thermal Transmission Properties for Steady State Conditions [6].

\subsection{TEST SPECIMENS}

Test specimens were cut from the rolls of materials received from the manufacturers. The Rapid-k test apparatus requires that specimens measure $305 \mathrm{~mm}$ x $305 \mathrm{~mm}$ (12 in x 12 in) square. Specimen sizes were marked on the materials using a felt tipped ink pen, and then each specimen was cut from the roll using scissors. Specimens were cut from each material and were stacked until they reached a height of $25 \mathrm{~mm}$ ( 1 in). The number of cut specimens varied between different materials based on the material's thickness. After all specimens were cut, three specimens were randomly selected from each set of materials. The specimen's dimensions were carefully measured using a ruler for large 


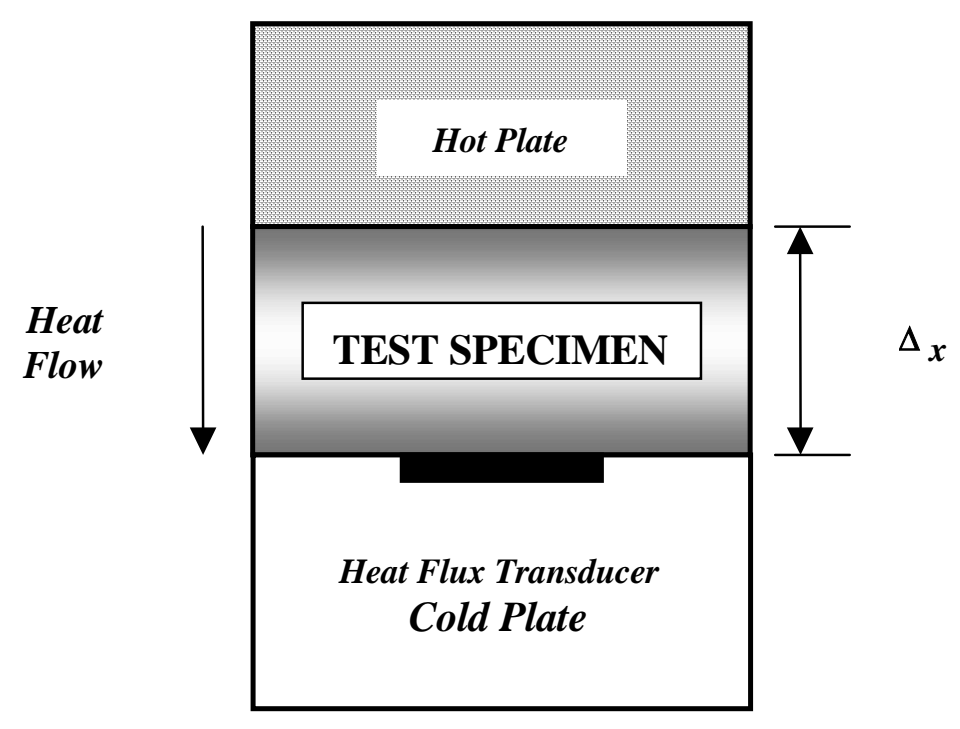

Figure 2 Schematic showing principle of Rapid-k operation.

dimensions and a micrometer for thickness. A magnifying lens was used to monitor contact/compression during the thickness measurements in order to insure that the micrometer made contact with the specimens, but did not compress the specimen. There was a minimum of twelve measurements made for each specimen dimension. Average dimensions were then calculated. In addition, each specimen was weighed using a laboratory balance to determine its mass. The density for each material was calculated using the collected data. See the results in Table 2.

\subsection{TEST PROCEDURE}

Thermal conductivity for each of the materials was measured at four different temperatures: 20/C (68/F), 48 /C (118/F), 55 /C (131/F), and 72 /C (162/F). These temperatures were selected from ASTM C1055, Standard Guide for Heated Systems Surface Conditions That Produce Contact Burn Injuries, and cover the range of temperatures that produce burn injuries [7]. The 20/C (68/F) temperature represents room temperature, $48 / \mathrm{C}(118 / \mathrm{F})$ represents a human tissue temperature where a first degree burn occurs, $55 / \mathrm{C}(131 / \mathrm{F})$ is the human tissue temperature that is likely to cause a second degree burn [8], and $72 / \mathrm{C}(162 / \mathrm{F})$ is the human tissue temperature where an instantaneous burn injury is likely to occur.

Before testing, specimens were conditioned to mass equilibrium (moisture uptake) in a controlled laboratory environment. This environment was $23 / \mathrm{C} \pm 3 / \mathrm{C}(73 / \mathrm{F} \pm 5 / \mathrm{F})$ and a $50 \% \pm 10 \%$ relative humidity. Test room conditions were the same as the conditioning environment. The following test procedures were used to measure thermal conductivity for each of the materials at each of the temperatures listed above. The mean temperature for each of the test conditions was established by 
adjusting the thermally controlled apparatus plates so there would be a temperature difference of $15 / \mathrm{C}(27 / \mathrm{F})$ between the plates. Two replicate tests were conducted on each of the materials, at each mean temperature setting, and each specimen stack thickness. Before material specimens were tested, SRM 1450c was used to calibrate the test apparatus at one of the four selected mean test temperatures [9][10] . Calibration values for SRM 1450c are shown in Figure 3. Calibration using the SRM provided the apparatus computer program with a reference thermal conductivity for the mean temperature setting. This reference value was calculated from the response of the apparatus heat flow meter. After the calibration was completed and verified, testing began. The mass of each test specimen stack was measured and recorded. The specimen stack was placed into the test apparatus and positioned on the lower plate. The test apparatus was closed by raising the lower plate and specimen until the specimen's top surface was in direct contact with the upper plate. Thespecimen and lower plate were locked into place. A transducer attached to the lower plate of the apparatus provided a measurement of specimen thickness, and specimen density was calculated using the mass data developed earlier. The test apparatus remained in automatic mode throughout the test period when the specimen reached a steady-state temperature condition. At this point, the computer program calculated and recorded the specimen's thermal conductivity.

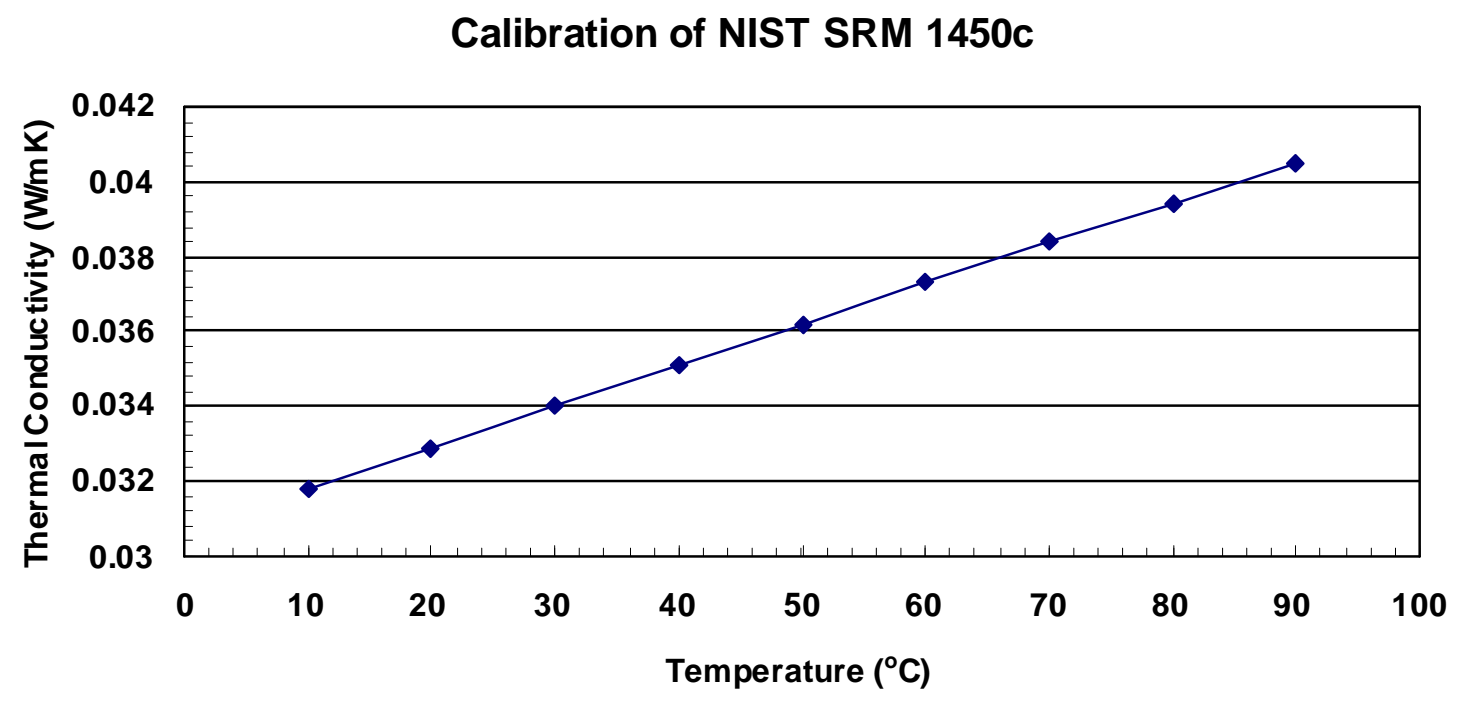

Figure 3 Certified calibration values for SRM 1450c.

\subsection{SPECIFIC HEAT}

The complete Report of Analysis for the specific heat measurements is found in Appendix A. Descriptions of the apparatus, and test procedure are drawn from this report. 


\subsection{APPARATUS}

A differential scanning calorimetry (DSC) was used to measure the specific heat of the ten materials. The instrument used to make these measurements was a Perkin-Elmer DSC7 Differential Scanning Calorimeter. The DSC7 operation is based on a power compensated "null balance" principle where energy absorbed by a test specimen is compensated by adding an equivalent amount of electrical energy to a heater located in the apparatus specimen holder. This measurement of specific heat is based on a comparison of energy required to maintain a specimen at a given temperature as compared to the energy required to maintain a standard reference material at the same temperature. For additional information on this test and to review the original data plots see Appendix A.

\subsection{TEST SPECIMENS}

The test materials were conditioned in a $23 / \mathrm{C} \pm 3 / \mathrm{C}(73 / \mathrm{F} \pm 5 / \mathrm{F})$ and a $50 \% \pm 10 \%$ relative humidity environment for more than six months before test specimens were prepared. Twelve specific heat test specimens were cut from each of the materials using a punch that cut test specimens measuring $4.3 \mathrm{~mm}(0.170 \mathrm{in})$ in diameter. The test specimens for each material were placed in a clean glass vial and sealed with a screw top until they were removed for testing. Prior to testing, each specimen was weighed and placed in a specimen pan. The edges of the pans were rolled to seal the cover of the pan and keep the specimen in thermal contact with both the pan's bottom and cover. Rolled edge specimen pans were used for all test specimens except Cotton Duck, Nomex ${ }^{\circledR}$ E-89 Crosstech ${ }^{\circledR}$, and Neo-Guard ${ }^{\circledR}$. These three materials were difficult to encapsulate, and they were tested in pans without rolled edges.

\subsection{TEST PROCEDURE}

The test method used for making specific heat measurements was ASTM E1269, Standard Test Method for Determining Specific Heat Capacity by Differential Scanning Calorimetry [11]. Before testing began, the DSC was calibrated. The temperature for the fusion of water and indium were used to calibrate the temperature axis of the apparatus output. The NIST Standard Reference Material (SRM) 720 was used for specific heat capacity calibration[12]. This SRM is made from a synthetic sapphire. In addition, the specific heat of an empty test specimen pan was measured to correct for the thermal effects produced by the pan. The test specimen was then measured. Automatic and continuous adjustment of heater power (energyper unit time) was necessary to keep the test specimen temperature identical to that measured for the SRM 720 specimen used for apparatus calibration. DSC measurements were made across a range from $-10 / \mathrm{C}$ to $110 / \mathrm{C}(14 / \mathrm{F}$ to $230 / \mathrm{F})$, and heat capacities were calculated for each material across the range of $0 / \mathrm{C}$ to $100 / \mathrm{C}(32 / \mathrm{F}$ to $212 / \mathrm{F})$. Three DSC test specimens of each of the protective clothing materials were prepared and their specific heat was measured. The three measurement values were averaged and the results are reported in section 6.2. 


\subsection{THERMO-OPTICAL PROPERTIES}

The complete test report for protective clothing thermo-optical properties is contained in Appendix $\mathrm{B}$ of this report. The following descriptions of the apparatus, test procedure, and precision were drawn from this report.

\subsection{APPARATUS}

Measurements forreflectance and transmittance of the protective clothing specimens were made using an optical radiation source with wavenumber selectivity produced by a Bio-Rad FTS-60a Fourier Transform Infrared (FTIR) spectrophotometer that was configured with a ceramic-coated global source and a Ge-coated $\mathrm{KBr}$ beamsplitter. The $50 \mathrm{~mm}$ diameter output beam from the FTIR was focused onto an external $4 \mathrm{~mm}$ diameter aperture with $\mathrm{f} / 4$ optics and re-collimated before being focused at the sample position. The incident beam had a f/6 focusing geometry, with a central axis tilted $8^{\circ}$ with respect to the specimen normal, and the spot size on the specimen measured approximately $10 \mathrm{~mm}$ in diameter. Spectral directional-hemispherical reflectance and transmittance of the protective clothing specimen materials were measured over the range of $550 \mathrm{~cm}^{-1}$ to $6500 \mathrm{~cm}^{-1}$, with a spectral resolution of $16 \mathrm{~cm}^{-1}$. This directional-hemispherical measurement geometry was implemented using a diffuse-gold coated $150 \mathrm{~mm}$ diameter integrating sphere, with the specimens mounted on a port cut into the sphere's surface. A liquid-nitrogen cooled photoconductive $\mathrm{HgCdTe}$ detector was mounted on top of the sphere with a field of view restricted to a portion of the bottom surface of the sphere. The measurement apparatus is housed in a purged environment where water vapor and $\mathrm{CO}_{2}$ have been largely removed from the atmosphere, and the tests are conducted at a temperature of $23^{\circ} \mathrm{C} \pm 0.5^{\circ} \mathrm{C}$. A detailed description of the apparatus and measurement procedure are given by Hanssen and Kaplan [13].

\subsection{TEST SPECIMENS}

Square test specimens measuring approximately $50 \mathrm{~mm}$ on a side were cut from each of the sample materials. The specimens were handled only with clean plastic laboratory gloves, and mounted onto the integrating sphere apparatus described above by clamping them under an aluminum washer having a $25 \mathrm{~mm}$ diameter hole that allowed optical access. For the Scotchlite material, two pieces were prepared to test both the silver strip and the red surface.

\subsection{TEST PROCEDURE}

The measurement procedure for developing direction-hemispherical reflectance and transmittance consisted of three processes. A reference measurement was made first. This reference spectrum reference was acquired as the incident beam travels through the reference port and strikes the integrating sphere wall at a point where the specularly reflected or transmitted beam from the test specimen struck. Second, the sphere was rotated so that the beam entered the sphere through the entrance port and was reflected from the test specimen. Finally, the sphere was rotated so that the 
beam was incident on the outside surface of the test specimen and the beam was transmitted through the specimen into the sphere. Reflectance and transmittance measurements were repeated three times to develop an average value for each property. For materials that had different finishes on the front and back surfaces, they were removed from the apparatus, turned over, and another set of three measurements was made.

The directional-hemispherical reflectance and transmittance were calculated as the ratios of the last two measurements to the first measurement, times a correction factor needed to account for the difference in throughput of the sphere for light incident on the specular position of the sphere wall, versus light scattered from the specimen which fills the entire sphere. Test specimen absorptance was derived using the following equation: $A_{b}=1-R_{f}-T_{r}$ where $A_{b}$ is absorptance, $R_{f}$ is reflectance and $\mathrm{T}_{\mathrm{r}}$ is transmittance.

\subsection{TEST RESULTS}

\subsection{THERMAL CONDUCTIVITY}

Data from each of the test temperature conditions were analyzed by linear regression, and the single layer thermal conductivity was estimated using the generated linear equation for each material and condition combination. Test results giving the least square equation for thermal conductivity $(\mathrm{k})$, at temperature (T), the correlation coefficient for the data $\left(\mathrm{R}^{2}\right)$, and a calculated $\mathrm{k}$ value at $20^{\circ} \mathrm{C}$ are shown in table 3.

These data show that the thermal conductivity generally increases as exposure temperature increases. Only one material, Neo-Guard, showed noticeable deviation within this trend. Plots showing thermal conductivity are presented in Figures $4-8$. Note that this is not in the same order as found in earlier tables. The materials selected for each graph were grouped to minimize overlapping data sets.

As a comparison, the following are thermal conductivity values reported for some materials similar to those measured in this study: Cotton, $0.0589 \mathrm{~W} / \mathrm{mK}$ [14]; wool felt, $0.0519 \mathrm{~W} / \mathrm{mK}$ [14]; silk, $0.0364 \mathrm{~W} / \mathrm{mK}$ [14]; protective clothing shell fabric, $0.0470 \mathrm{~W} / \mathrm{mK}$ [15]; hard rubber, $0.1506 \mathrm{~W} / \mathrm{mK}$ [9]; soft rubber, $0.012 \mathrm{~W} / \mathrm{mK}$ [16]; glass wool insulation, $0.038 \mathrm{~W} / \mathrm{mk}$ [16]. Thermal conductivity values for the referenced materials listed above generally fall within the range of values measured for materials discussed in this report. Some variation in thermal conductivity would be expected with the comparative values shown in this paragraph since the finished form of the material and density were not generally reported by the reference documents.

\subsection{SPECIFIC HEAT}

Three specimens of each protective clothing material were measured for specific heat. The values were averaged, plotted, and a regression analysis was conducted. The letter report and the original data plots for these measurements are located in Appendix A. Polynomial fits were conducted on the 


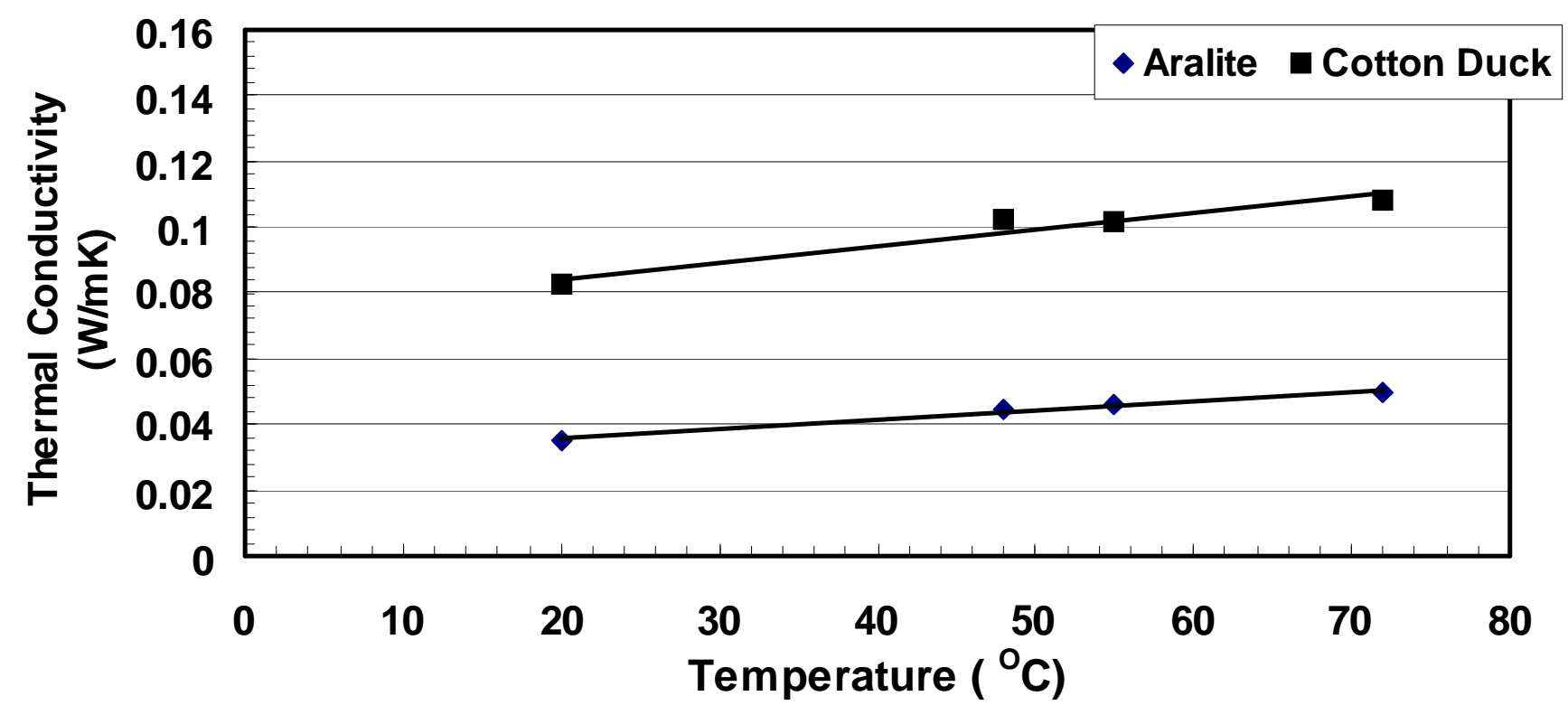

Figure 4 Estimated thermal conductivity for Aralite ${ }^{\circledR}$ and Cotton Duck.

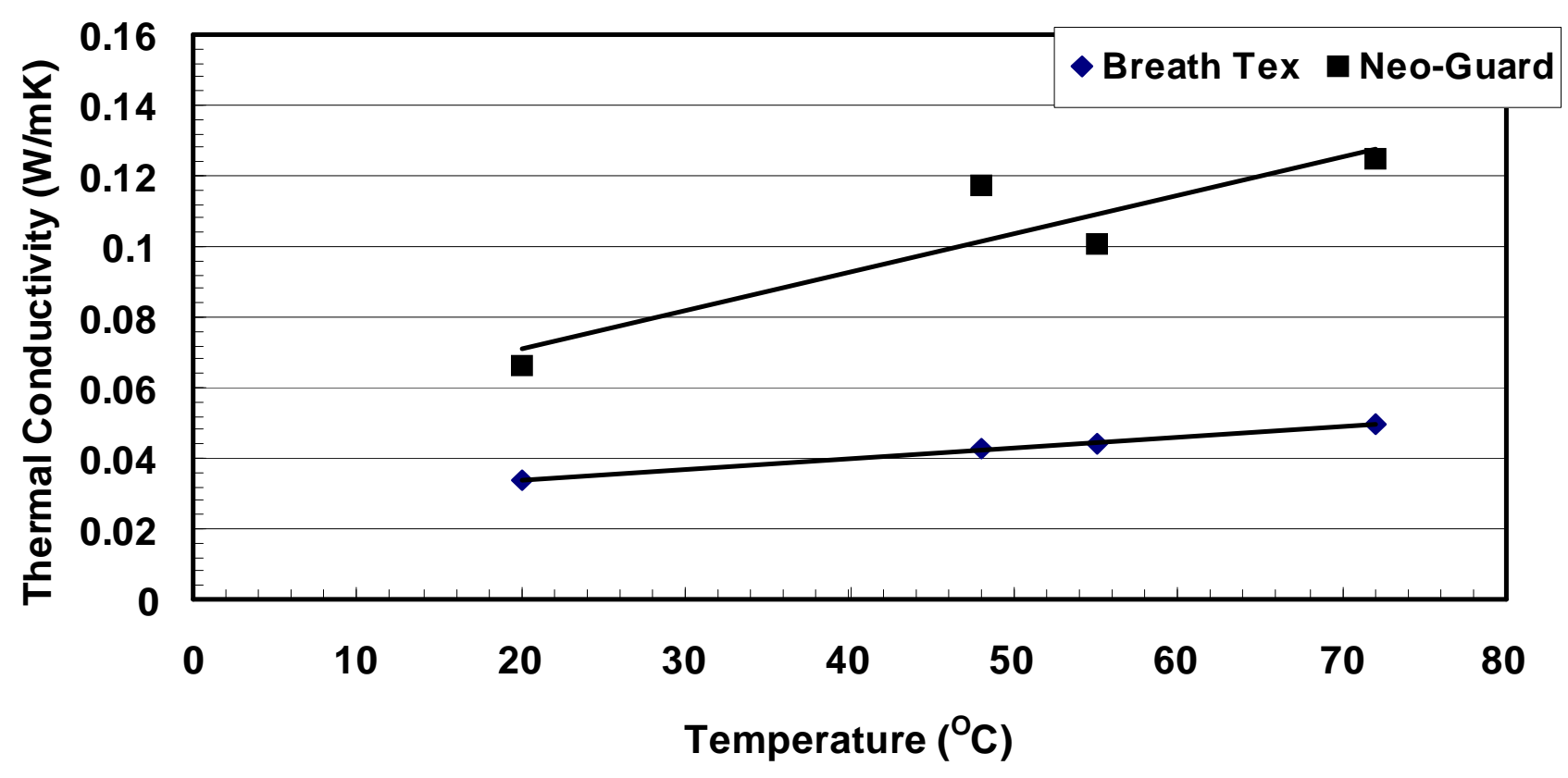

Figure 5 Estimated thermal conductivity for Breath Tex ${ }^{\circledR}$ and Neo-Guard ${ }^{\circledR}$. 


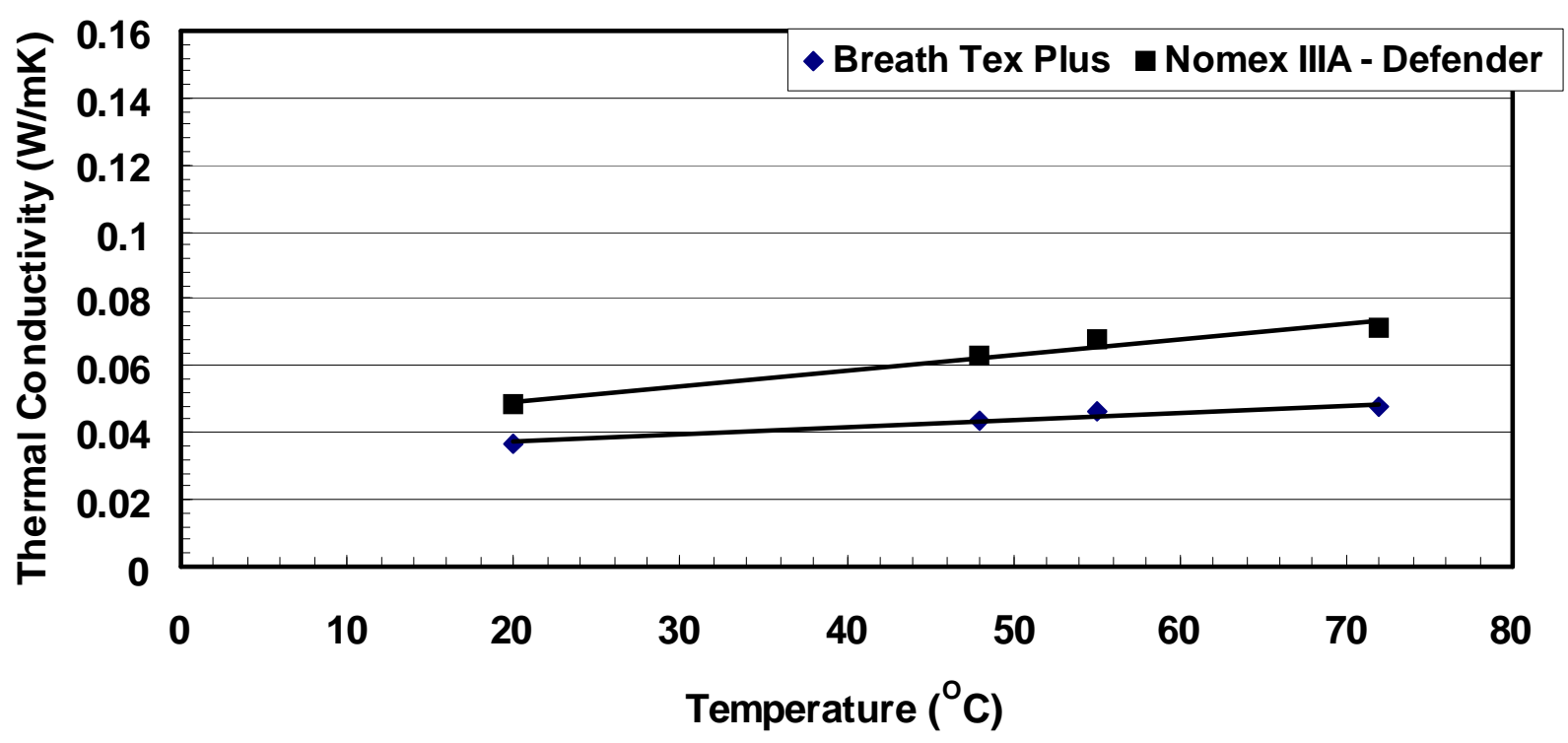

Figure 6 Estimated thermal conductivity for Breath Tex ${ }^{\circledR}$ Plus and Nomex ${ }^{\circledR}$ IIIA-Defender ${ }^{\text {TM }}$.

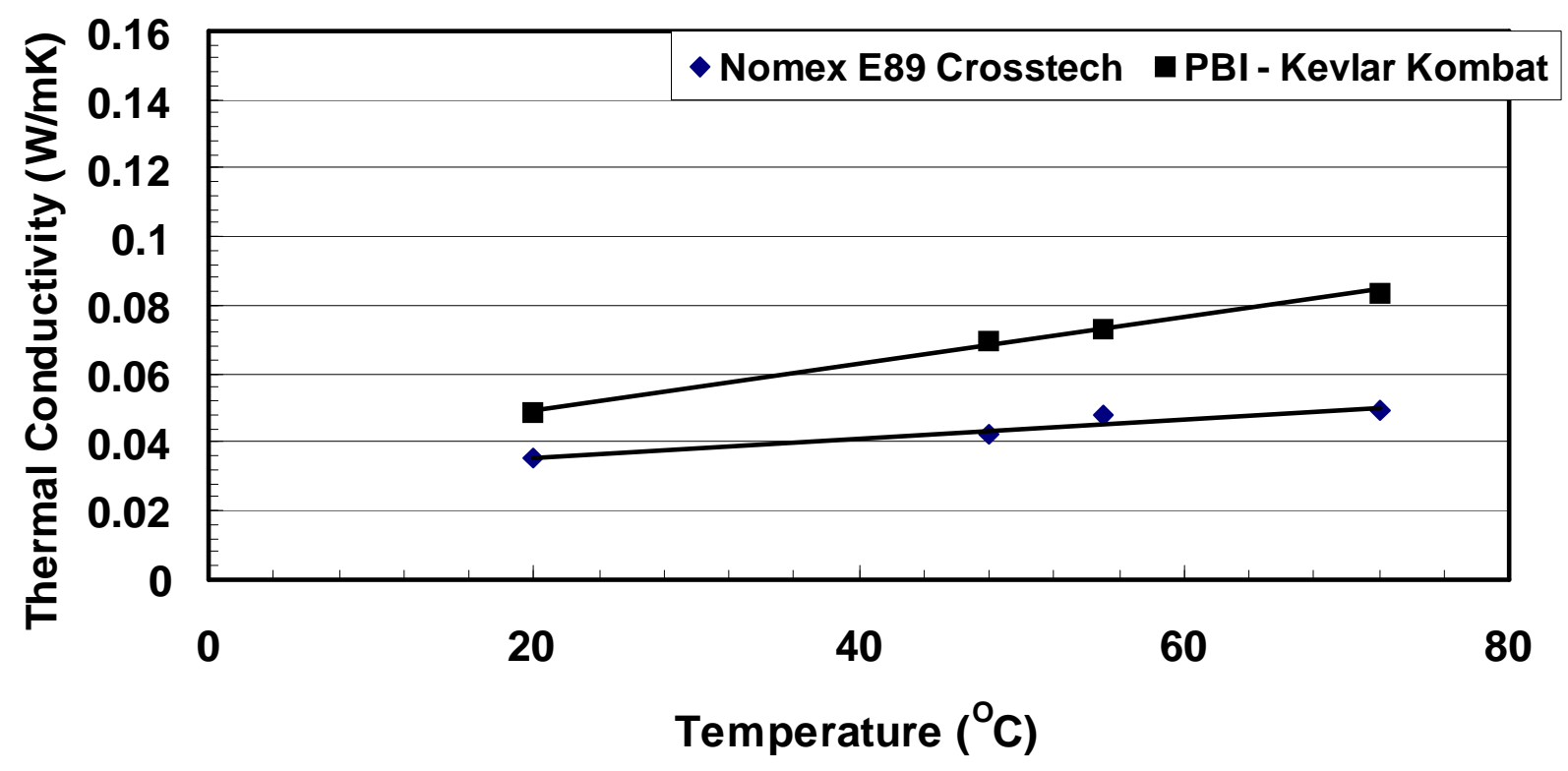

Figure 7 Estimated thermal conductivity for Nomex ${ }^{\circledR}$ E89 Crosstech ${ }^{\circledR}$ and PBI $^{\text {TM}}-$ Kevlar® Kombat $^{\mathrm{TM}}$. 


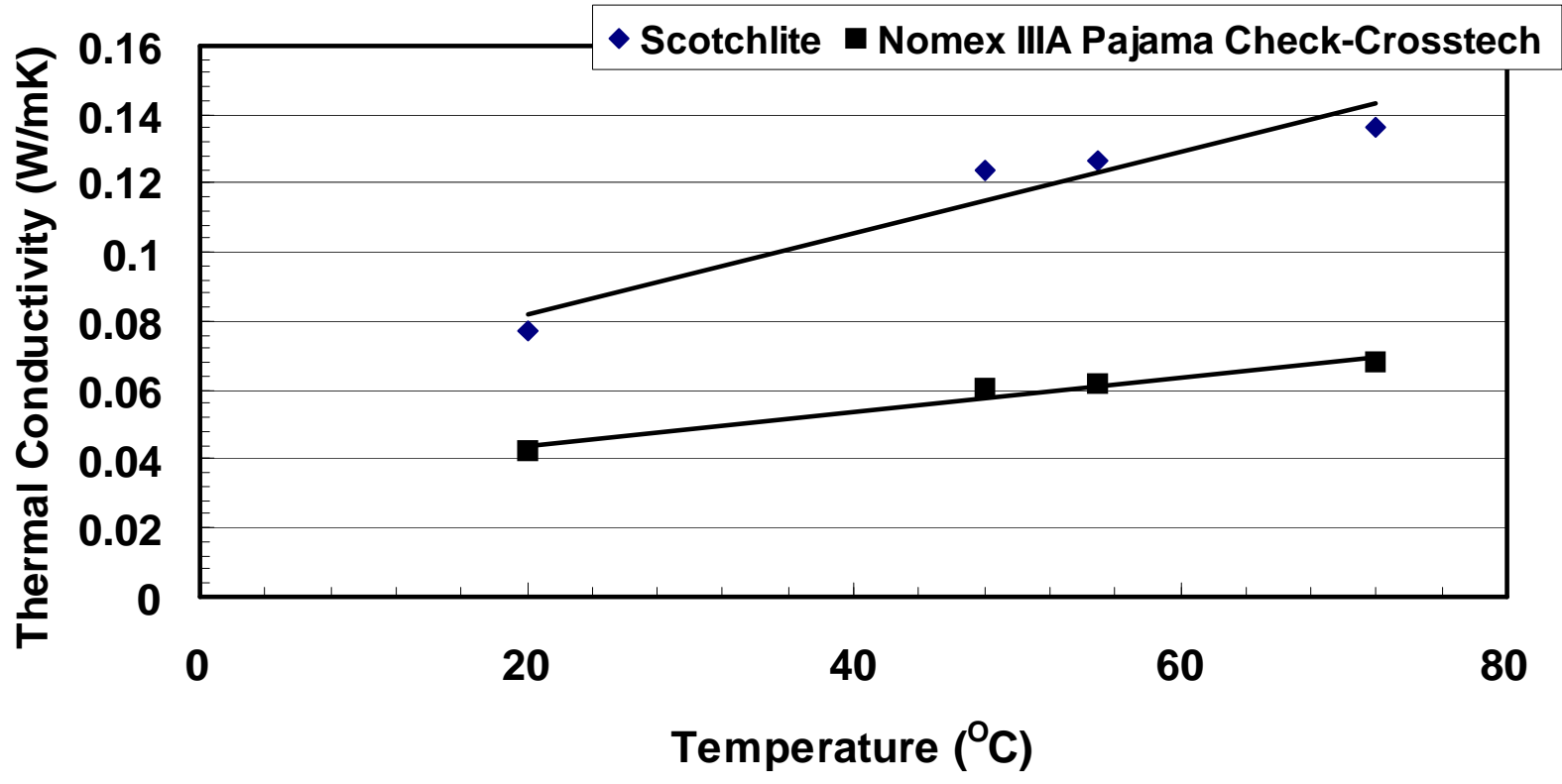

Figure 8 Estimated thermal conductivity for Scotchlite® and Nomex ${ }^{\circledR}$ IIIA

data plots for these measurements are located in Appendix A. Polynomial fits were conducted on the test results. Results from each of the protective clothing materials exhibited some curvature. Some of this curvature may be attributed to swelling of the test materials upon heating. This swelling likely fills the empty "head space" in the specimen pan and changes the specimen pan's heat balance.

Test results giving the polynomial equations for specific heat $\left(\mathrm{C}_{\mathrm{p}}\right)$, at temperature $(\mathrm{T})$, the correlation coefficient for the data $\left(\mathrm{R}^{2}\right)$, and calculated $\mathrm{C}_{\mathrm{p}}$ values at $20^{\circ} \mathrm{C}$ are shown in Tables 4 .

\subsection{THERMO-OPTICAL PROPERTIES}

Thermo-optical properties data reported are presented in Appendix B.

It is important to note with the thermo-optical data for cases where the materials had different surface finishes on the front and back of the specimens, measurements were made from both sides of the material. For these materials, it was found that transmittance was indistinguishable for the two directions of incidence. However, reflectance differed substantially with some of the materials. 
Table 3 Thermal conductivity results from $20{ }^{\circ} \mathrm{C}$ to $70^{\circ} \mathrm{C}$.

\begin{tabular}{|c|c|c|c|}
\hline Material & $\begin{array}{c}\text { Correlation } \\
\text { Coefficient }\left(\mathrm{R}^{2}\right)\end{array}$ & $\begin{array}{l}\text { Least Square Equation } \\
\qquad\left(\mathrm{T} \text { in }{ }^{\circ} \mathrm{C}\right)\end{array}$ & $\begin{array}{l}\mathrm{k} \text { at } 20^{\circ} \mathrm{C} \\
(\mathrm{W} / \mathrm{mK})\end{array}$ \\
\hline Aralite $\AA$ & 0.980 & $\mathrm{k}=0.0003 \mathrm{~T}+0.0304$ & 0.036 \\
\hline Breathe-Tex® & 0.998 & $\mathrm{k}=0.0003 \mathrm{~T}+0.0282$ & 0.034 \\
\hline Breathe-Tex®Plus & 0.962 & $\mathrm{k}=0.0002 \mathrm{~T}+0.0332$ & 0.037 \\
\hline Cotton Duck & 0.941 & $\mathrm{k}=0.0005 \mathrm{~T}+0.0740$ & 0.084 \\
\hline Nomex $\AA$ E-89 Crosstech® & 0.930 & $\mathrm{k}=0.0003 \mathrm{~T}+0.0299$ & 0.036 \\
\hline Neo-Guard® & 0.827 & $\mathrm{k}=0.0011 \mathrm{~T}+0.0491$ & 0.071 \\
\hline Nomex ${ }^{\circledR}$ III- Defender ${ }^{\mathrm{TM}}$ & 0.966 & $\mathrm{k}=0.0005 \mathrm{~T}+0.0401$ & 0.050 \\
\hline $\begin{array}{c}\text { Nomex® IIIA Pajama Check® } \\
\text { Crosstech } ®\end{array}$ & 0.967 & $\mathrm{k}=0.0005 \mathrm{~T}+0.0337$ & 0.044 \\
\hline PBI $^{\mathrm{TM}}$ Kevlar ${ }^{\circledR}$ Kombat ${ }^{\mathrm{TM}}$ & 0.995 & $\mathrm{k}=0.0007 \mathrm{~T}+0.0354$ & 0.049 \\
\hline Scotchlite ${ }^{\circledR}$ & 0.924 & $\mathrm{k}=0.0012 \mathrm{~T}+0.0584$ & 0.082 \\
\hline
\end{tabular}

Table 4. Specific heat results, polynomial fit (J/gAC).

\begin{tabular}{|c|c|c|c|}
\hline Material & \begin{tabular}{|c} 
Correlation \\
Coefficient $\left(\mathrm{R}^{2}\right)$
\end{tabular} & Polynomial Equation & $\begin{array}{c}\mathrm{C}_{\mathrm{p}} \text { at } 20^{\circ} \mathrm{C} \\
(\mathrm{J} / \mathrm{gAC})\end{array}$ \\
\hline Aralite ${ }^{\circledR}$ & 0.985 & $\mathrm{C}_{\mathrm{D}}=-7 \mathrm{E}-06 \mathrm{~T}^{3}+0.0012 \mathrm{~T}^{2}-0.0446 \mathrm{~T}+1.798$ & 1.33 \\
\hline Breathe-Tex® & 0.954 & $\mathrm{C}_{\mathrm{p}}=-5 \mathrm{E}-06 \mathrm{~T}^{3}+0.0008 \mathrm{~T}^{2}-0.0312 \mathrm{~T}+2.4036$ & 2.06 \\
\hline Breathe-Tex®Plus & 0.946 & $\mathrm{C}_{\mathrm{p}}=-4 \mathrm{E}-06 \mathrm{~T}^{3}+0.0006 \mathrm{~T}^{2}-0.0218 \mathrm{~T}+2.1723$ & 1.94 \\
\hline Cotton Duck & 0.994 & $\mathrm{C}_{\mathrm{p}}=9 \mathrm{E}-08 \mathrm{~T}^{3}+2 \mathrm{E}-06 \mathrm{~T}^{2}-0.0028 \mathrm{~T}+1.4464$ & 1.39 \\
\hline Nomex $®$ E-89 Crosstech $®$ & 0.972 & $\mathrm{C}_{\mathrm{p}}=2 \mathrm{E}-06 \mathrm{~T}^{3}+7 \mathrm{E}-05 \mathrm{~T}^{2}-0.0274 \mathrm{~T}+2.9263$ & 2.42 \\
\hline Neo-Guard® & 0.963 & $C_{p}=1 E-06 T^{3}-7 E-05 T^{2}-0.0021 T+1.6263$ & 1.56 \\
\hline Nomex® III- DefenderTM & 0.976 & $C_{p}=-7 \mathrm{E}-06 \mathrm{~T}^{3}+0.0012 \mathrm{~T}^{2}-0.049 \mathrm{~T}+1.8322$ & 1.28 \\
\hline $\begin{array}{c}\text { Nomex® IIIA Pajama } \\
\text { Check® Crosstech® }\end{array}$ & 0.918 & $C_{n}=-6 \mathrm{E}-06 \mathrm{~T}^{3}+0.001 \mathrm{~T}^{2}-0.0419 \mathrm{~T}+2.3202$ & 1.84 \\
\hline $\mathrm{PBI}^{\mathrm{TM}}$ Kevlar® Kombat ${ }^{\mathrm{TM}}$ & 0.994 & $\mathrm{C}_{\mathrm{n}}=-2 \mathrm{E}-07 \mathrm{~T}^{3}+0.0004 \mathrm{~T}^{2}-0.037 \mathrm{~T}+1.8212$ & 1.25 \\
\hline Scotchlite $\AA$ & 0.990 & $\mathrm{C}_{\mathrm{p}}=-8 \mathrm{E}-07 \mathrm{~T}^{3}+0.000258 \mathrm{~T}^{2}-0.0163 \mathrm{~T}+1.2319$ & 1.09 \\
\hline
\end{tabular}

\subsection{MEASUREMENT UNCERTAINTY}

There are different components of uncertainty associated with each of the test methods used to generate data discussed in this report. Major issues that contribute to measurement uncertainty are: quality of the test method, apparatus calibration and control, and test operator variations. Two types of analysis are currently being used for estimating uncertainty, Type A and Type B. Type A uncertainties are those which are evaluated by statistical methods, and Type B are those evaluated by 
other means [17]. Type A, uncertainty estimates are prepared through statistical analysis of data sets produced by a test method. Type A analysis results are often expressed by presenting the mean and standard deviation of a series of independent observations. Type B analysis is typically based on scientific judgement using relevant test information. This may include knowledge of previous measurement data, knowledge related to measurement error, knowledge related to materials properties, manufacturer's specifications, and data provided from other reports or handbooks. After estimating uncertainties, using either the Type A or Type B analysis, the uncertainties are processed to yield a combined standard uncertainty. A coverage factor is applied to the combined standard uncertainty by multiplying the results by two. This provides and expanded uncertainty which corresponds to a $95 \%$ confidence interval, $2 \mathrm{~F}$.

\subsubsection{THERMAL CONDUCTIVITY TEST UNCERTAINTY}

Measurement uncertainty for thermal conductivity with the ASTM C518 test apparatus and procedure is significantly affected by the calibrations with SRM 1450c. Uncertainty values for SRM 1450c were reported to be less than $\pm 2 \%$ of the mean certified value across the temperature range used for certification [9]. A series of replicate comparative calibration tests was carried out during this study to better characterize test variability using the Rapid-k and SRM 1450c. These calibration tests were conducted at each of the four test temperature settings, 20 /C (68 /F), 48 /C (118/F), 55 /C (131 /F), and $72 / \mathrm{C}(162 / \mathrm{F})$. Results from these tests showed the following maximum deviations from the certified SRM values: $\pm 2 \%$ at $20 / \mathrm{C}(68 / \mathrm{F}), \pm 2 \%$ at $48 / \mathrm{C}(118 / \mathrm{F}), \pm 3 \%$ at $55 / \mathrm{C}(131 / \mathrm{F})$, and $\pm 4 \%$ at $72 / \mathrm{C}(162 / \mathrm{F})$. These calibration data indicate that measurement uncertainty is increasing as test temperatures are increased. This uncertainty becomes a component of uncertainty for thermal conductivity measurements reported in this document. The Rapid-k test apparatus precision reported by the manufacturer indicates that apparatus reproducibility is on the order of \pm 1 percent [10]. However, inter-laboratory imprecision reported in the ASTM C 518 standard, for thermal conductivity measurements using various types of insulating materials, ranged from 1.9 percent to 10.5 percent at a two standard deviation level [5]. These values reported by ASTM take into consideration issues related to materials variability and likely include all components of test variability. After considering many factors including experience with calibration of the Rapid-k with SRM 1450c, the typical performance of the Rapid-k instrument, the variability in the material, and the inter-laboratory measurements, the component standard uncertainties were estimated (see Table 5 ) and were combined in quadrature to yield a combined standard uncertainty of $5.8 \%$. A coverage factor of two is applied to the combined standard uncertainty to provide the total expanded uncertainty of $11.7 \%$ which corresponds to a $95 \%$ confidence interval, $2 \mathrm{~F}$.

\subsubsection{SPECIFIC HEAT TEST UNCERTAINTY}

The American Society for Testing and Materials conducted an inter-laboratory precision study for the ASTM E1269 test method using Differential Scanning Calorimetry (DSC). The study described in this report used the same test method and type of DSC as used in the inter-laboratory study. Results from this Type A analysis identified a mean within laboratory repeatability of $6.2 \%$ and a mean between laboratory reproducibility of $8.4 \%$. Each of the precision estimates are based on a 95 $\%$ confidence level [11]. After considering many factors including calibration 
Table 5. Uncertainty Components for Thermal Conductivity Measurements

\begin{tabular}{|l|c|}
\hline \multicolumn{1}{|c|}{ Component } & Component Standard Uncertainty \\
\hline Calibration & $\pm 2 \%$ \\
\hline Material Variability & $\pm 3 \%$ \\
\hline Rapid K Instrument & $\pm 1 \%$ \\
\hline Random* & $\pm 2 \%$ \\
\hline Repeatability & $\pm 4 \%$ \\
\hline \hline Combined Standard Uncertainty & $\pm 11.7 \%$ \\
\hline Total Expanded Uncertainty & \\
\hline Notes: & \\
$*$ Random component evaluated as Type A, other components as Type B.
\end{tabular}

of the Differential Scanning Calorimeter (DSC), the typical performance of the DSC instrument including the difficulty associated with fabric swelling and partially losing thermal contact, the mass determination, and the inter-laboratory measurements, the component standard uncertainties were estimated (see Table 6) and were combined in quadrature to yield a combined standard uncertainty of $27 \%$. A coverage factor of two is applied to the combined standard uncertainty to provide the total expanded uncertainty of $54 \%$ which corresponds to a $95 \%$ confidence interval, $2 \mathrm{~F}$.

\subsubsection{THERMO-OPTICAL PROPERTIES UNCERTAINTY}

Uncertainty estimates for the thermo-optical properties measurements data generated for this report were prepared and are tabulate in Appendix B. The uncertainties in the measured values of directional-hemispherical reflectance and transmittance consist of two main components. The first (type-A) component accounts for the repeatability of the measurement and is derived as the standard deviation of the series of three measurements divided by the square root of 3 . The main contributor to this component is noise in the detector element and amplifier, with a small contribution from drift in the interferometer alignment and source temperature.

The second main component is a systematic (type-B) component coming from the combination of non-uniformity in the sphere throughput and uncertainty in the flux distribution from the sample. As discussed above, a relative variation in throughput of up to $8 \%$ is expected for samples that range from perfectly specular to perfectly diffuse in their reflected flux distribution. We take half of the correction and apply it to the data in the absence of other information about the samples' scattering characteristics. A relative standard uncertainty component accounting for this lack of knowledge is taken as half of the residual, or approximately $1.5 \%$ to $2 \%$ as a function of wave number. Other 
Table 6. Uncertainty Components for Specific Heat Measurements

\begin{tabular}{|l|c|}
\hline Component & Component Standard Uncertainty \\
\hline Calibration & $\pm 2 \%$ \\
\hline Mass & $\pm 0.5 \%$ \\
\hline DSC Instrument & $\pm 25 \%$ \\
\hline Random* & $\pm 2 \%$ \\
\hline Repeatibility & $\pm 10 \%$ \\
\hline Combined Standard Uncertainty & $\pm 27 \%$ \\
\hline Total Expanded Uncertainty & $\pm 54 \%$ \\
\hline $\begin{array}{l}\text { Notes: } \\
* \text { Random component evaluated as Type A, other components as Type B. }\end{array}$ \\
\hline
\end{tabular}

type-B uncertainty components, due to detector non-linearity, ambient thermal emission, interreflections, and phase error in the interferometer, are less than $0.1 \%$ and not important in this case. The zero-offset of the scale, due to stray light reaching the detector, is approximately $0.05 \%$ and negligible compared to the noise in the low-level transmittance and reflectance results.

The combined expanded uncertainty was calculated by adding the repeatability (type-A) and systematic uncertainty due to flux throughput non-uniformity (type-B) in quadrature, and multiplying the result by the coverage factor $\mathrm{k}=2$ for $95 \%$ confidence intervals [2]. The uncertainties are a function of wave number and are plotted for each material in Figures 20B - 38B(Appendix B).

\subsubsection{MATERIAL PROPERTIES UNCERTAINTY}

Uncertainty estimates were prepared for the material properties which included thickness, mass, and density. These estimates were based on data from the instrument manufacturer, experimental data, and previous experience in conducting these types of measurements.

The combined expanded uncertainty was calculated by adding the repeatability (type-A) and systematic uncertainty due to calibration, thickness, and mass (type-B) in quadrature, and multiplying the result by the coverage factor $\mathrm{k}=2$ for $95 \%$ confidence intervals [2]. After considering many factors including calibration of the mass balance and micrometer, as well as past experience in making thickness measurements, the component standard uncertainties were estimated (see Table 7) and were combined in quadrature to yield a combined standard uncertainty of $5 \%$. A coverage factor of two is applied to the combined standard uncertainty to provide the total expanded uncertainty of $10 \%$ which corresponds to a $95 \%$ confidence interval, $2 \mathrm{~F}$. 
Table 7. Uncertainty Components for Density Measurements

\begin{tabular}{|l|c|}
\hline Component & Component Standard Uncertainty \\
\hline Calibration & $\pm 2 \%$ \\
\hline Mass & $\pm 2 \%$ \\
\hline Thickness & $\pm 1 \%$ \\
\hline Random* & $\pm 2 \%$ \\
\hline Repeatibility & $\pm 4 \%$ \\
\hline \hline Combined Standard Uncertainty & $\pm 5 \%$ \\
\hline Total Expanded Uncertainty & $\pm 10 \%$ \\
\hline $\begin{array}{c}\text { Notes: } \\
* \text { Random component evaluated as Type A, other components as Type B. }\end{array}$ \\
\hline
\end{tabular}

\subsection{SUMMARY}

Nine materials typically used in the fabrication of fire fighters' protective clothing and one cotton fabric were tested to develop estimates of thermal conductivity, specific heat, and the thermo-optical properties of transmittance, reflectance, and absorptance. These fire fighters' protective clothing materials included outer shell fabrics, moisture barriers, thermal liner batting, and reflective trim. All measurements were made using commercially manufactured test apparatus and standard test procedures. The materials were tested at a mean room temperature of $20 / \mathrm{C}(68 / \mathrm{F})$ and across a range of skin tissue temperatures, 48 /C (118/F), 55 /C (131/F), and 72/C (162/F), known to produce burn injuries in humans. Results measured in this study compared favorably with the thermal properties of several other common materials. Thermal conductivity and specific heat data for the thermal protective clothing materials have been formed into least square equation tables that may be easily referenced for use. Data for the thermo-optical properties are presented in graphical format since each property is strongly dependent on wavelength of incident radiation.

The data presented in this report provide a complete set of thermal properties values for the selected protective clothing materials. These data, plus the reported density for each material, may be incorporated into computer models for predicting the thermal performance of fire fighters' protective clothing systems. The data presented in this report do not address the thermal performance of fire fighter protective clothing systems that have undergone thermal degradation. Additional work is required to insure that protective clothing predictive models have valid thermal properties data for wet, aged or used, dirty, and thermally degraded fire fighters' protective clothing materials. Also, the thermal properties data base must be extended to all materials used to manufacture fire fighters' protective clothing systems. 


\subsection{ACKNOWLEDGMENTS}

Appreciation is extended to Mr. Robert T. McCarthy of the United States Fire Administration for assistance provided during this project. The United States Fire Administration provided funding for the Building and Fire Research Laboratory to study the thermal properties of fire fighters' protective clothing. Appreciation is extended to Southern Mills Inc. for providing protective clothing fabrics for this study. Mr. Michael Stanhope, Ms. Denise Statham and Ms. Susan Tribble of Southern Mills Inc. also provided assistance for this project. Appreciation is extended to Ms. Diane Hess of the Celanese Corporation for assisting with this effort. Appreciation is extended to W.L. Gore and Associates, Inc. for providing moisture barrier materials for this study. Mr. Dan Gohlke, Mr. Ron Bove, and Mr. Craig Lack of W.L. Gore and Associates, Inc. assisted with technical discussions related to this project. Appreciation is extended to Alden Industries, Inc. for supplying moisture barrier materials, in particular Mr. Dan Silvestri and Mr. Bill Grob provided assistance. Appreciation is also extended to 3M, Minnesota Mining and Manufacturing Company, Safety and Security Systems Division for supplying retroreflective trim materials for this effort. Mr. Bob Jensen of $3 \mathrm{M}$ is recognized for his assistance with this project. 


\subsection{REFERENCES}

[1] Mell, William E. and Lawson, J. Randall, “A Heat Transfer Model for Fire Fighter's Protective Clothing”, NISTIR 6299, National Institute of Standards and Technology, Gaithersburg, MD, January 1999.

[2] Bennett, C.O. and Myers, J.E., Momentum, Heat, and Mass Transfer, Second Edition, McGraw-Hill Book Company, New York, 1974.

[3] Miller, Franklin Jr., Dillon, Thomas J., and Smith, Malcolm K., Concepts in Physics, Third Edition, Harcourt Brace Jovanovich, Publishers, Orlando, FL, 1980.

[4] Lawson, J. Randall and Pinder, Tershia A., "Estimates of Thermal Conductivity for Materials Used in Fire Fighters' Protective Clothing", NISTIR 6512, National Institute of Standards and Technology, Gaithersburg, MD, May 2000.

[5] American Society for Testing and Materials, C 518, Standard Test Method for Steady-State Thermal Transmission Properties by Means of the Heat Flow Meter Apparatus, Annual Book of ASTM Standards, Vol. 04.06, West Conshohocken, PA, 1998.

[6] American Society for Testing and Materials, C 1045, Practice for Calculating Thermal Transmission Properties from Steady-State Conditions, Annual Book of ASTM Standards, Vol. 04.06, West Conshohocken, PA, 1998.

[7] American Society for Testing and Materials, C 1055 , Standard Guide for Heated Systems Surface Conditions That Produce Contact Burn Injuries, Annual Book of ASTM Standards, Vol. 04.06, West Conshohocken, PA 1998.

[8] Stoll, Alice M. and Chianta, Maria A., Method and Rating System for Evaluation of Thermal Protection, Aerospace Medicine, Vol. 40(11), pp. 1232-1237, November 1969.

[9] National Institute of Standards and Technology, Certificate, Standard Reference Material 1450c, Gaithersburg, MD March 1997.

[10] Rapid-k Operation and Maintenance Manual, Version 6.0, 4/94, Holometrix, Bedford, MA.

[11] American Society for Testing and Materials, ASTM E1269, Standard Test Method for Determining Specific Heat Capacity by Differential Scanning Calorimetry, Annual Book of ASTM Standards, Vol. 14.02, West Conshohocken, PA, 1999.

[12] National Institute of Standards and Technology, Standard Reference Material 720, Gaithersburg, MD. 
[13] Hanssen, Leonard M. and Kaplan, Simon, "Infrared diffuse reflectance instrumentation and standards at NIST, " Anal. Chem. Act. 380, 289-302 (1999).

[14] Rohsenow, Warren M. and Hartnett James P., Editors, Handbook of Heat Transfer, McGraw-Hill Book Company, New York, 1973.

[15] Torvi, D.A., "Heat Transfer in Thin Fibrous Materials Under High Heat Flux Conditions", PhD Thesis, Mechanical Engineering Department, University of Alberta, Calgary, Alberta, 1997.

[16] Ozisik, M.N., Heat Transfer A Basic Approach, McGraw-Hill, Inc., New York, NY, 1985.

[17] Taylor, Barry N. and Kuyatt, Chris E., "Guidelines for Evaluating and Expressing the Uncertanity of NIST Measurement Results”, NIST Technical Note 1297, Gaithersburg, MD 1994. 


\section{Appendix A}

\section{Report of Analysis}

September 15, 2000

To: $\quad$ James R. Lawson

Fire Safety Engineering Division

Subject: $\quad$ Specific Heat of Fabrics

Method: Differential Scanning Calorimetry. A Perkin-Elmer DSC \& Differential Scanning Calorimeter was used for these measurements. The operation of the DSC7 is based upon PerkinElmer's unique power compensation "null balance" DSC principle, in which energy absorbed by the sample is compensated by adding an equivalent amount of electrical energy to a heater located in the sample holder. Platinum resistance heaters and thermometers are used in the DSC7 to accomplish the temperature and energy measurements. The continuous and automatic adjustment of heater power necessary to keep the sample holder temperature identical to that of the reference holder provides a varying electrical signal equivalent to the varying thermal behavior of the sample. This measurement is made directly in differential power units (milliwatts) providing true electrical energy measurement of heat capacity displacements. The Perkin-Elmer DSC measures the energy of a heat capacity displacement directly.

Procedure: Three DSC fabric specimens were prepared from each of the ten fabric samples submitted by division 864 . The samples weighed from 3 to $9 \mathrm{mg}$ depending on the sample density. The temperatures of fusion of Water and Indium were used to calibrate the temperature axis. The heat capacity of NIST SRM 720, synthetic sapphire, was used to calibrate the energy axis. The heat capacity of NIST SRM 720 is certified from 10 to $2250 \mathrm{~K}$. ASTM E1269, Standard Test Method for Determining Specific Heat Capacity by Differential Scanning Calorimetry, was used for these measurements. Three measurements are required to obtain the specific heat of each DSC fabric specimen. The first measurement is of an empty pan to provide a baseline curve for the heat capacity of the sample pan. The second measurement is of a sample pan containing a known weight of synthetic sapphire, NIST SRM 720. The third measurement is of a sample pan containing a known weight of the fabric sample. The energy signal of the fabric sample is compared to the energy signal of the SRM 720 sample that has a certified value. Slight adjustments are made for any difference in weights of the sample pans used. DSC measurements were made from $-10^{\circ} \mathrm{C}$ to $110^{\circ} \mathrm{C}$. 
Heat capacities were calculated form $0{ }^{\circ} \mathrm{C}$ to $100{ }^{\circ} \mathrm{C}$ for each fabric run. The DSC heat capacity traces all contained some curvature. Several types of sample pans are routinely used in differential scanning calorimetry. A pan for volatile samples leaves an empty "head space" above the DSC specimen, and the pan is hermetically sealed to prevent loss of sample. Heat capacities determined in these pans showed a large increase in heat capacity at high temperatures. It appears that the fabrics swell into the empty "head space" and lose thermal contact with the pan requiring more heat to be applied to the sample. The most common type of pan used for non-volatile samples is a pan with a cover that is slightly less in diameter than the pan so that the can cover lies directly on top of the sample, inside the pan. The edges of the pan are then rolled over to seal the cover in the pan, and the sample is in good thermal contact with both the pan and pan cover. This type of pan greatly reduced the curvature of the specific heat curves. Attempts to further reduce the curvature by lowering the scanning rate did not significantly reduce the curvature. Therefore "rolled" pans were used, except for fabrics D, E, and F where significant difficulty was encountered in encapsulating the samples, at a scanning rate of five degrees per minute.

Results: $\quad$ Results for each fabric sample were averaged and plotted on an Excel spreadsheet. All of the curves have some curvature. A linear line and polynomial curve were fit to the heat capacity data. Table 1 presents a least squares fit equation for the heat capacity fit which is valid from $0{ }^{\circ} \mathrm{C}$ to $100{ }^{\circ} \mathrm{C}$ for each fabric sample. Specific heat was evaluated at $50{ }^{\circ} \mathrm{C}$ using the least squares fit equation and compared to the experiment data (Table 2). Average values for the experimental data over the range $0{ }^{\circ} \mathrm{C}$ to $100{ }^{\circ} \mathrm{C}$ were compared to the values generated using the least squares fit equation (Table 3 ). Table 4 presents a polynomial fit equation for the heat capacity fit which is valid from $0{ }^{\circ} \mathrm{C}$ to $100{ }^{\circ} \mathrm{C}$ for each fabric sample. Specific heat was evaluated at $50{ }^{\circ} \mathrm{C}$ using the polynomial fit equation and compared to the experiment data (Table 5). Average values for the experimental data over the range $0^{\circ} \mathrm{C}$ to $100{ }^{\circ} \mathrm{C}$ were compared to the values generated using the polynomial fit equation (Table 6).

\section{Analyzed by:}

Duane R. Kirklin, Research Chemist

Physical and Chemical Properties Division 
Table 1. Specific Heat Capacity of Several Fabrics Using Least Squares Fit.

\begin{tabular}{|c|l|c|}
\hline \multicolumn{2}{|c|}{ Fabric ID } & Specific Heat Capacity, $C_{p}$ \\
J/g ${ }^{\circ} \mathrm{C}$
\end{tabular}


Table 2. Specific Heat Capacity of Several Fabrics Evaluated at $50{ }^{\circ} \mathrm{C}$ Using Least Squares

Fit.

\begin{tabular}{|c|c|c|c|c|}
\hline \multirow{2}{*}{\multicolumn{2}{|c|}{ Fabric ID }} & \multicolumn{3}{|c|}{$\begin{array}{l}\text { Specific Heat Capacity, } \mathrm{C}_{\mathrm{p}} \\
\mathrm{J} / \mathrm{g}{ }^{\circ} \mathrm{C}\end{array}$} \\
\hline & & \multirow{2}{*}{$\begin{array}{c}\begin{array}{c}\text { Experiment } \\
\text { at } \\
50^{\circ} \mathrm{C}\end{array} \\
1.62 \\
\end{array}$} & \multirow{2}{*}{ 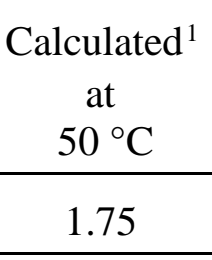 } & \multirow{2}{*}{$\begin{array}{c}\text { Percent } \\
\text { Difference }\end{array}$} \\
\hline A & Aralite & & & \\
\hline B & Breathe-Tex & 2.28 & 2.28 & 0.0 \\
\hline $\mathrm{C}$ & Breathe-Tex Plus & 2.05 & 2.06 & -0.8 \\
\hline $\mathrm{D}$ & Cotton Duck & 1.62 & 1.62 & 0.3 \\
\hline $\mathrm{E}$ & Nomex E89 Crosstech & 1.90 & 2.24 & -18.3 \\
\hline $\mathrm{F}$ & Neo-Guard & 1.48 & 1.53 & -3.3 \\
\hline $\mathrm{G}$ & Nomex III Defender & 1.51 & 1.74 & -15.3 \\
\hline $\mathrm{H}$ & Nomex III Pajama Check Crosstech & 1.93 & 2.06 & -6.5 \\
\hline I & PBI Kevlar Kombat & 0.89 & 1.23 & -38.2 \\
\hline $\mathrm{J}$ & Scotchlite Trim & 0.95 & 1.06 & -12.1 \\
\hline & $\begin{array}{l}\text { ted using least square fit equation } \\
\text { iment - Calculated)/ Experiment) }\end{array}$ & 1 of this at & & \\
\hline
\end{tabular}


Table 3. Specific Heat Capacity of Several Fabrics Evaluated $0{ }^{\circ} \mathrm{C}$ to $100{ }^{\circ} \mathrm{C}$ Using Least Squares Fit.

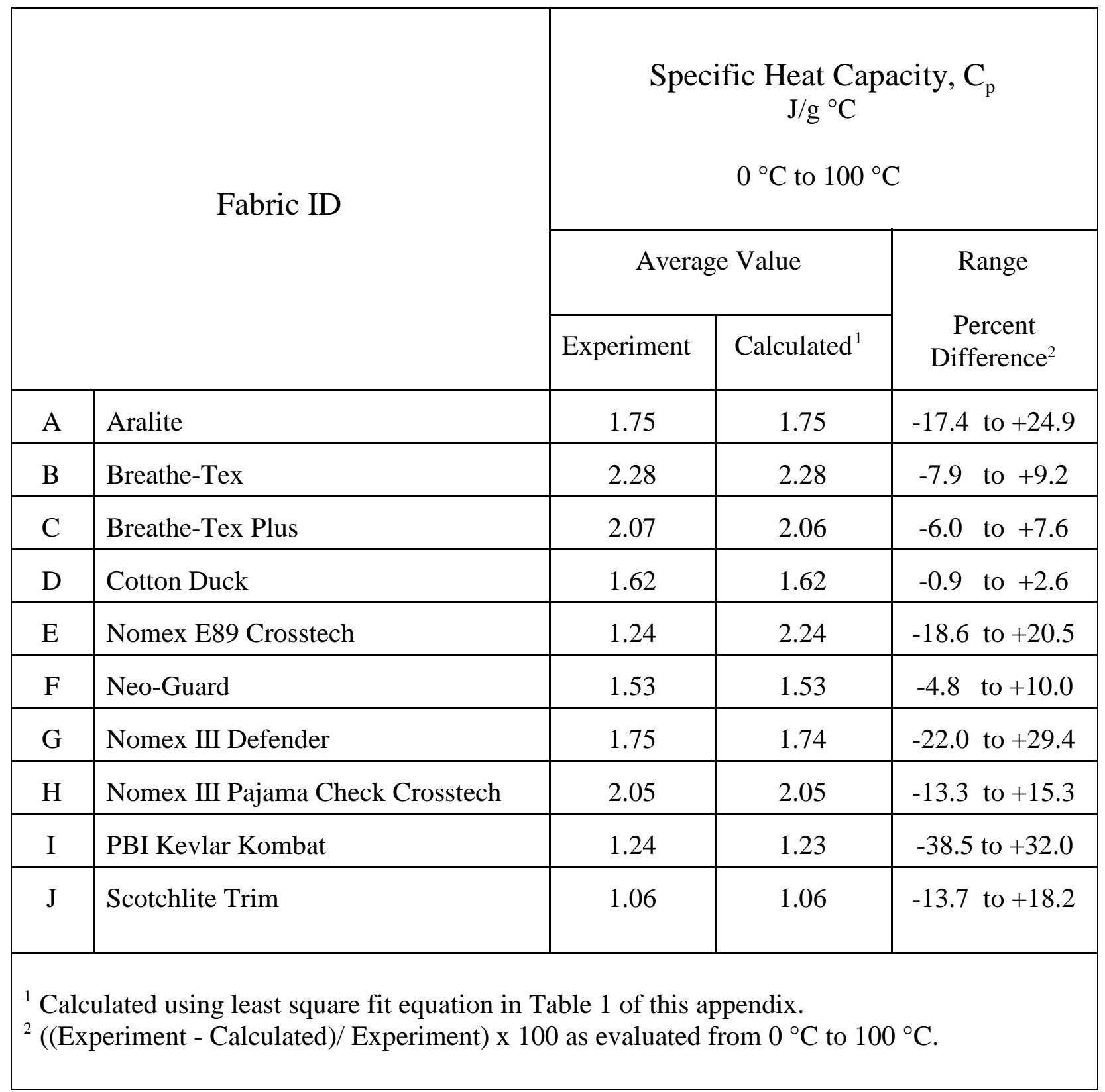


Table 4. Specific Heat Capacity of Several Fabrics Using Polynomial Fit.

\begin{tabular}{|l|l|c|}
\hline \multicolumn{2}{|c|}{ Fabric ID } & \multicolumn{1}{c|}{$\begin{array}{c}\text { Specific Heat Capacity, } \mathrm{C}_{\mathrm{p}} \\
\mathrm{J} / \mathrm{g}{ }^{\circ} \mathrm{C}\end{array}$} \\
\hline A & Aralite & $\mathrm{C}_{\mathrm{p}}=-0.000007 \mathrm{~T}^{3}+0.0012 \mathrm{~T}^{2}-0.0446 \mathrm{~T}+1.798$ \\
\hline B & Breathe-Tex & $\mathrm{C}_{\mathrm{p}}=-0.000005 \mathrm{~T}^{3}+0.0008 \mathrm{~T}^{2}-0.0312 \mathrm{~T}+2.4036$ \\
\hline C & Breathe-Tex Plus & $\mathrm{C}_{\mathrm{p}}=-0.000004 \mathrm{~T}^{3}+0.0006 \mathrm{~T}^{2}-0.0218 \mathrm{~T}+2.1723$ \\
\hline D & Cotton Duck & $\mathrm{C}_{\mathrm{p}}=-0.00000009 \mathrm{~T}^{3}+0.000002 \mathrm{~T}^{2}-0.0028 \mathrm{~T}+1.4464$ \\
\hline E & Nomex E89 Crosstech & $\mathrm{C}_{\mathrm{p}}=0.000002 \mathrm{~T}^{3}+0.000007 \mathrm{~T}^{2}-0.0274 \mathrm{~T}+2.9263$ \\
\hline F & Neo-Guard & $\mathrm{C}_{\mathrm{p}}=0.000001 \mathrm{~T}^{3}-0.00007 \mathrm{~T}^{2}-0.0021 \mathrm{~T}+1.6263$ \\
\hline G & Nomex III Defender & $\mathrm{C}_{\mathrm{p}}=-0.000007 \mathrm{~T}^{3}+0.0012 \mathrm{~T}^{2}-0.049 \mathrm{~T}+1.8322$ \\
\hline $\mathrm{H}$ & $\begin{array}{l}\text { Nomex III Pajama Check } \\
\text { Crosstech }\end{array}$ & $\mathrm{C}_{\mathrm{p}}=-0.000006 \mathrm{~T}^{3}+0.001 \mathrm{~T}^{2}-0.0419 \mathrm{~T}+2.3202$ \\
\hline I & PBI Kevlar Kombat & $\mathrm{C}_{\mathrm{p}}=-0.0000002 \mathrm{~T}^{3}+0.0004 \mathrm{~T}^{2}-0.037 \mathrm{~T}+1.8212$ \\
\hline $\mathrm{J}$ & Scotchlite Trim & $\mathrm{C}_{\mathrm{p}}=-0.0000008 \mathrm{~T}^{3}+0.000258 \mathrm{~T}^{2}-0.0163 \mathrm{~T}+1.2319$ \\
\hline
\end{tabular}


Table 5. Specific Heat Capacity of Several Fabrics Evaluated at $50{ }^{\circ} \mathrm{C}$ Using Polynomial Fit.

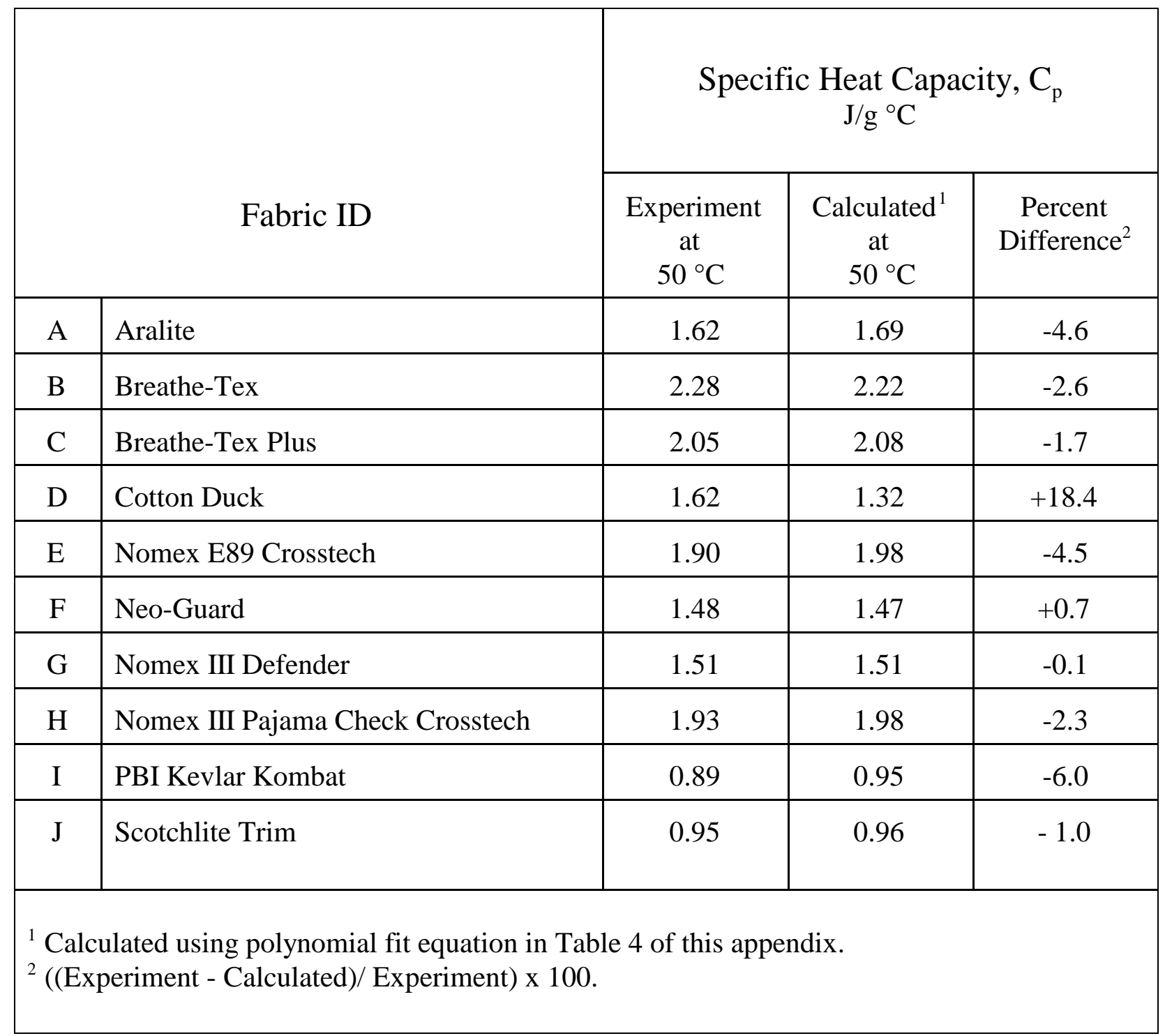


Table 6. Specific Heat Capacity of Several Fabrics Evaluated $0{ }^{\circ} \mathrm{C}$ to $100{ }^{\circ} \mathrm{C}$ Using Polynomial Fit.

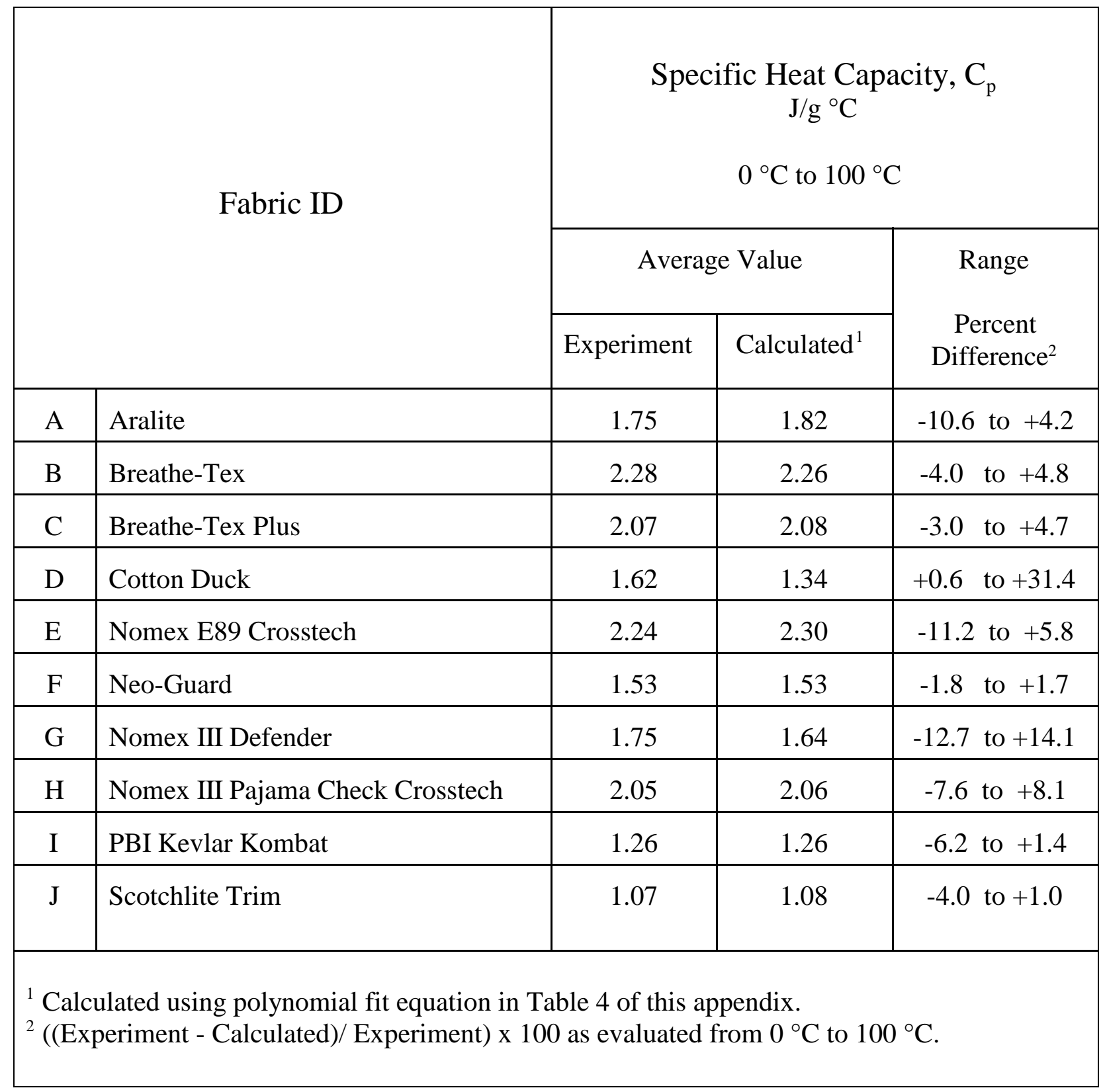




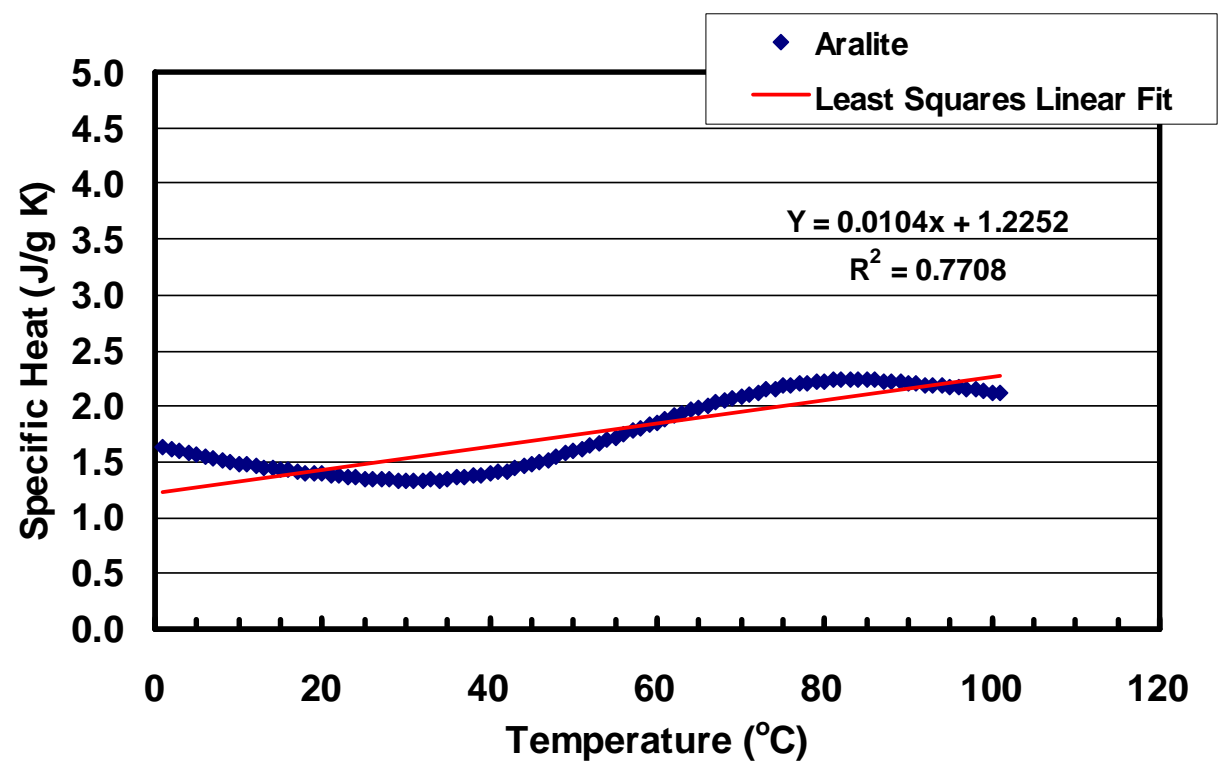

Figure 1A Specific Heat Capacity versus Temperature for Aralite ${ }^{\circledR}$. Least Squares Linear Fit to Experimental Data.

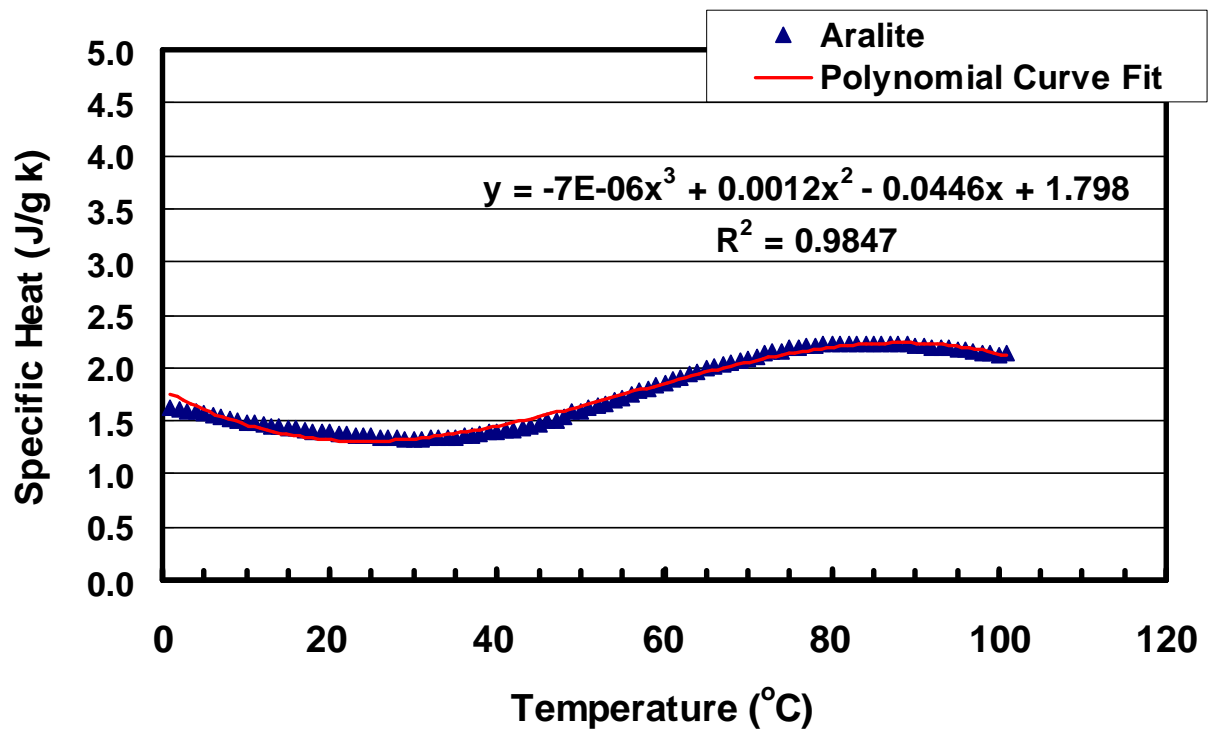

Figure 2A Specific Heat Capacity versus Temperature for Aralite®. Polynomial Curve Fit to Experimental Data. 


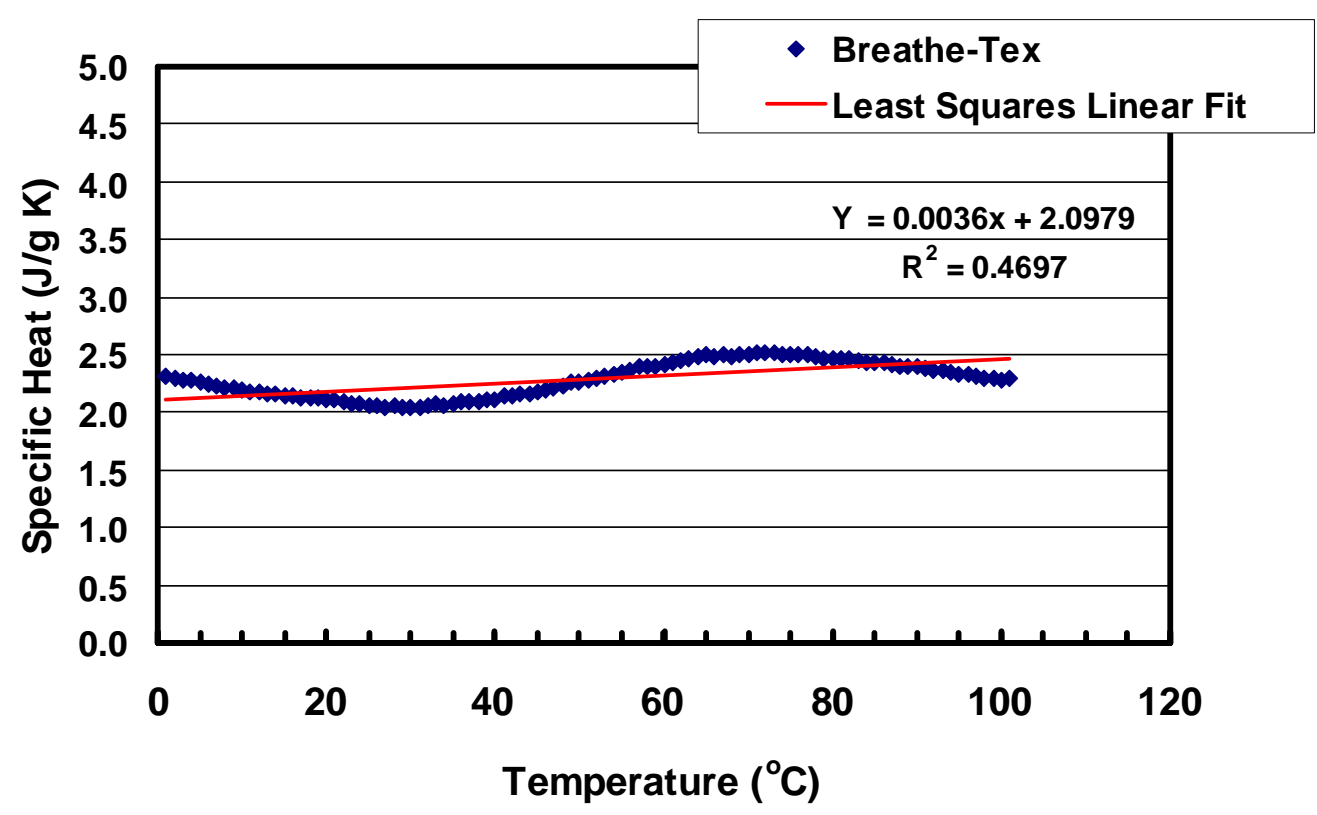

Figure 3A Specific Heat Capacity versus Temperature for Breathe-Tex®. Least Squares Linear Fit to Experimental Data.

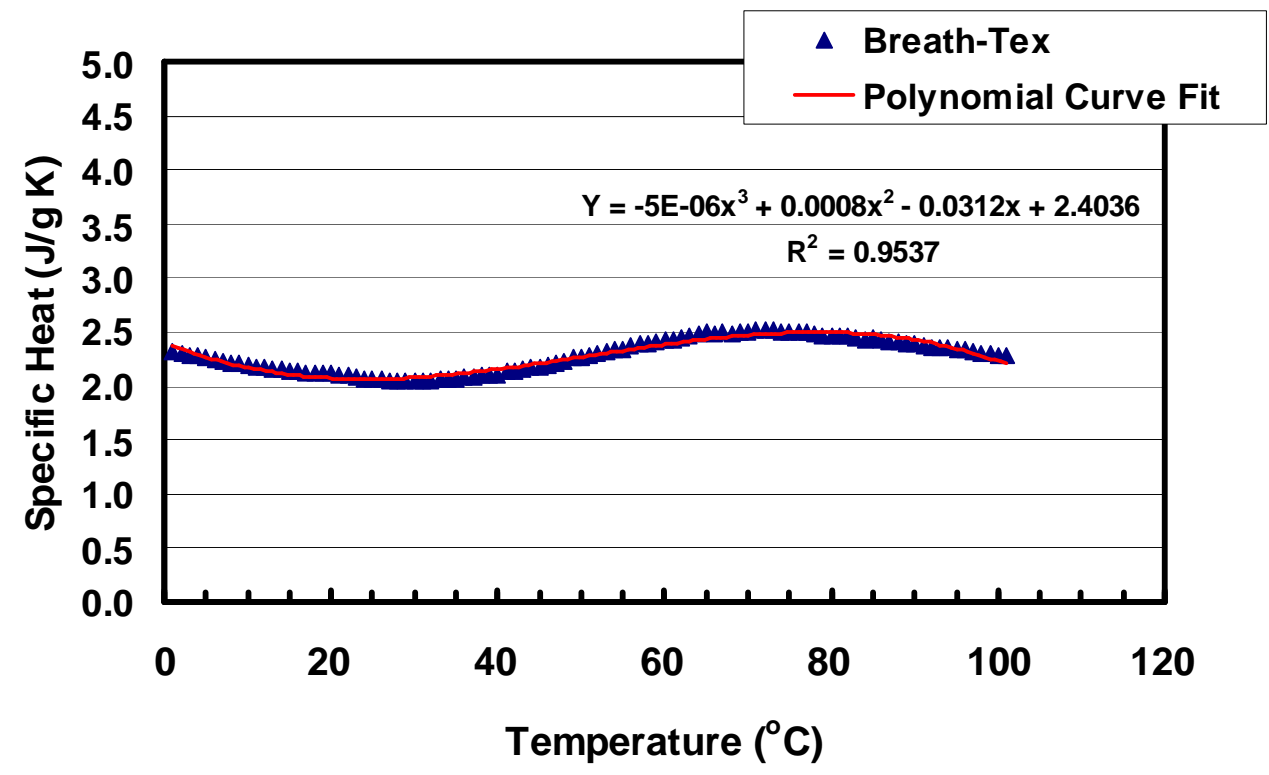

Figure 4A Specific Heat Capacity versus Temperature for Breathe-Tex ${ }^{\circledR}$.

Polynomial Curve Fit to Experimental Data. 


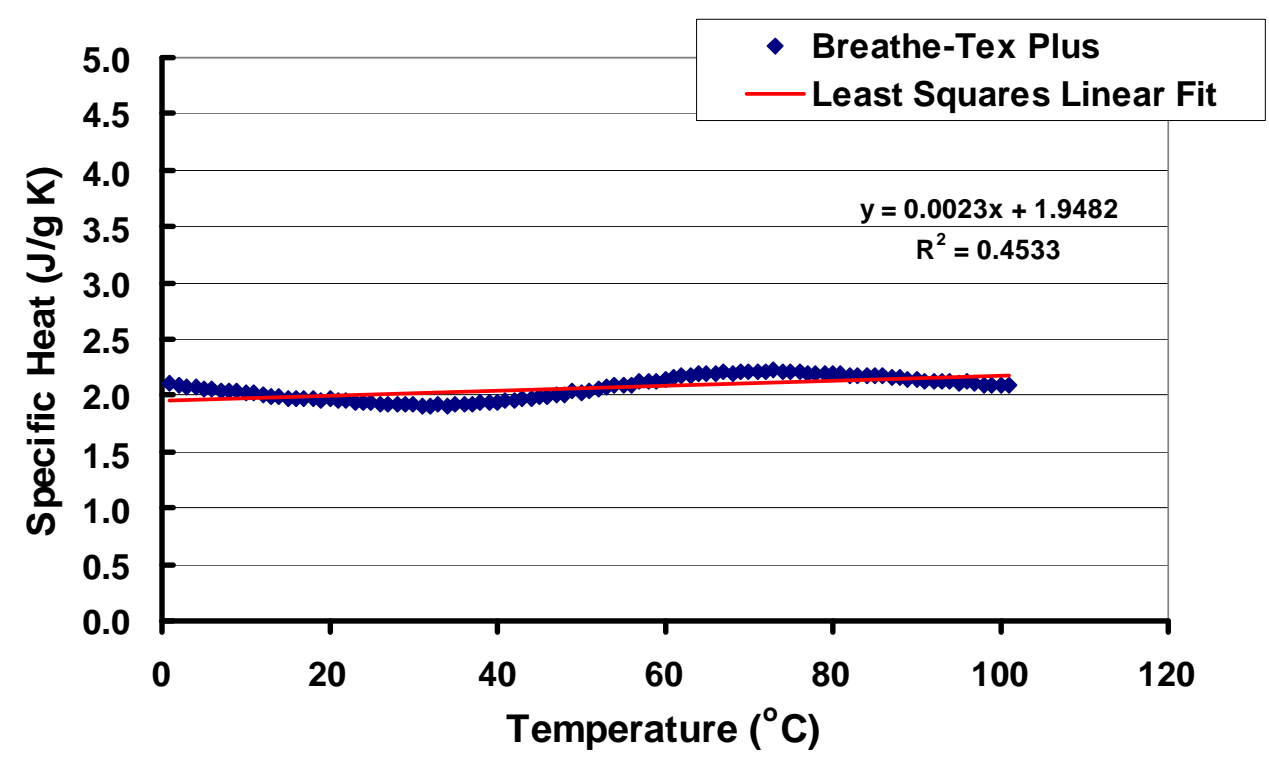

Figure 5A Specific Heat Capacity versus Temperature for Breathe-Tex Plus ${ }^{\circledR}$ Least Squares Linear Fit to Experimental Data.

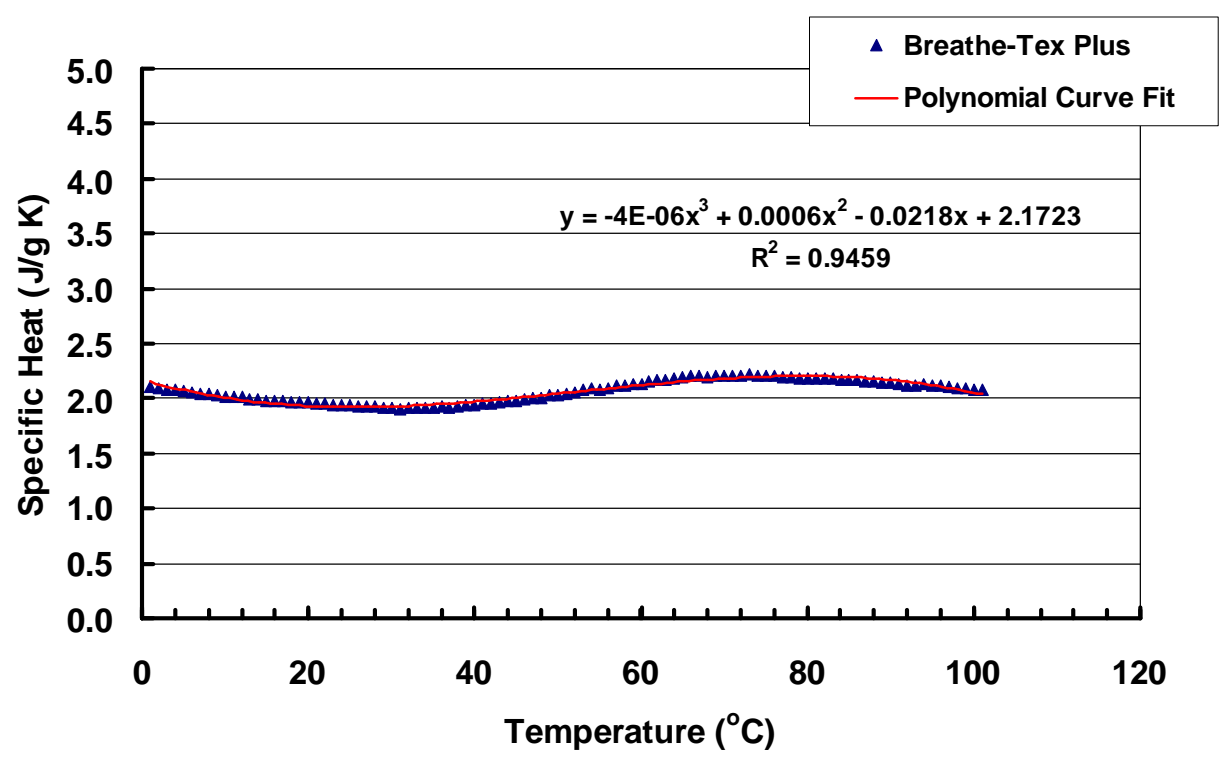

Figure 6A Specific Heat Capacity versus Temperature for Breathe-Tex Plus®. Polynomial Curve Fit to Experimental Data. 


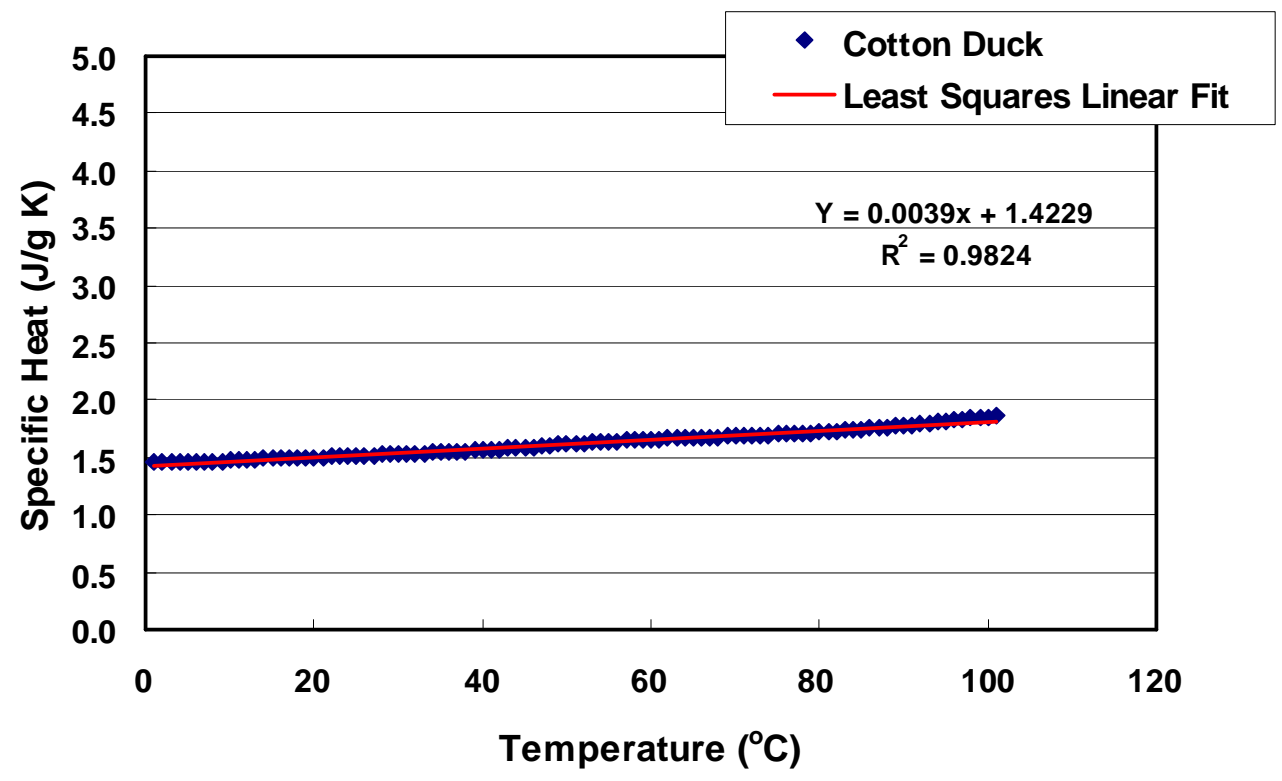

Figure 7A Specific Heat Capacity versus Temperature for Cotton Duck. Least Squares Linear Fit to Experimental Data.

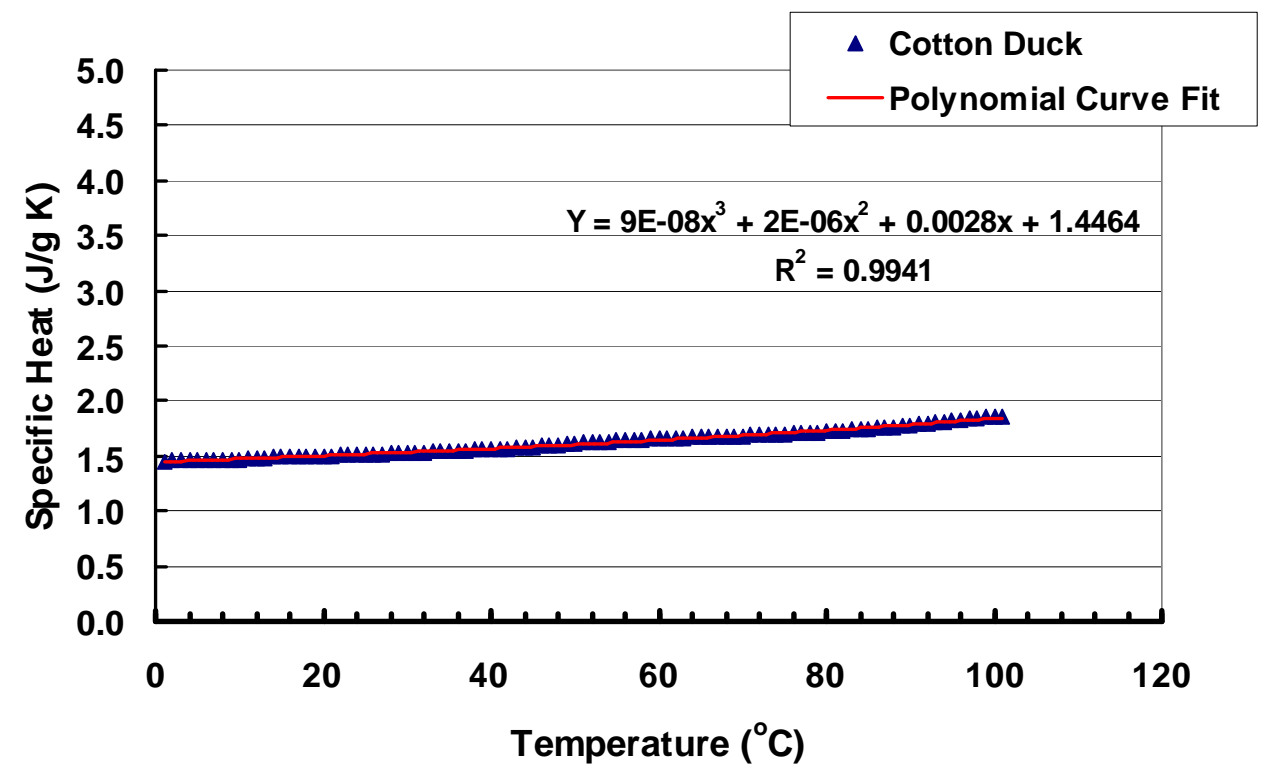

Figure 8A Specific Heat Capacity versus Temperature for Cotton Duck.

Polynomial Curve Fit to Experimental Data. 


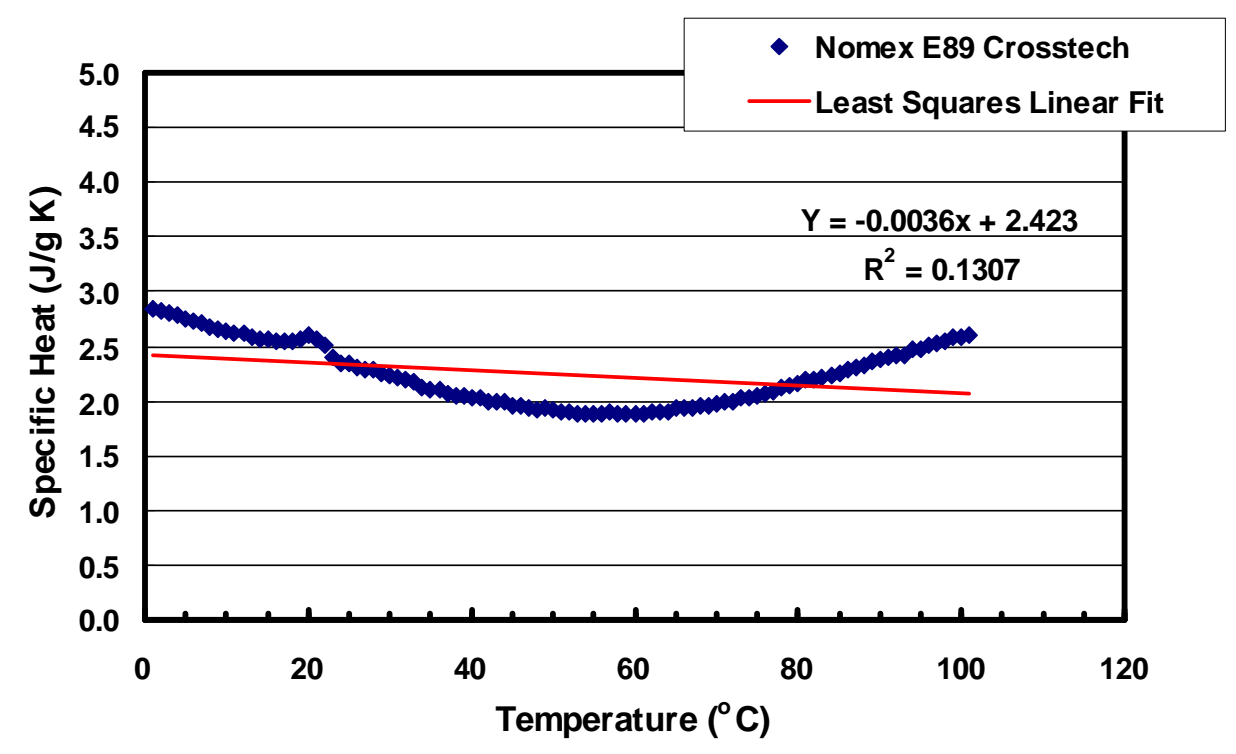

Figure 9A Specific Heat Capacity versus Temperature for Nomex E89 Crosstech $®$. Least Squares Linear Fit to Experimental Data.

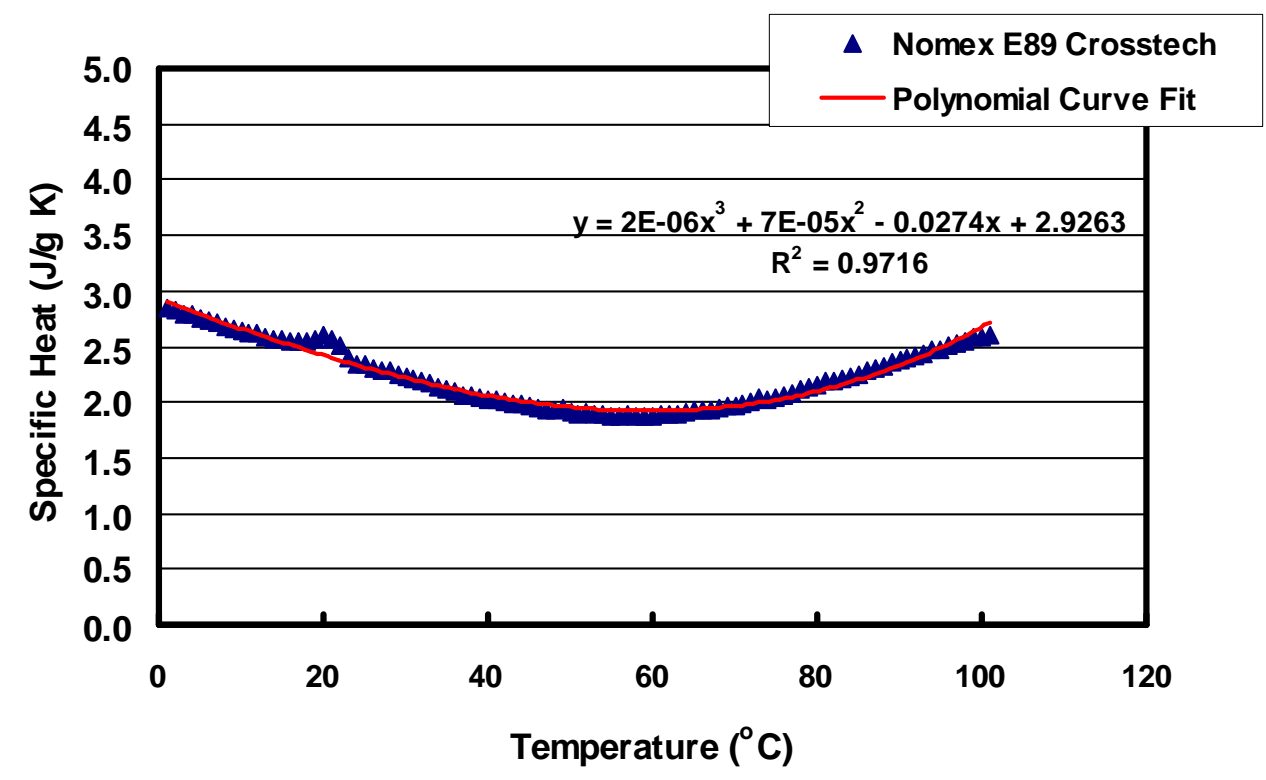

Figure 10A Specific Heat Capacity versus Temperature for Nomex E89 Crosstech®. Polynomial Curve Fit to Experimental Data. 


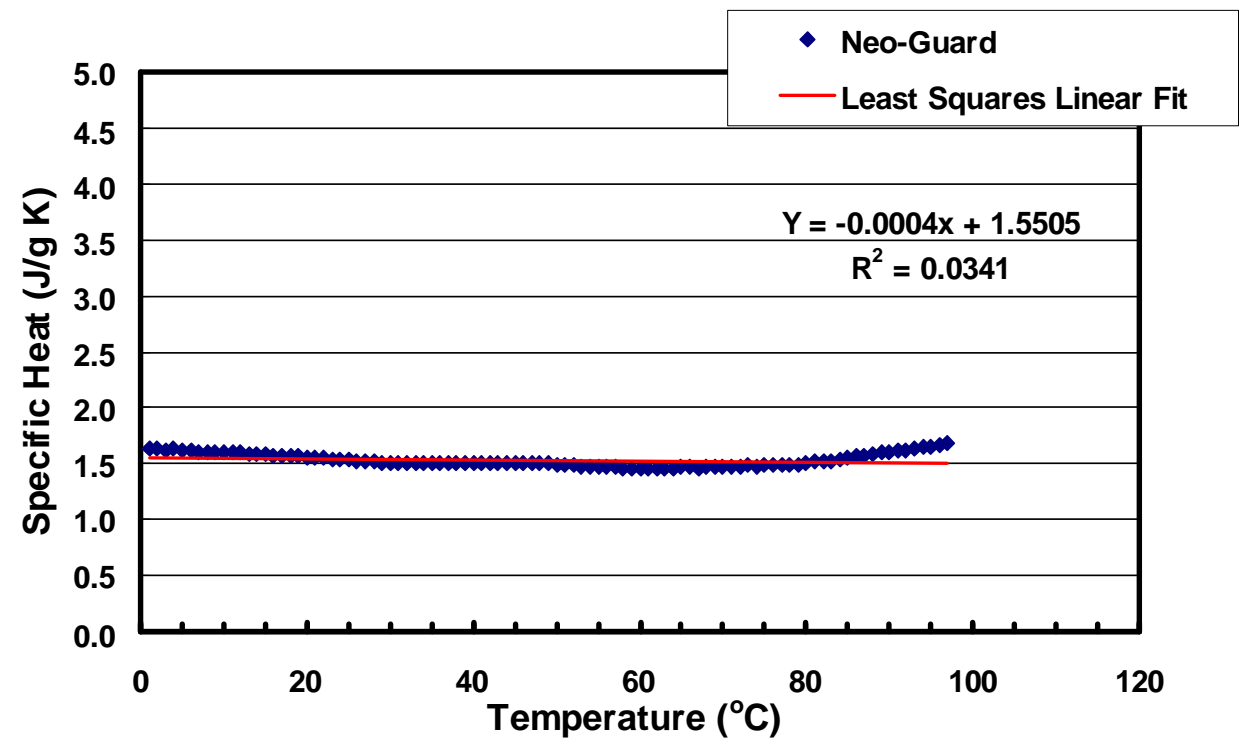

Figure 11A Specific Heat Capacity versus Temperature for Neo-Guard®. Least Squares Linear Fit to Experimental Data.

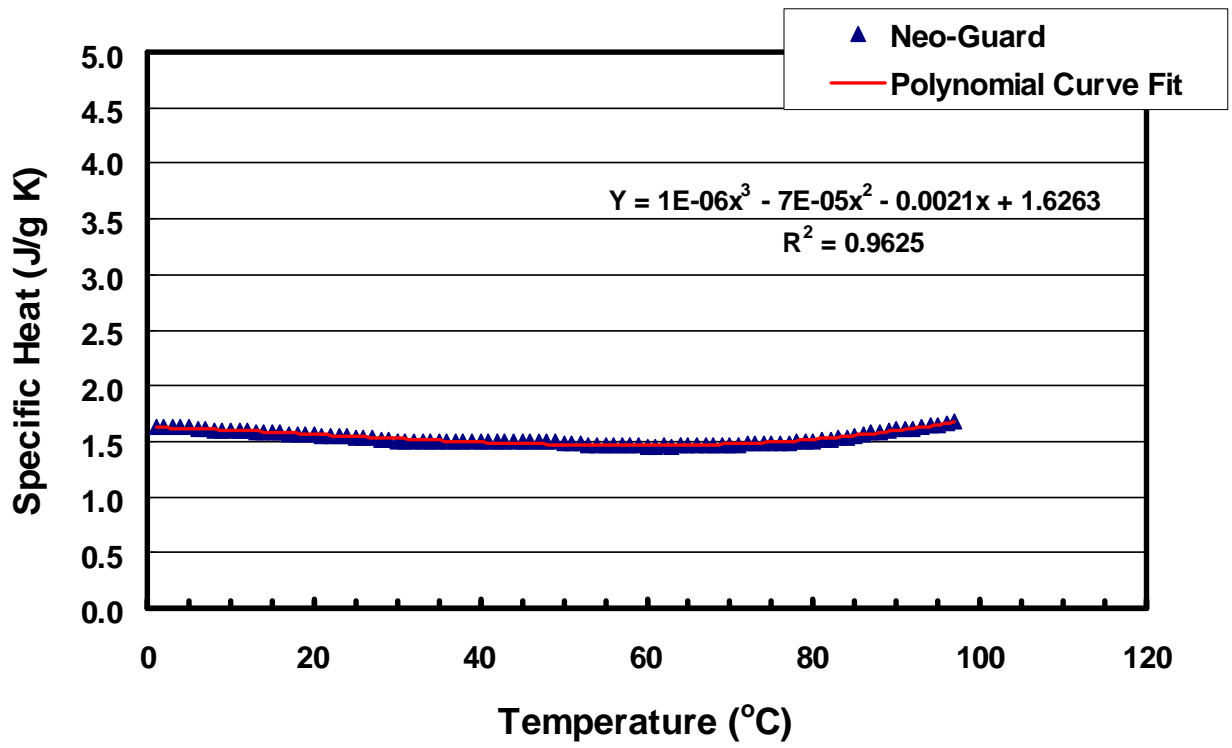

Figure 12A Specific Heat Capacity versus Temperature for Neo-Guard®. Polynomial Curve Fit to Experimental Data. 


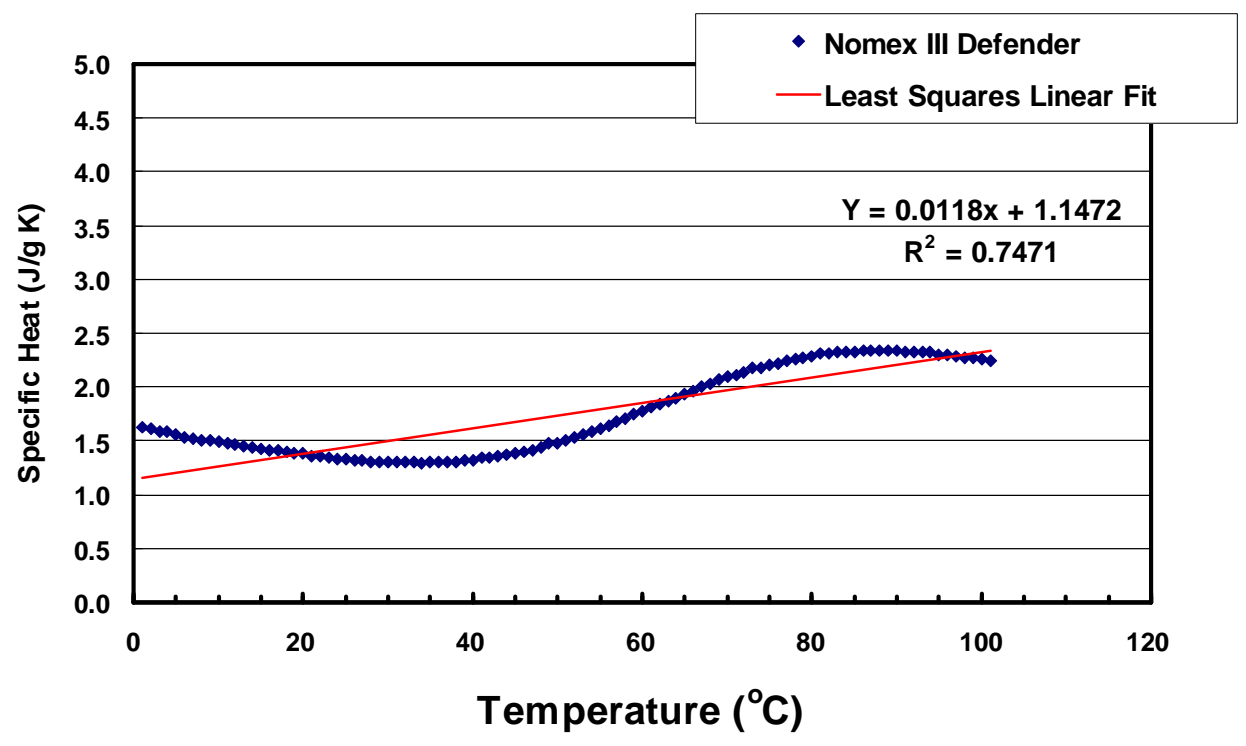

Figure 13A Specific Heat Capacity versus Temperature for Nomex III Defender®. Least Squares Linear Fit to Experimental Data.

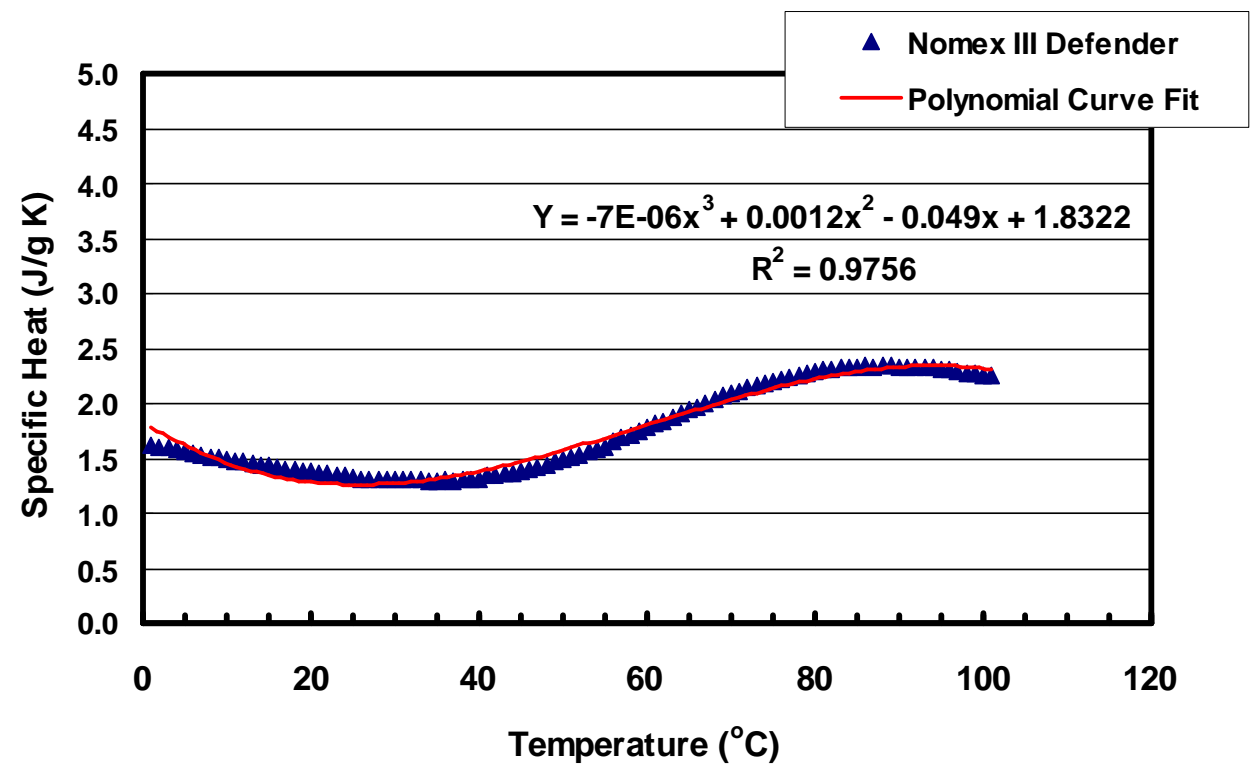

Figure 14A Specific Heat Capacity versus Temperature for Nomex III Defender®. Polynomial Curve Fit to Experimental Data. 


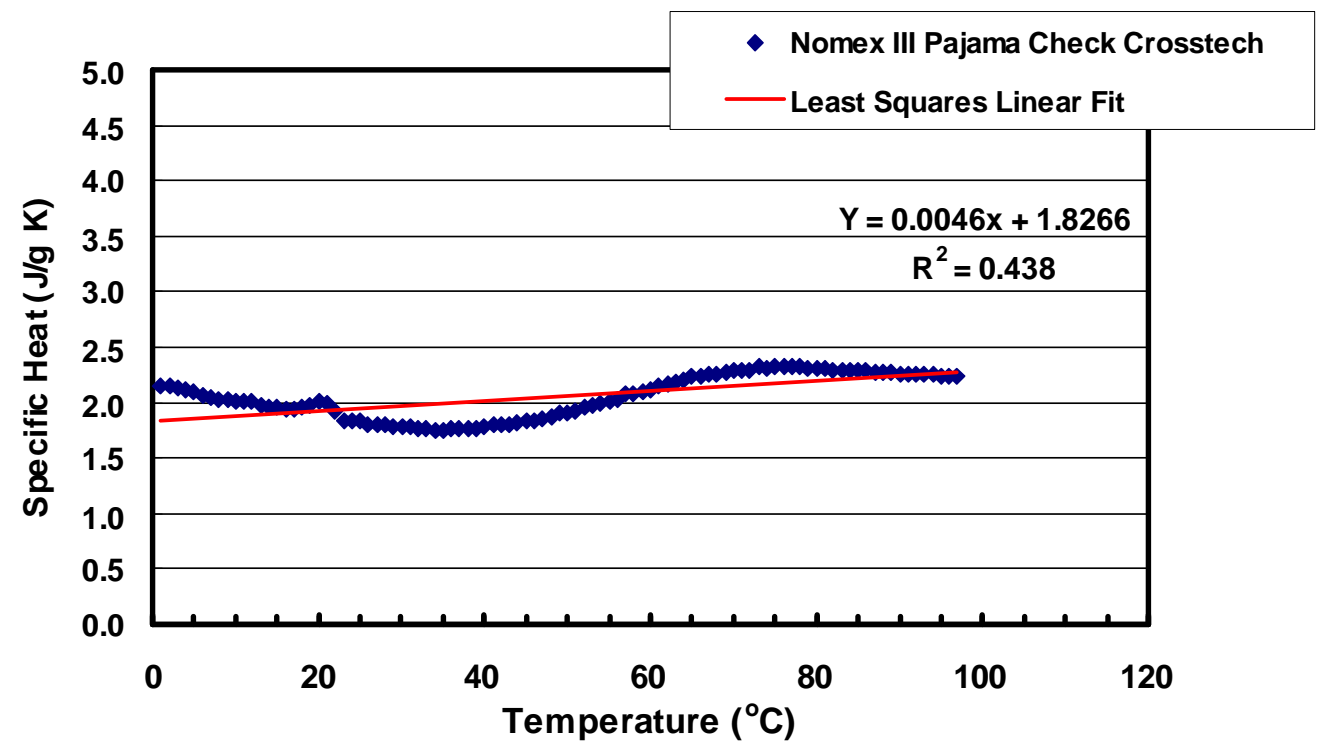

Figure 15A Specific Heat Capacity versus Temperature for Nomex III Pajama Check Crosstech®. Least Squares Linear Fit to Experimental Data.

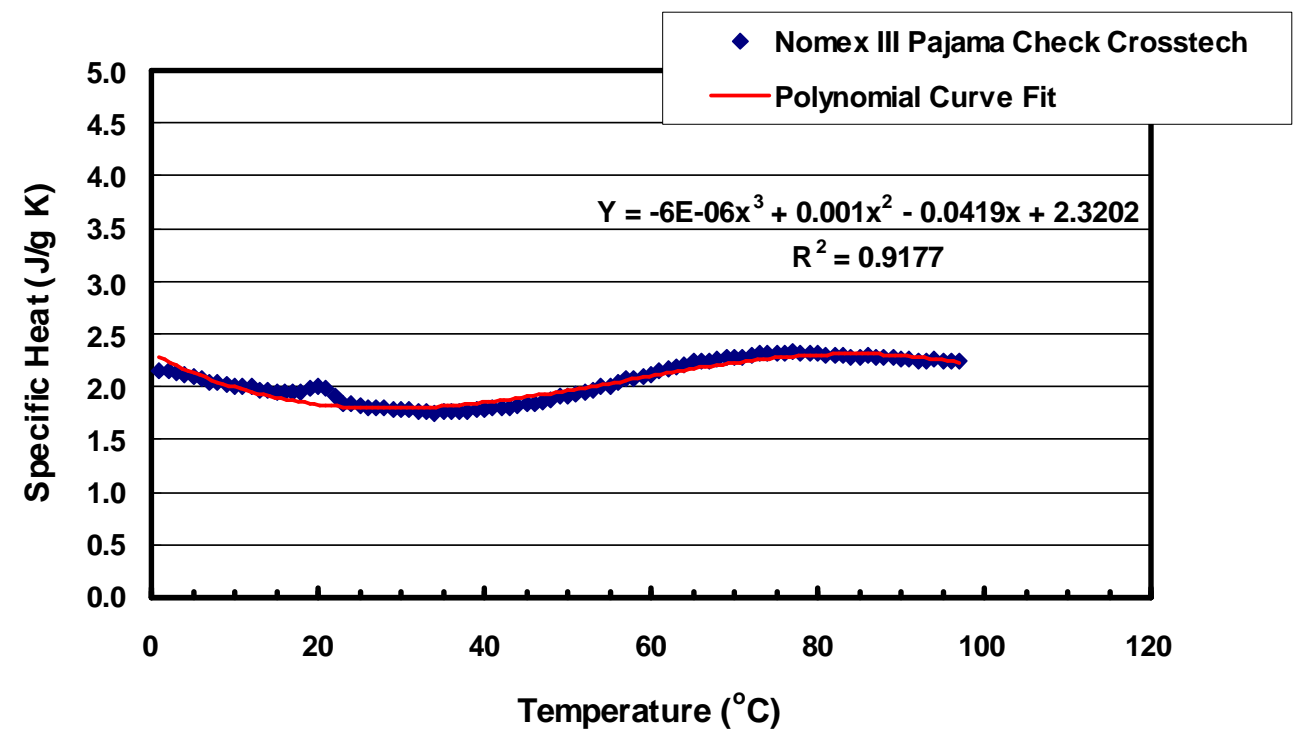

Figure 16A Specific Heat Capacity versus Temperature for Nomex III Pajama Check Crosstech®. Polynomial Curve Fit to Experimental Data. 


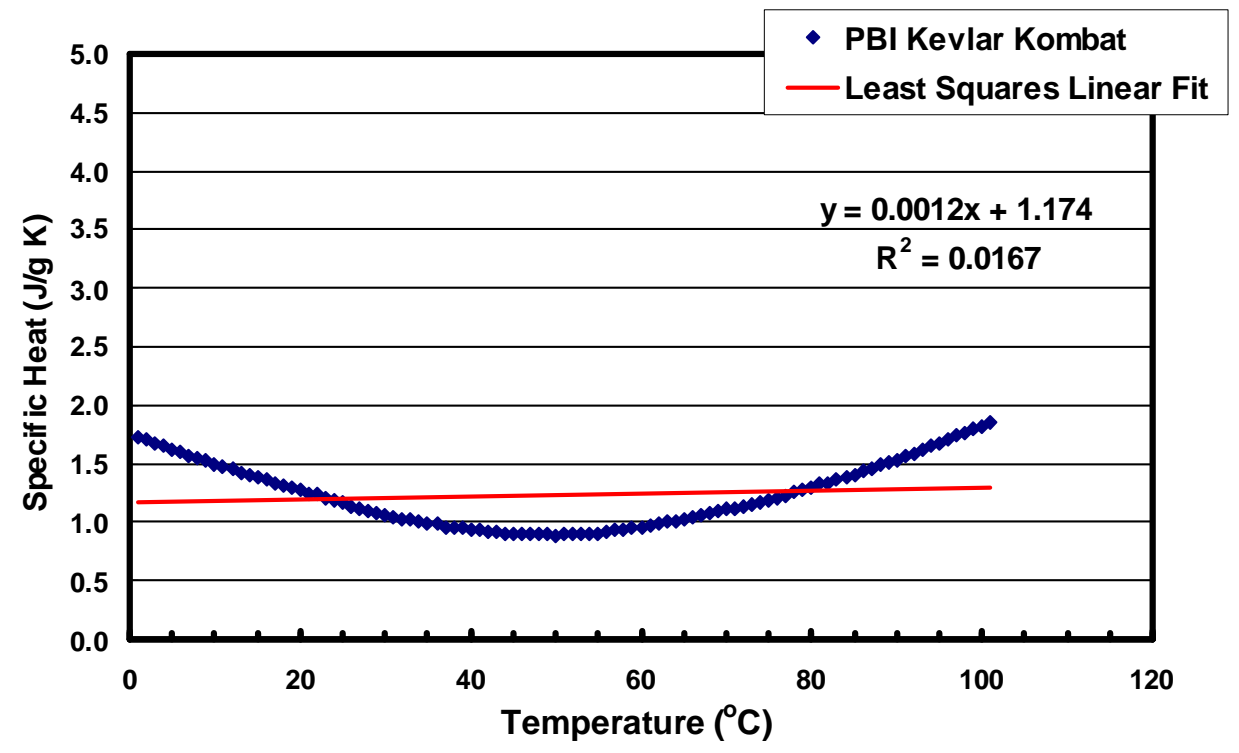

Figure 17A Specific Heat Capacity versus Temperature for PBI Kevlar Kombat ${ }^{\circ}$. Least Squares Linear Fit to Experimental Data.

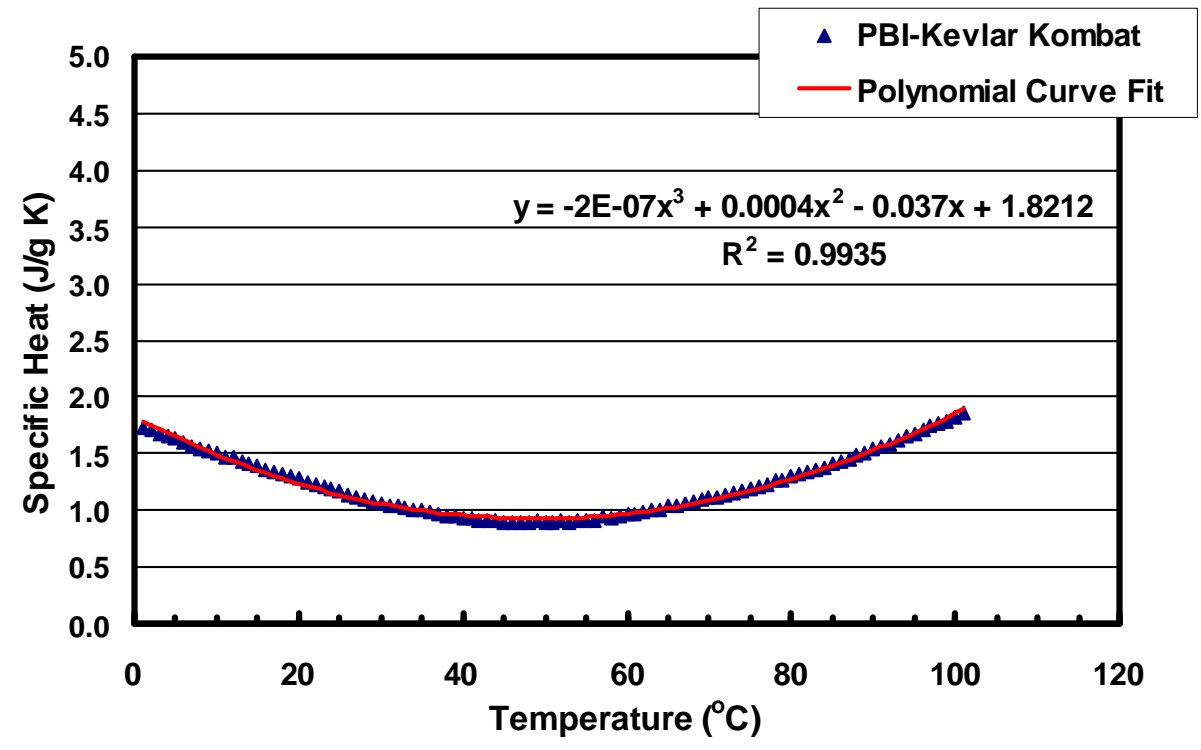

Figure 18A Specific Heat Capacity versus Temperature for PBI Kevlar Kombat@. Polynomial Curve Fit to Experimental Data. 


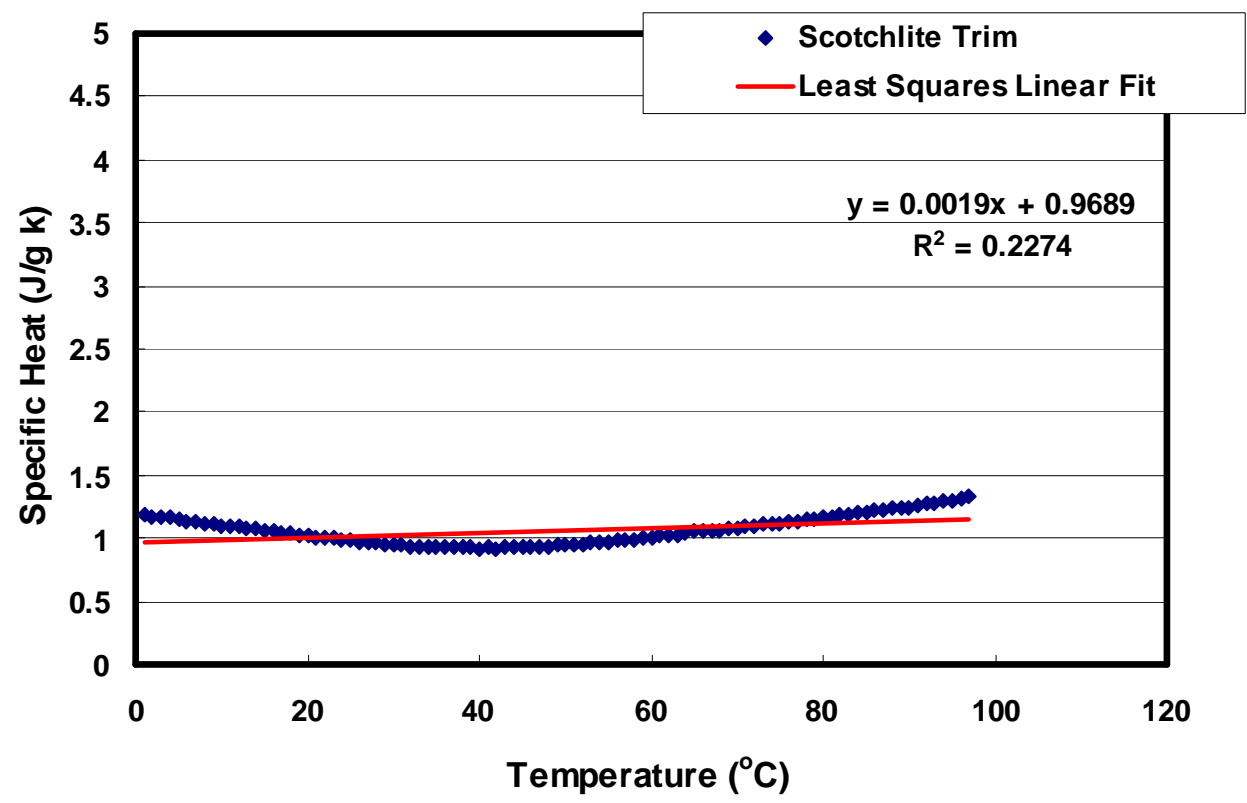

Figure 19A Specific Heat Capacity versus Temperature for Scotchlite® Trim. Least Squares Linear Fit to Experimental Data.

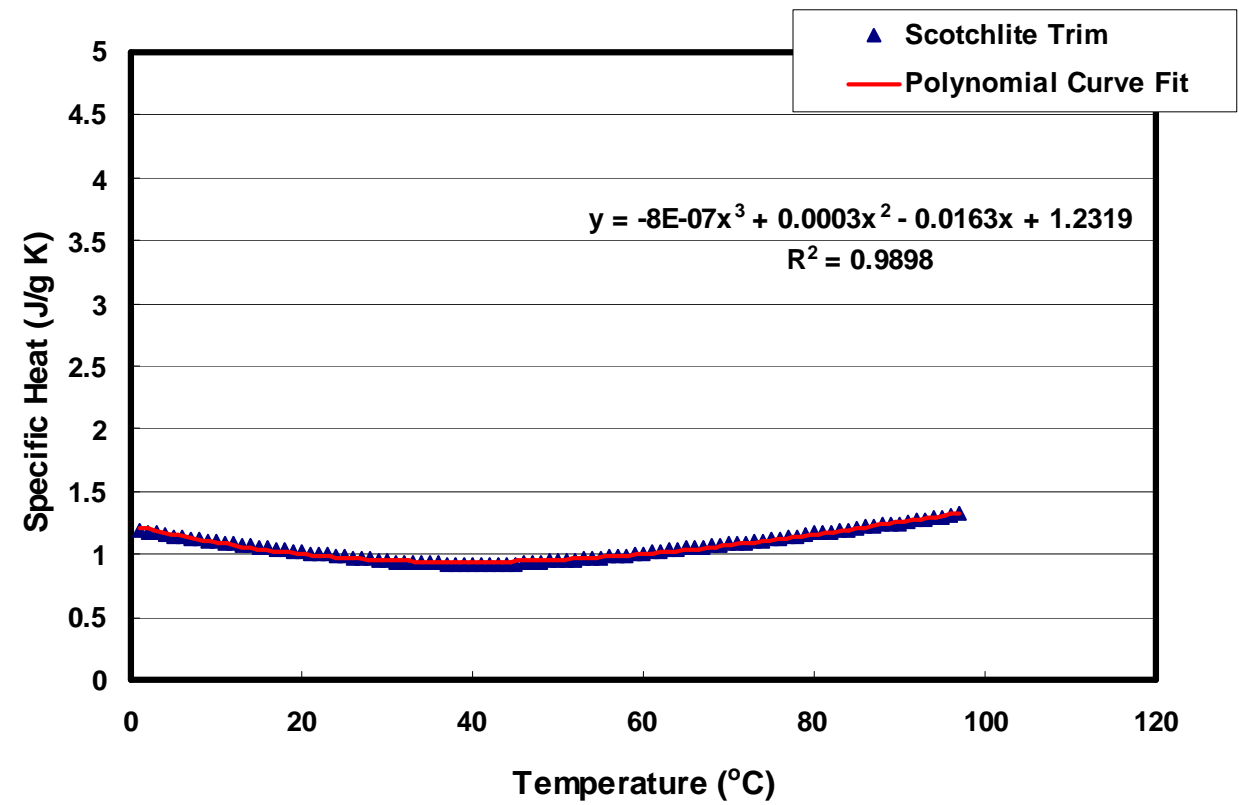

Figure 20A Specific Heat Capacity versus Temperature for Scotchlite ${ }^{\circledR}$ Trim. Polynomial Curve Fit to Experimental Data. 


\title{
Appendix B
}

\section{REPORT: Measurement of the Infrared Transmittance and Reflectance of Fabric Samples for Building and Fire Research Laboratory}

\author{
Simon Kaplan, Optical Technology Division, NIST \\ Report Date: 30 November, 2000
}

Description of Samples: Fabric swaths of 10 different commercial materials used in fire-protection clothing were supplied to the Optical Technology Division. The set included samples of the following materials: Aralite ${ }^{\circledR}$, Breathe-Tex ${ }^{\circledR}$, Breathe-Tex ${ }^{\circledR}$ Plus, Cotton Duck, Neo-Guard $\AA$, Nomex ${ }^{\circledR}$ E89, Nomex® III Defender ${ }^{\mathrm{TM}}$, Nomex ${ }^{\circledR}$ IIIa Pajama Check-Crosstech®, PBI ${ }^{\mathrm{TM}}$ Kevlar$^{\circledR} K_{0 m b a t}{ }^{\mathrm{TM}}$, and ScotchLite®. Several of the materials have no apparent difference between the two sides, while others are clearly a composite of more than one sheet of material, with different properties on the two sides. One material, Scotchlite, has three distinct phases - the backside material, and orange and silver colored material on the front.

Sample Handling: Square sections of material approximately $50 \mathrm{~mm}$ on a side were cut from the provided samples. The samples were only handled with clean plastic gloves, and mounted onto the integrating sphere apparatus described below by clamping them underneath an aluminum washer with a $25 \mathrm{~mm}$ diameter clearance hole to allow optical access. In the case of the Scotchlite material, two pieces were prepared to test both the silver-striped and orange parts of the fabric. The measurement apparatus is housed in a purged environment in which the water-vapor and $\mathrm{CO}_{2}$ have been largely removed from the atmosphere, and the temperature is $23 / \mathrm{C} \pm 0.5 / \mathrm{C}$.

Experimental Details: Measurements were made of the spectral directional-hemispherical reflectance and transmittance of the fabric samples over the range from $550 \mathrm{~cm}^{-1}$ to $6500 \mathrm{~cm}^{-1}$, with a spectral resolution of $16 \mathrm{~cm}^{-1}$. The incident beam had an $\mathrm{f} / 6$ focusing geometry, with the central axis tilted by 8/ with respect to the sample normal, and the spot size at the sample is approximately $10 \mathrm{~mm}$. The optical radiation source and wavenumber selectivity were provided by a Bio-Rad FTS-60a FourierTransform Infrared (FTIR) spectrophotometer, which was configured with a ceramic-coated globar source and a $\mathrm{Ge}$-coated $\mathrm{KBr}$ beamsplitter. The nearly collimated, $50 \mathrm{~mm}$ diameter output beam from theFTIR was focused onto an external $4 \mathrm{~mm}$ diameter aperture with $\mathrm{f} / 4$ optics and re-collimated before being focused (f/6) at the sample position.

The directional-hemispherical measurement geometry is implemented by using a diffuse-gold coated $150 \mathrm{~mm}$ diameter integrating sphere, with the samples mounted on a port cut into the surface of the sphere. A liquid-nitrogen-cooled photoconductive $\mathrm{HgCdTe}$ detector is mounted on top of the sphere with its field of view restricted to a portion of the bottom surface of the sphere. The design considerations and measurement procedure using this apparatus have been described previously [1]. 
The sequence of measurements to produce values for directional-hemispherical reflectance and transmittance consists of three parts. First, a spectrum is acquired as the incident beam travels through the reference port and strikes the wall of the integrating sphere at a point where the specularly reflected or transmitted beam from the sample would strike. This is the reference measurement. Then the sphere is rotated so that the beam enters the sphere through the entrance port and is reflected from the sample. Finally, the sphere is rotated so that the beam is incident on the outside surface of the sample and is transmitted into the sphere.

The directional-hemispherical reflectance and transmittance are calculated as the ratios of the last two measurements to the first measurement, times a correction factor needed to account for the difference in throughput of the sphere for light incident on the specular position of the sphere wall, versus light scattered from the sample which fills the entire sphere. A correction factor, which varies from about $6 \%$ to $8 \%$ over the measured spectral range, was obtained from mapping the sphere throughput variation in both latitude and longitude, and strictly applies only to ideal Lambertian samples. For perfectly specular samples, the correction factor is very small $(\sim 0.2 \%)$. Most reasonably diffuse samples with no strong directionality in their scattering will fall somewhere between these two limits. Without any additional knowledge of the scattering characteristics of the sample, we take one half of the Lambertian correction factor and apply it the raw measurement results. The uncertainty in the actual flux distribution from the sample leads to the dominant source of uncertainty in the measured values, as described below.

The measurements were repeated three times for each sample and averaged together, resulting in approximately 30 minutes of collection time for each complete set of data. The standard deviation of the three values was used to determine the repeatability (type-A) component of the expanded uncertainty described below. For samples with different properties for the front and back surfaces, the samples were removed and flipped over for another set of measurements. In these cases, the transmittance was found to be indistinguishable for the two directions of incidence, as would be expected for isotropic materials, although the reflectances differed substantially in some cases.

Uncertainty Analysis: The uncertainties in the measured values of directional-hemispherical reflectance and transmittance consist of two main components. The first (type-A) component accounts for the repeatability of the measurement and is derived as the standard deviation of the series of three measurements divided by the square root of 3 . The main contributor to this component is noise in the detector element and amplifier, with a small contribution from drift in the interferometer alignment and source temperature.

The second main component is a systematic (type-B) component coming from the combination of nonuniformity in the sphere throughput and uncertainty in the flux distribution from the sample. As discussed above, a relative variation in throughput of up to $8 \%$ is expected for samples that range from perfectly specular to perfectly diffuse in their reflected flux distribution. We take half of the correction and apply it to the data in the absence of other information about the samples' scattering characteristics. A relative standard uncertainty component accounting for this lack of knowledge is taken as half of the residual, or approximately $1.5 \%$ to $2 \%$ as a function of wavenumber. Other type-B uncertainty components, due to detector nonlinearity, ambient thermal emission, inter-reflections, and phase error 
in the interferometer, are less than $0.1 \%$ and not important in this case. The zero-offset of the scale, due to stray light reaching the detector, is approximately $0.05 \%$ and negligible compared to the noise in the low-level transmittance and reflectance results.

The combined expanded uncertainty was calculated by adding the repeatability (type-A) and systematic uncertainty due to flux throughput non-uniformity (type-B) in quadrature, and multiplying the result by the coverage factor $\mathrm{k}=2$ for $95 \%$ confidence intervals [2]. The uncertainties are a function of wavenumber and are listed in the accompanying data files along with the measured transmittance and reflectance values.

Results and Discussion: The measured values of directional-hemispherical reflectance and transmittance, corrected as described above, are displayed in the 11 accompanying figures. For samples which had a difference between the front and back surfaces of the fabric, the respective figures show the reflectance of both sides (the transmittance being the same either way). The error bars show the combined expanded uncertainties. Also displayed on each figure is the absorptance of the sample, derived as $1-T-R$, where $T$ and $R$ represent the measured reflectance and transmittance. The uncertainty in the absorptance is the quadrature sum of the uncertainties in the reflectance and transmittance.

\section{References:}

[1] Leonard M. Hanssen and Simon Kaplan, "Infrared diffuse reflectance instrumentation and standards at NIST," Anal. Chim. Act. 380, 289-302 (1999).

[2] B. N. Taylor and C. E. Kuyatt, "Guidelines for Evaluating and Expressing the Uncertainty of NIST Measurement Results", NIST Technical Note 1297, U. S. Government Printing Office, Washington, D. C. (1994). 


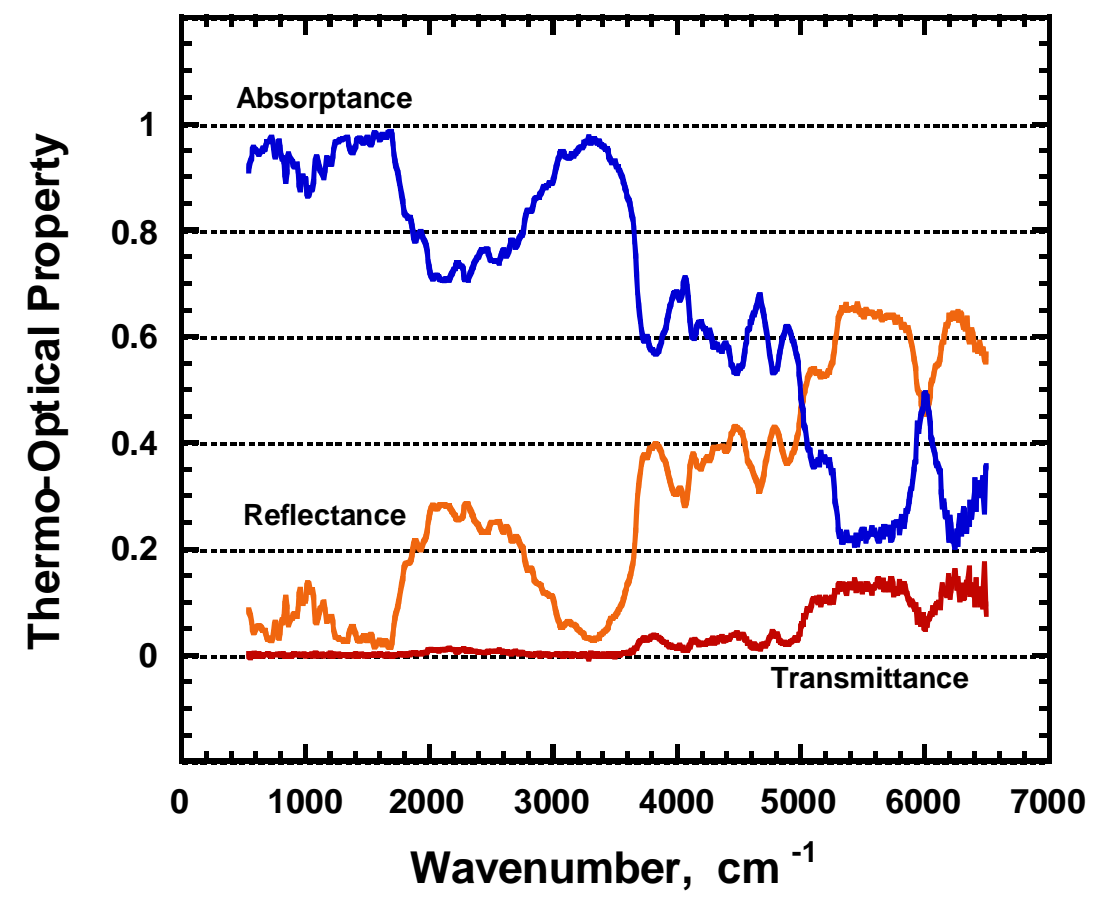

Figure 1B. Absorptance, Reflectance, and Transmittance for Front Surface of Aralite Material.

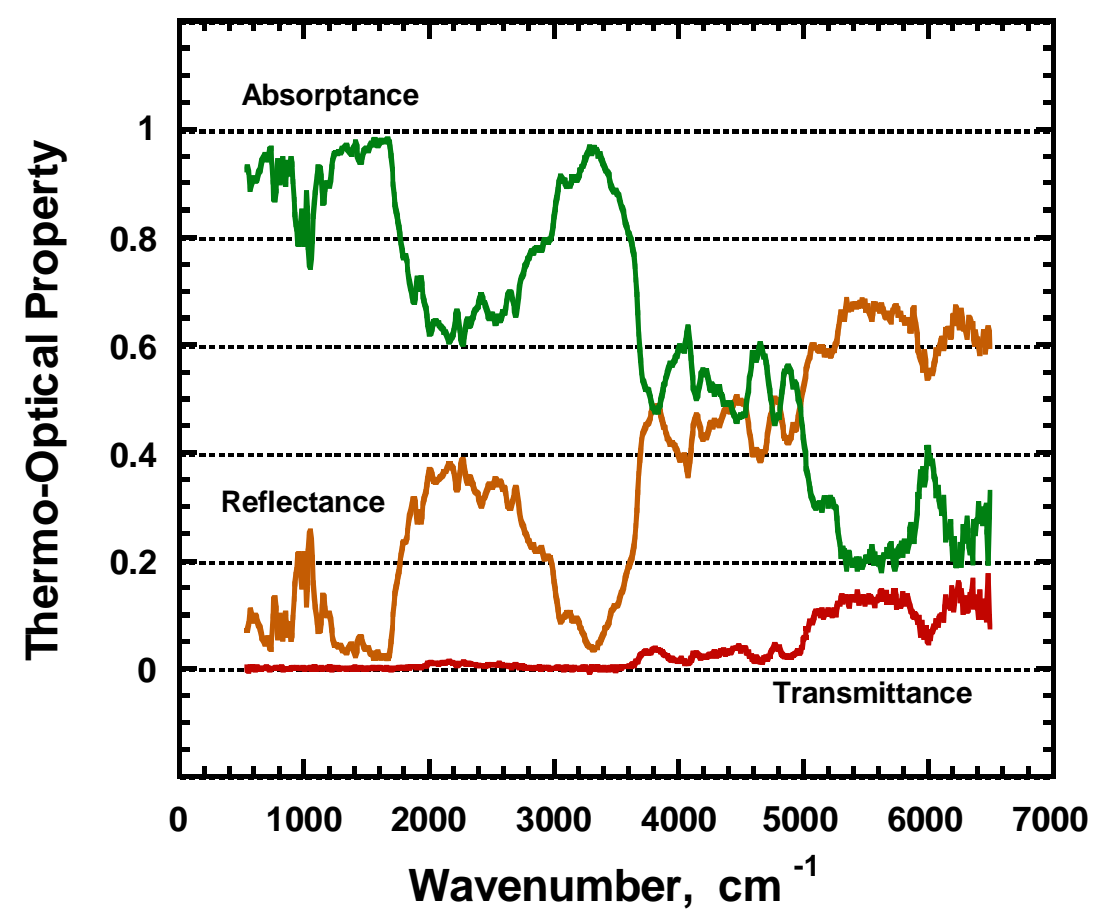

Figure 2B. Absorptance, Reflectance, and Transmittance for Back Surface of Aralite Material. 


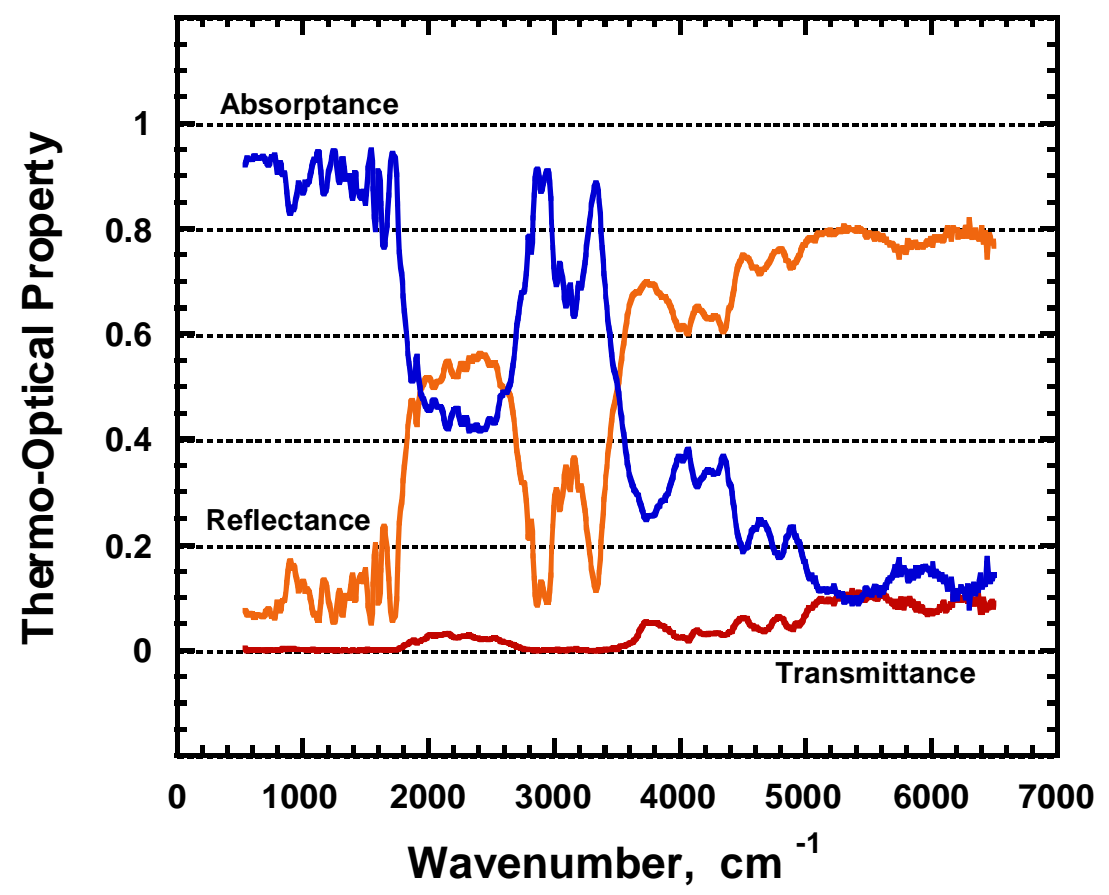

Figure 3B. Absorptance, Reflectance, and Transmittance for Front Surface of Breathe-Tex Material.

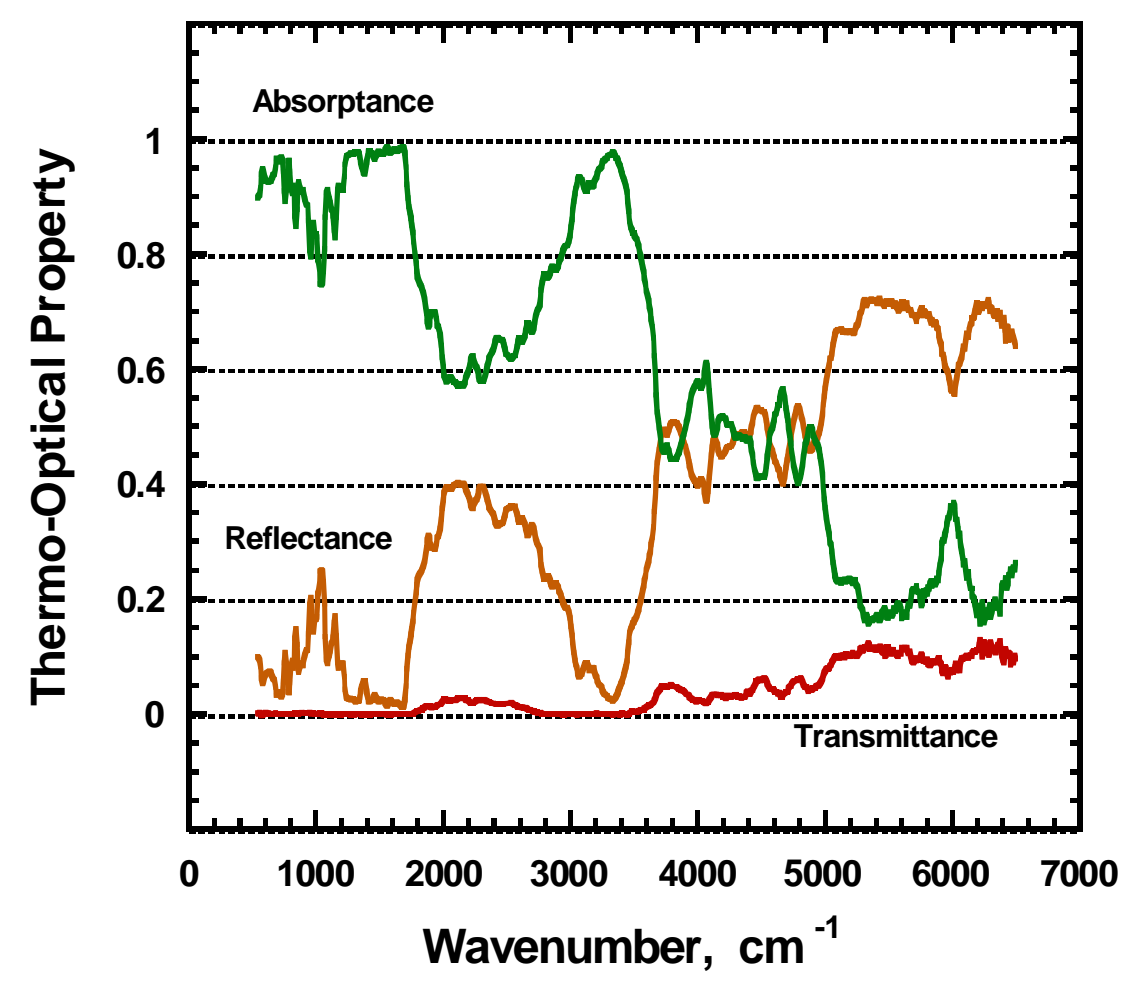

Figure 4B. Absorptance, Reflectance, and Transmittance for Back Surface of Breathe-Tex Material. 


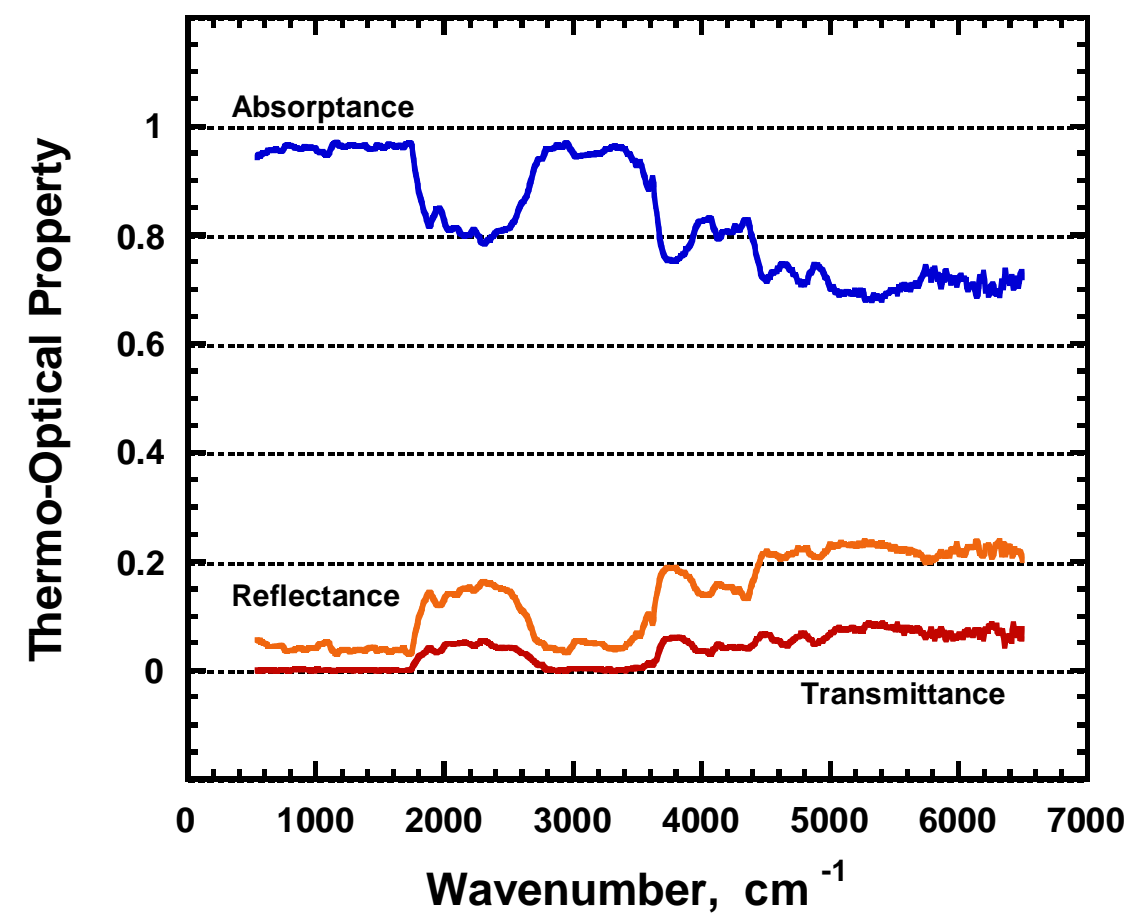

Figure 5B. Absorptance, Reflectance, and Transmittance for Front Surface of Breathe-Tex Plus Material.

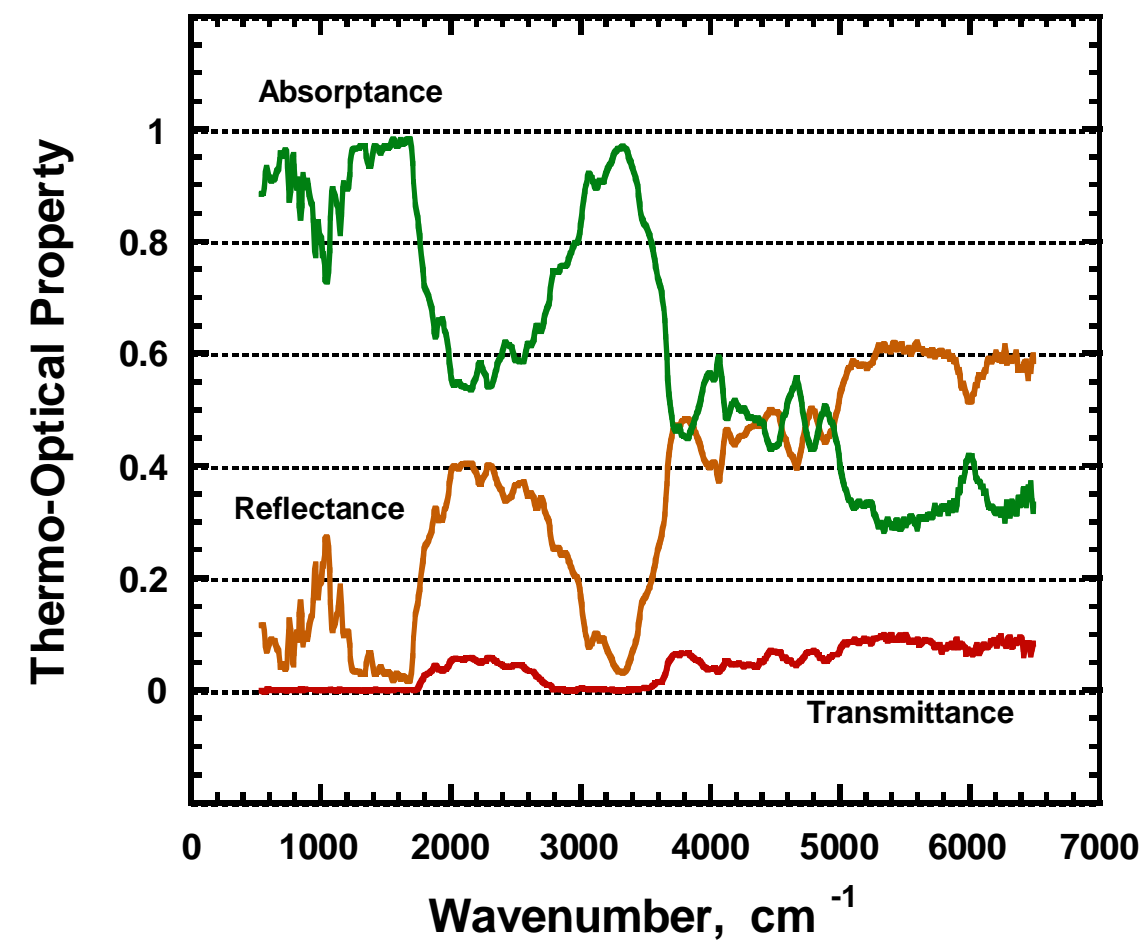

Figure 6B. Absorptance, Reflectance, and Transmittance for Back Surface of Breathe-Tex Plus Material. 


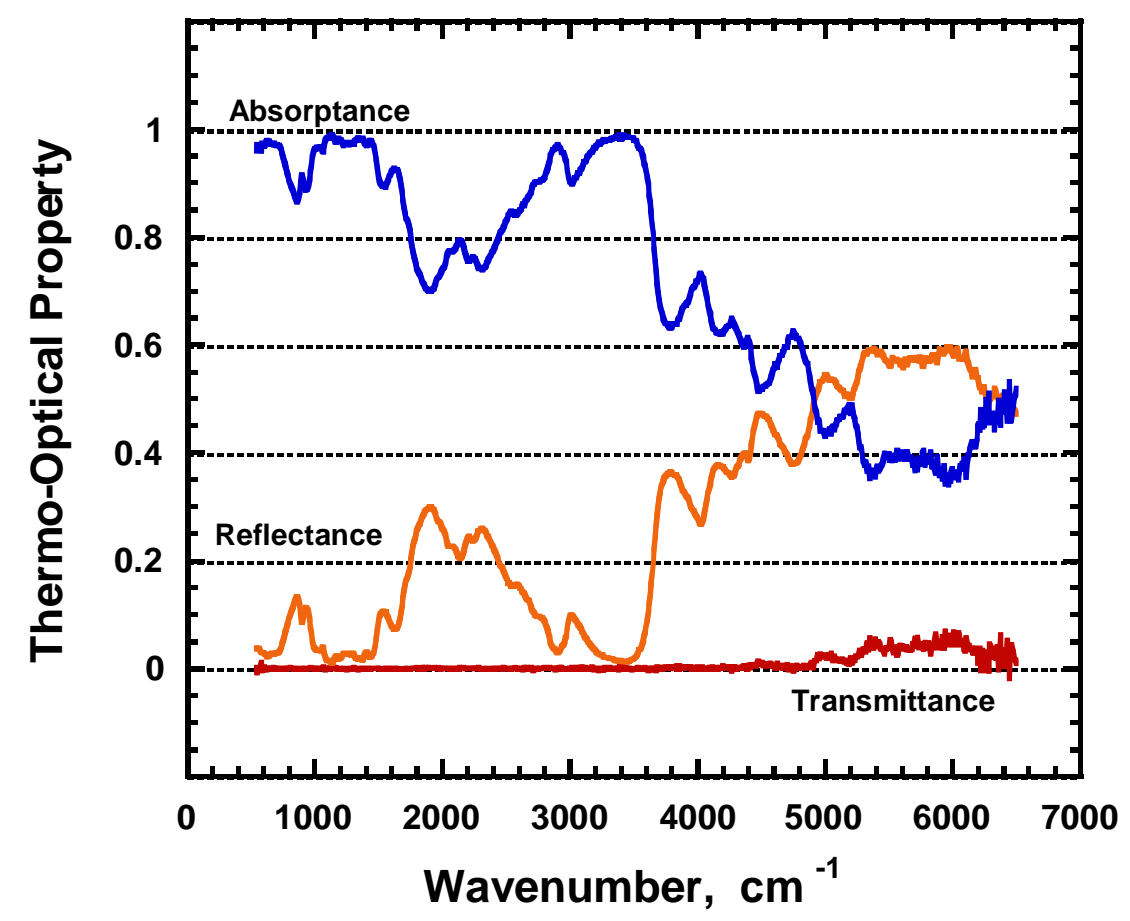

Figure 7B. Absorptance, Reflectance, and Transmittance for Cotton Duck Material.

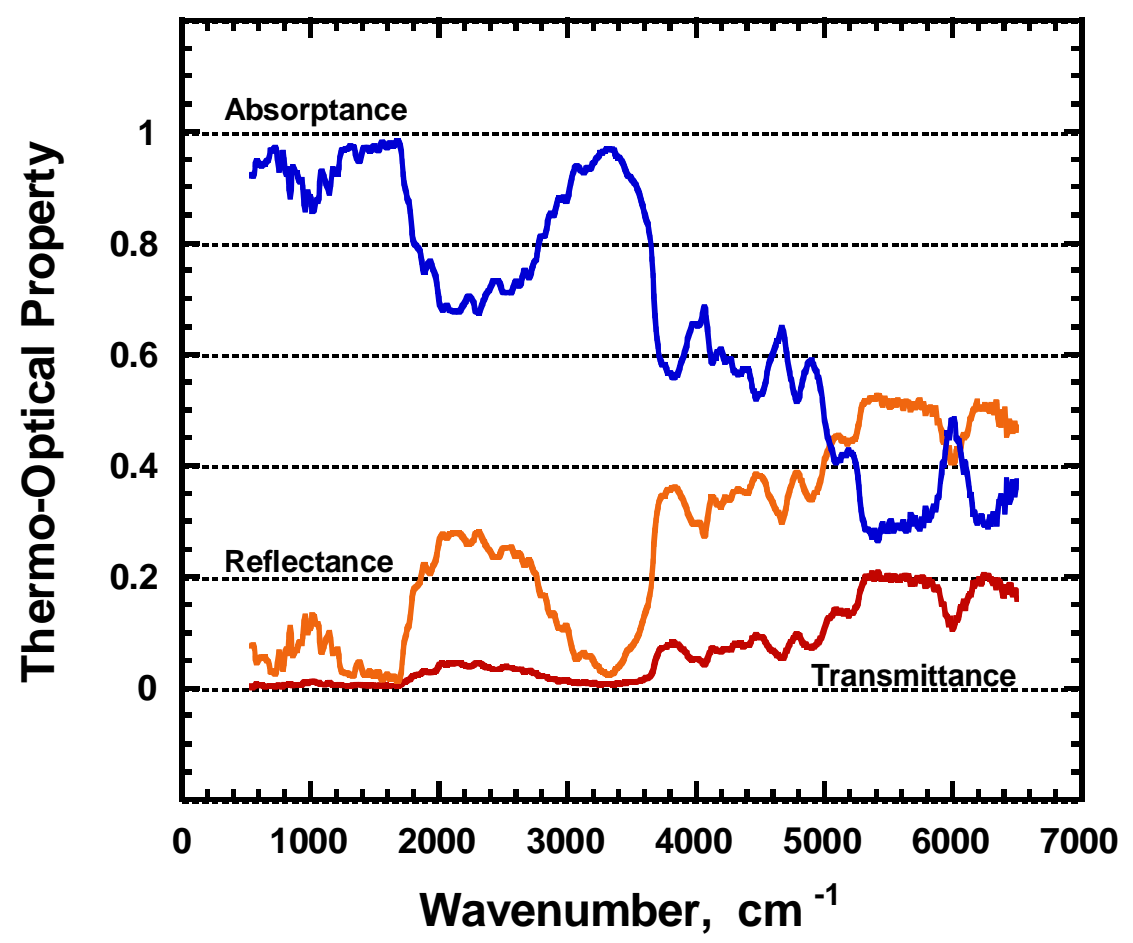

Figure 8B. Absorptance, Reflectance, and Transmittance for Nomex III Defender Material. 


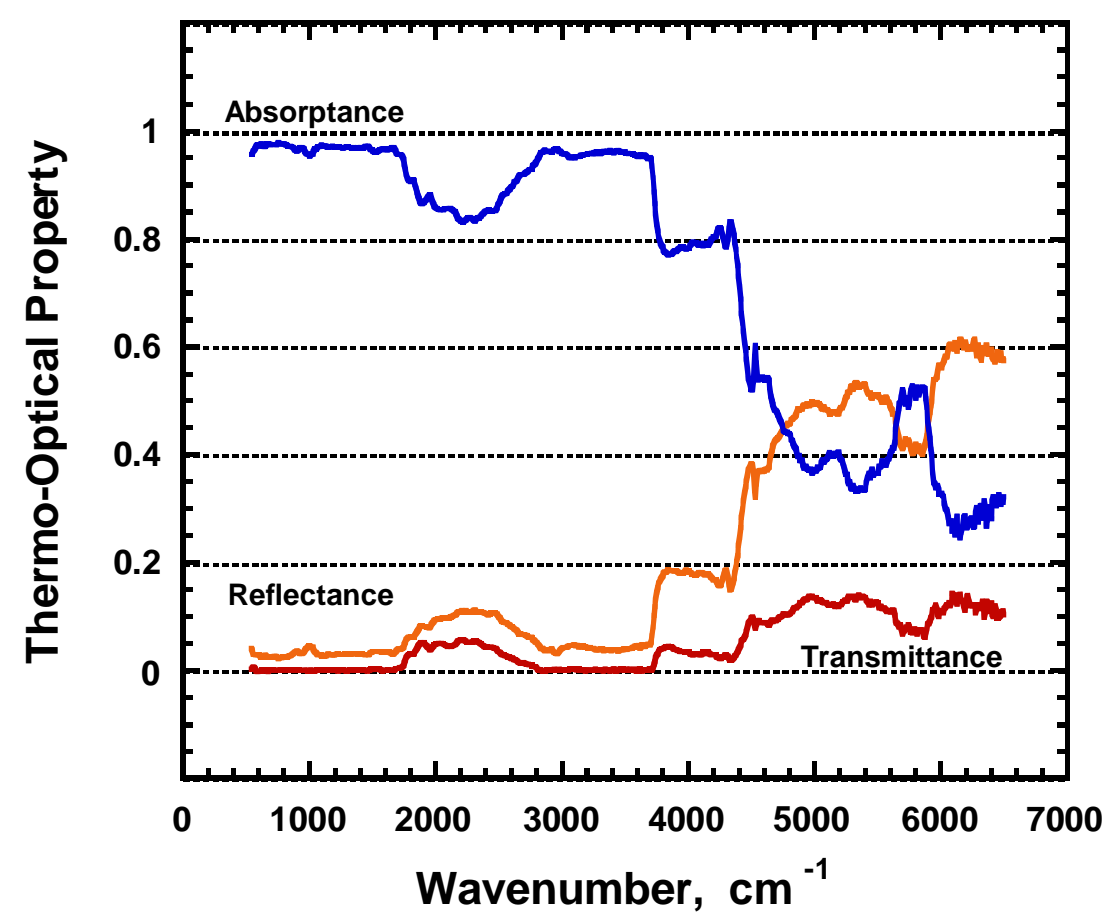

Figure 9B. Absorptance, Reflectance, and Transmittance for Front Surface of Neo-Guard Material.

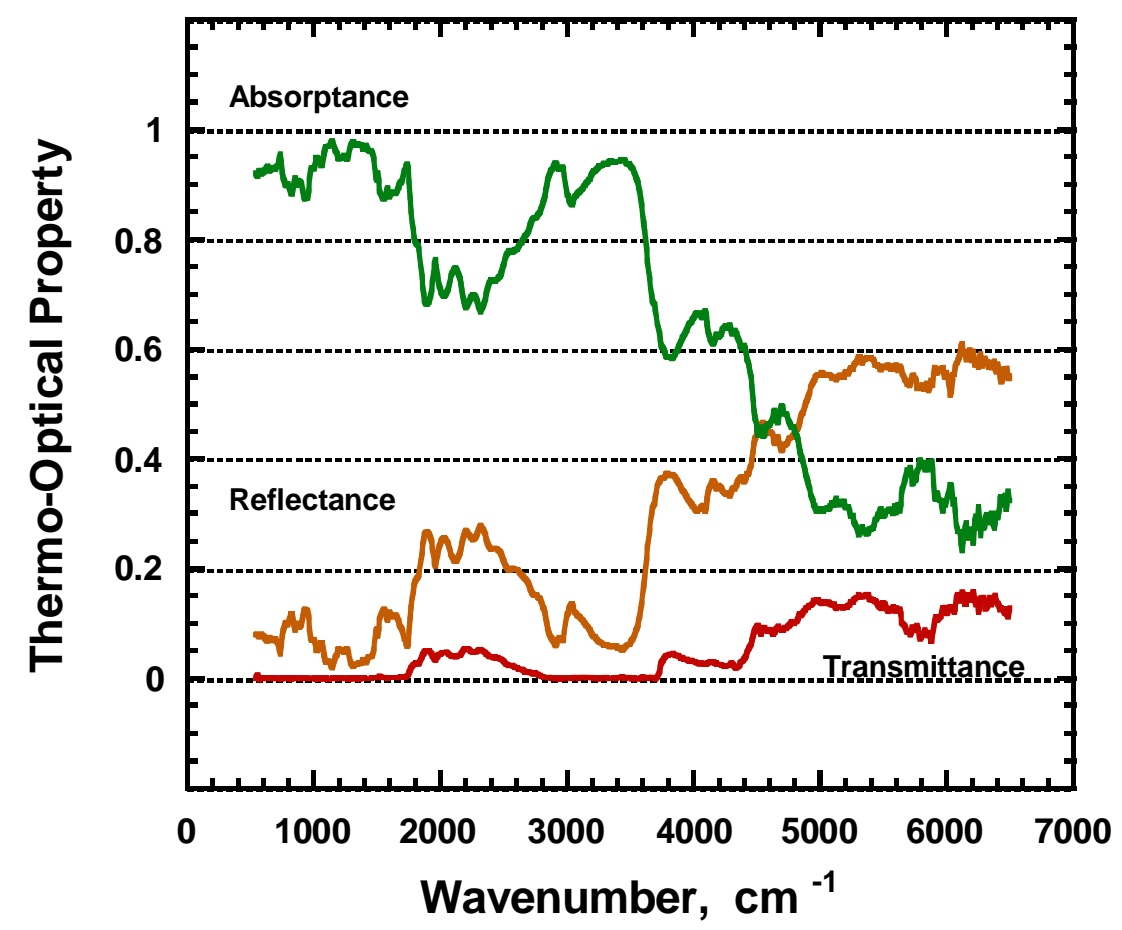

Figure 10B. Absorptance, Reflectance, and Transmittance for Back Surface of Neo-Guard Material. 


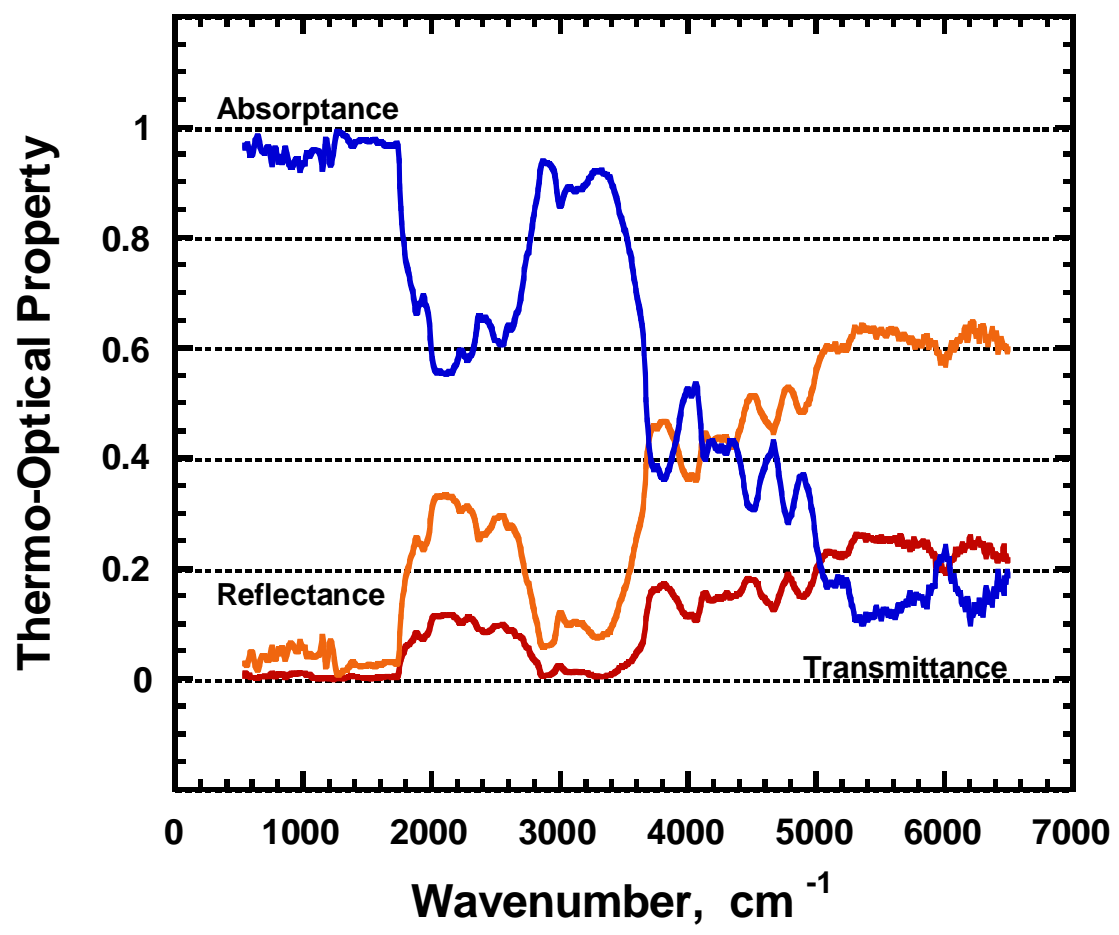

Figure 11B. Absorptance, Reflectance, and Transmittance for Front Surface of Nomex E89 Material.

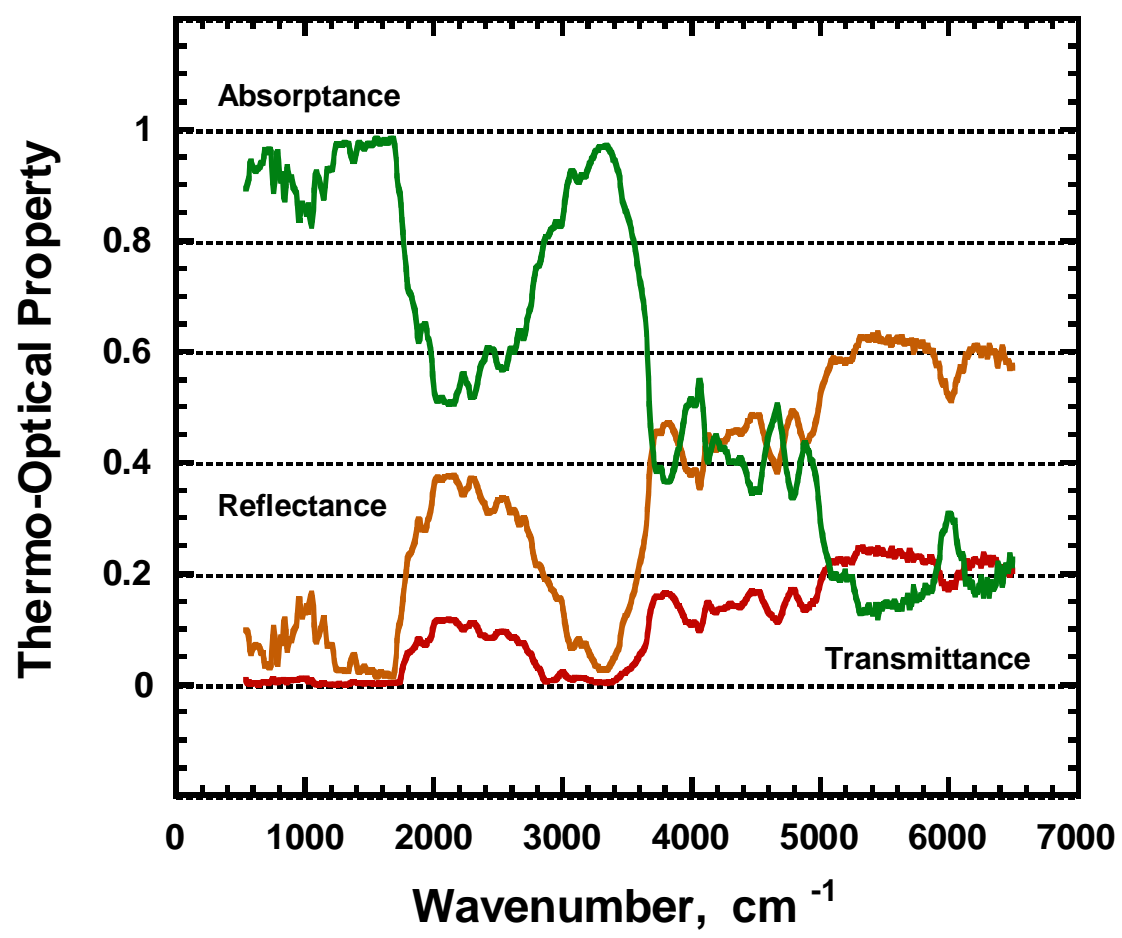

Figure 12B. Absorptance, Reflectance, and Transmittance for Back Surface of Nomex E89 Material. 


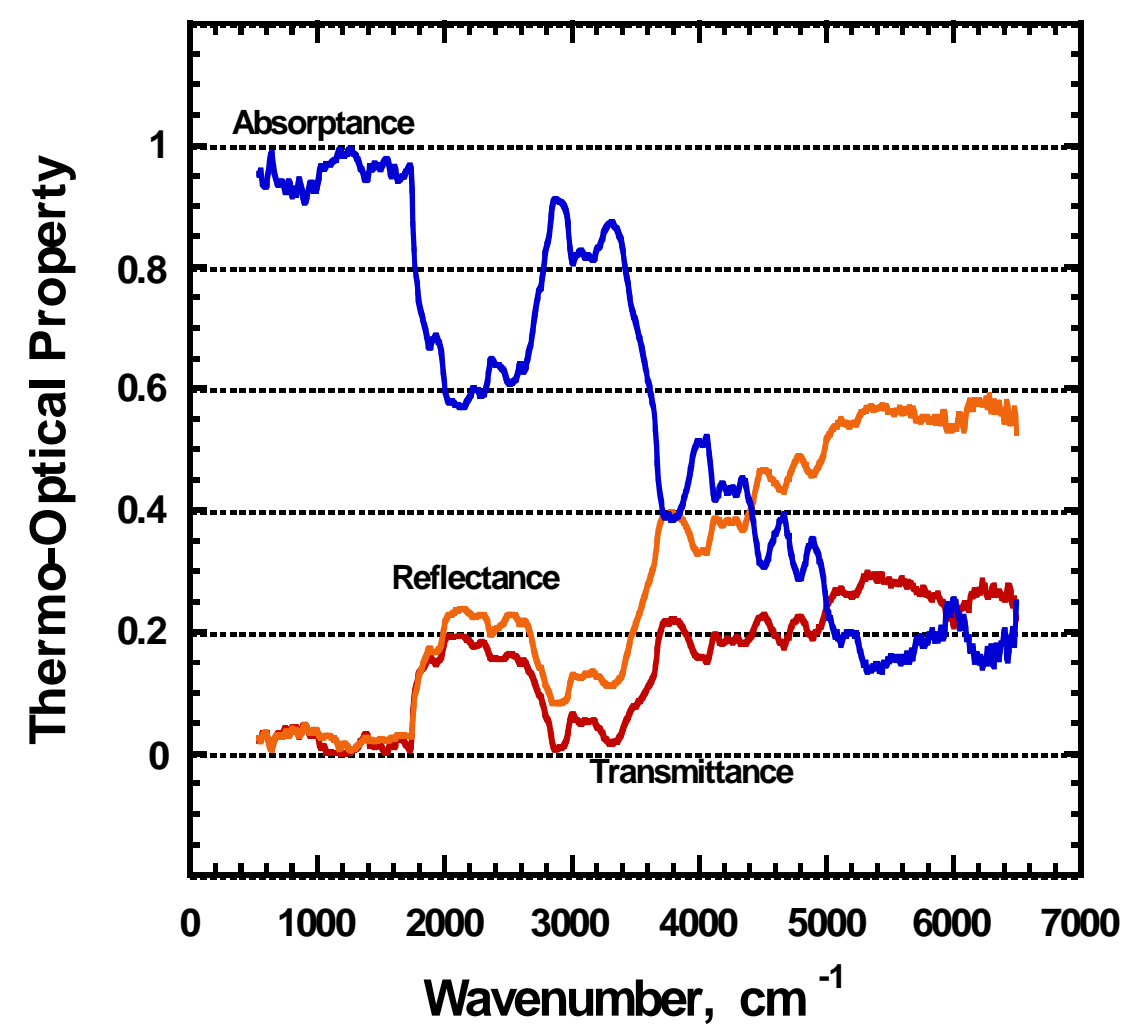

Figure 13B. Absorptance, Reflectance, and Transmittance for Front Surface of Nomex IIIA Material.

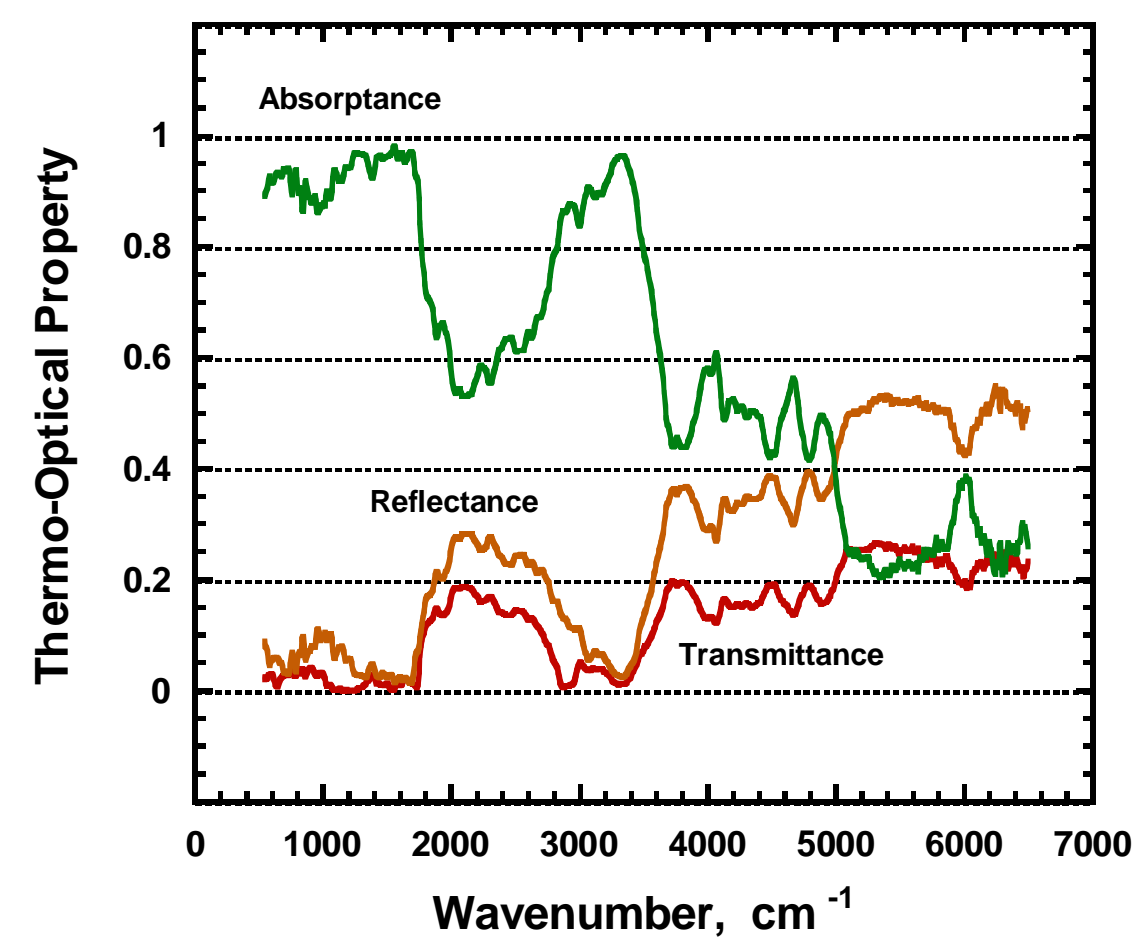

Figure 14B. Absorptance, Reflectance, and Transmittance for Back Surface of Nomex IIIA Material. 


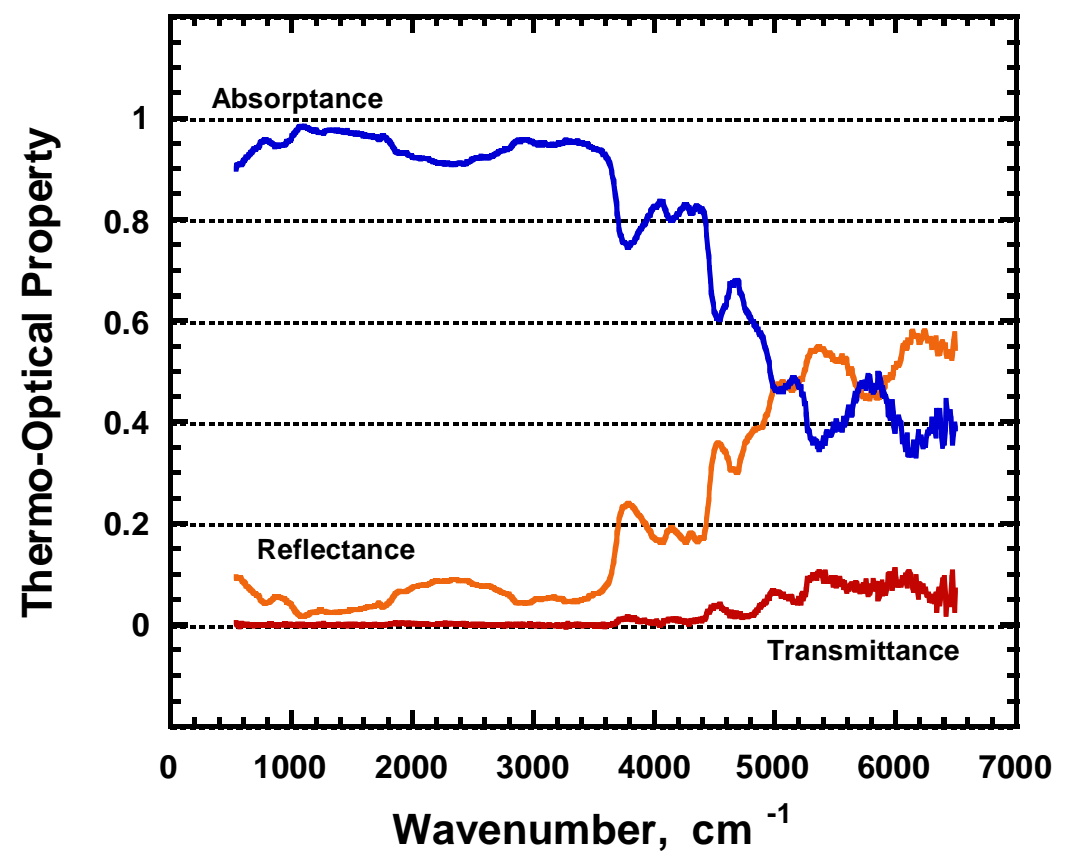

Figure 15B. Absorptance, Reflectance, and Transmittance for Front Surface of Scotchlite Orange Material.

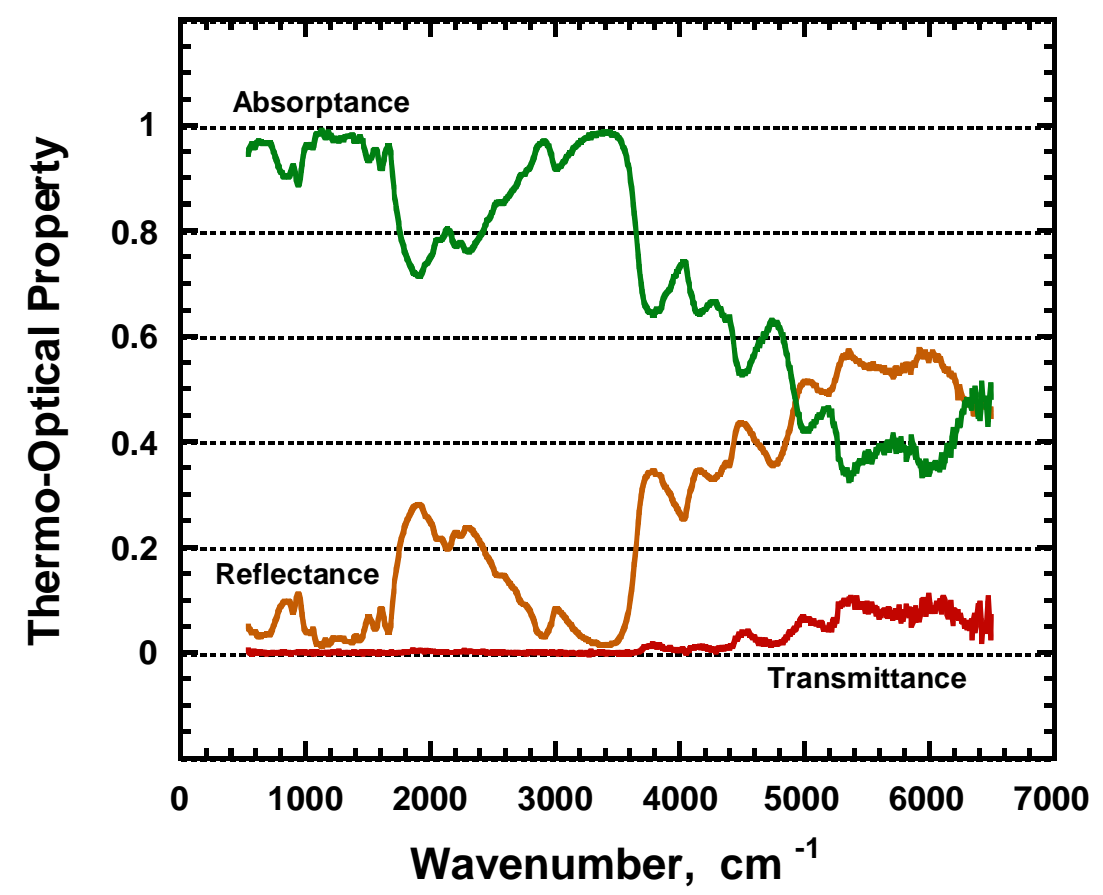

Figure 16B. Absorptance, Reflectance, and Transmittance for Back Surface of Scotchlite Orange Material. 


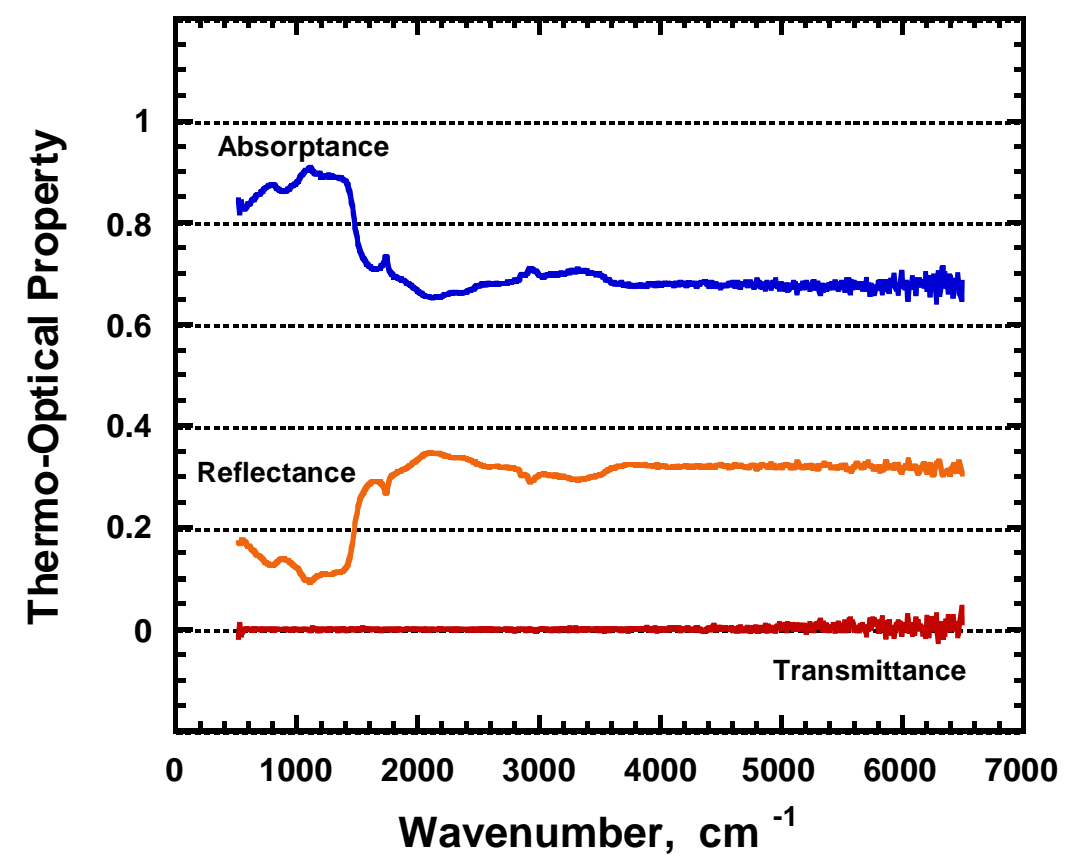

Figure 17B. Absorptance, Reflectance, and Transmittance for Front Surface of Scotchlite Silver Material.

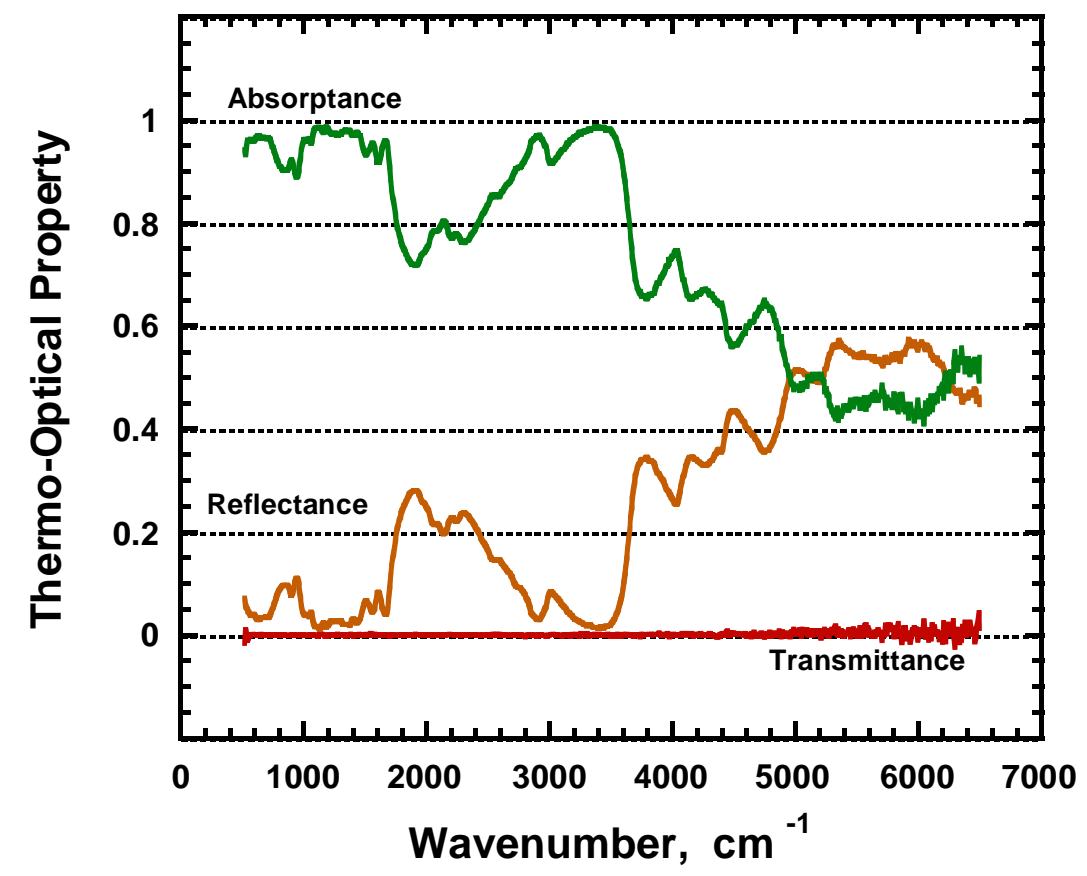

Figure 18B. Absorptance, Reflectance, and Transmittance for Rear Surface of Scotchlite Silver Material. 


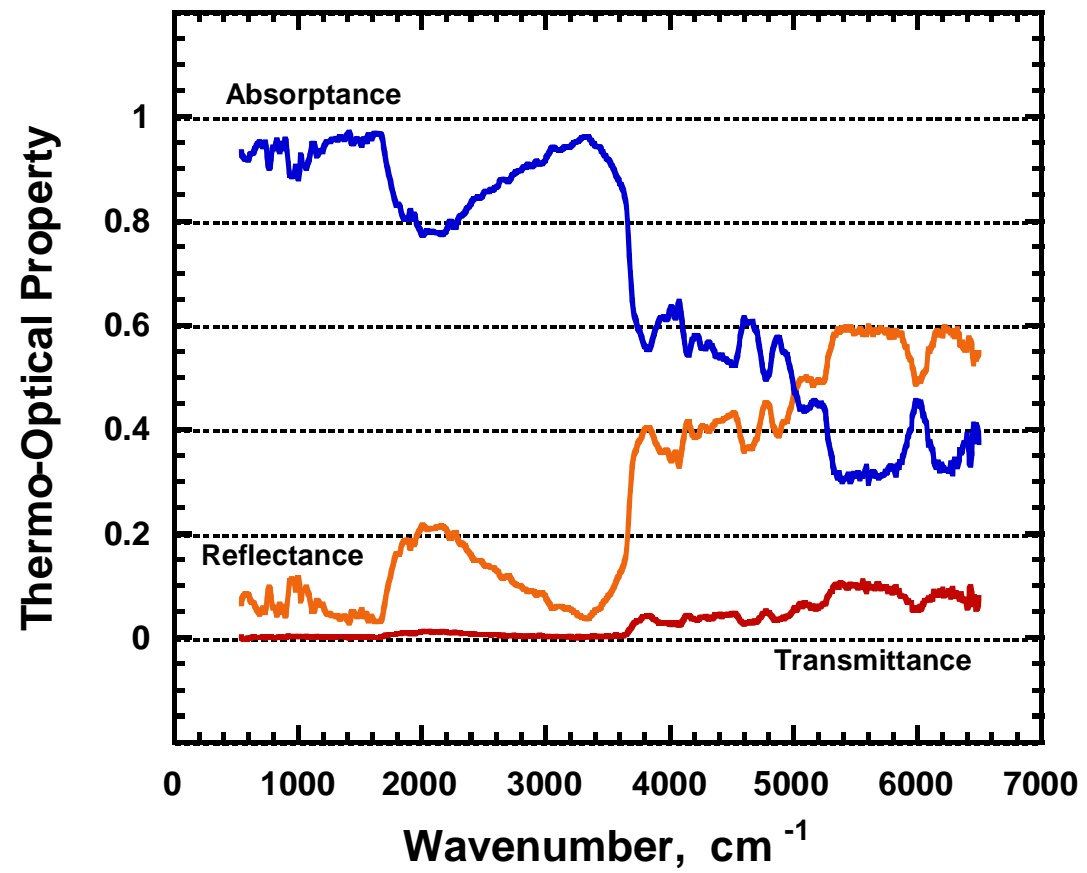

Figure 19B. Absorptance, Reflectance, and Transmittance for PBI Kevlar Kombat Material. 


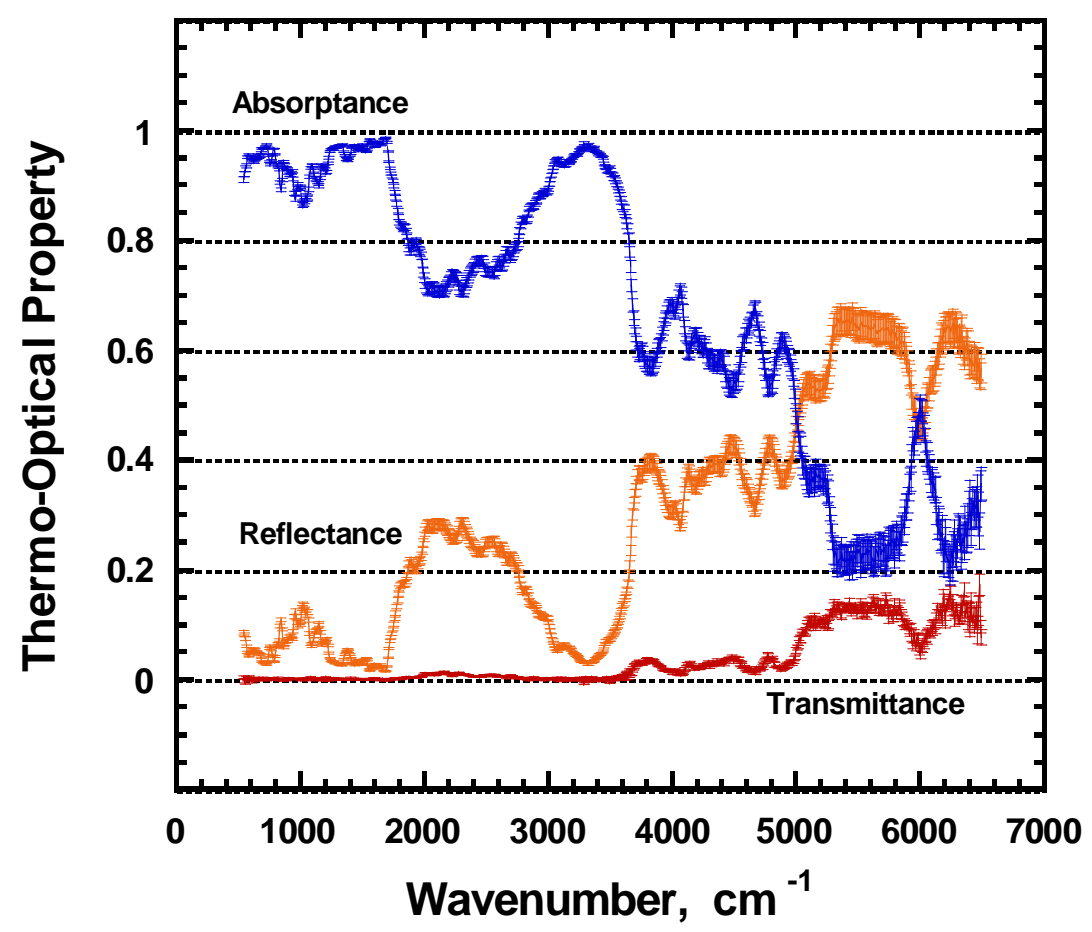

Figure 20B. Absorptance, Reflectance, and Transmittance with uncertainty bars for Front Surface of Aralite Material

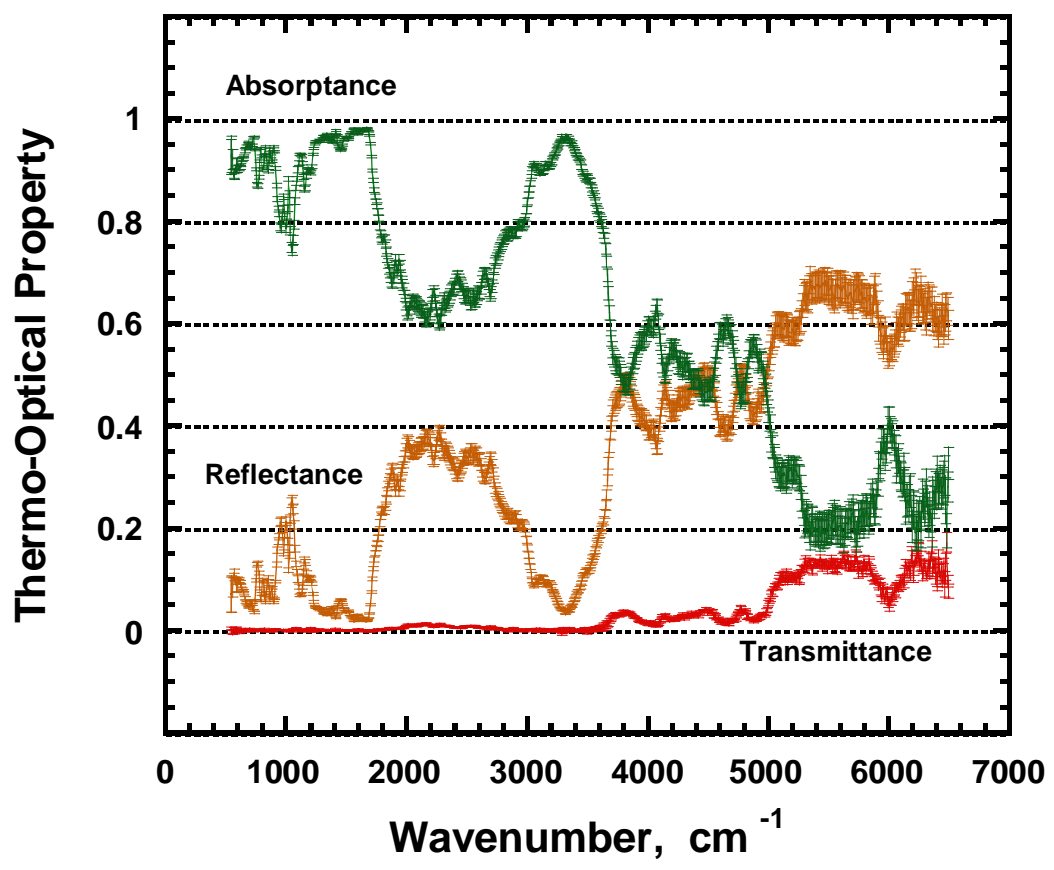

Figure 21B. Absorptance, Reflectance, and Transmittance with uncertainty bars for Back Surface of Aralite Material 


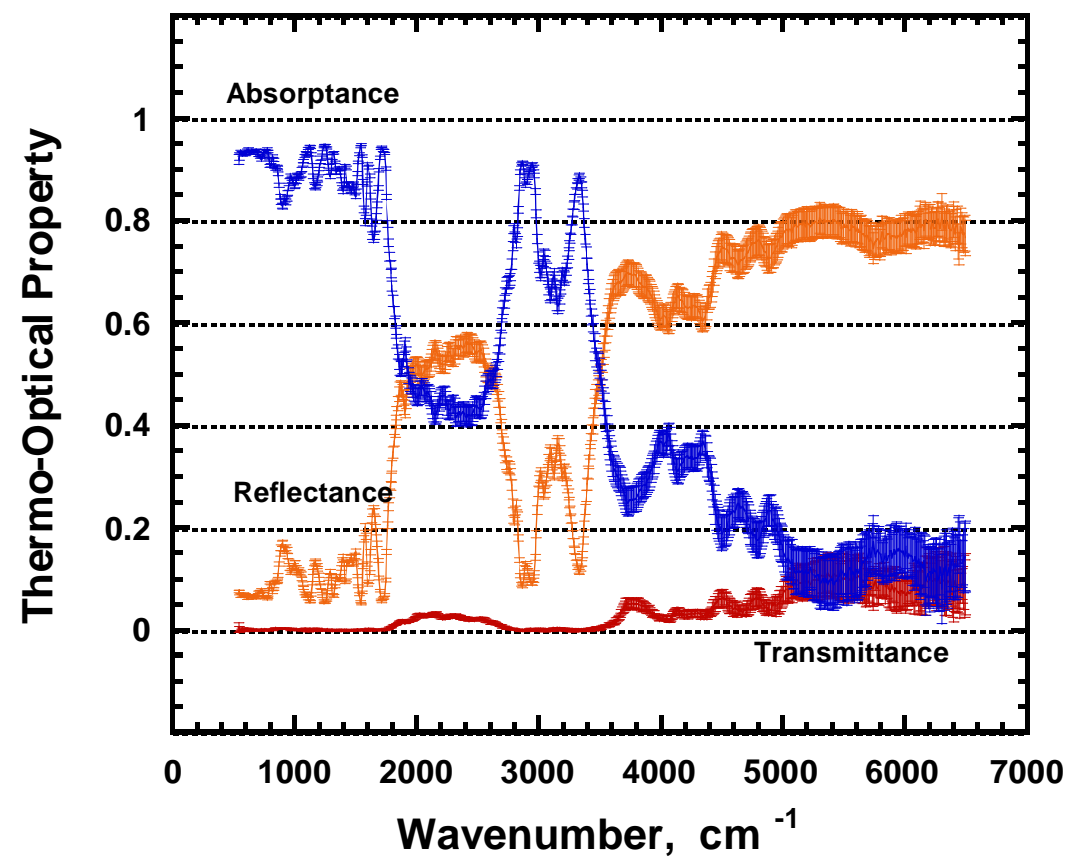

Figure 22B. Absorptance, Reflectance, and Transmittance with uncertainty bars for Front Surface of BreatheTex Material.

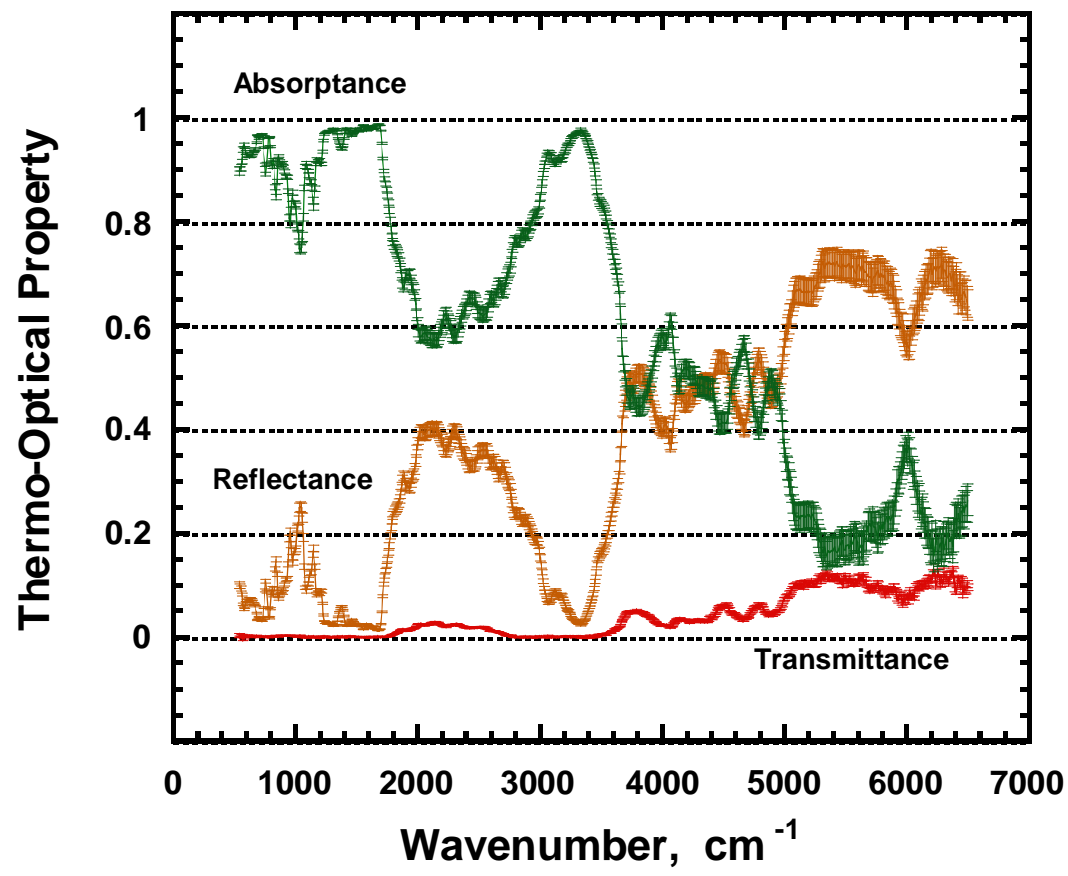

Figure 23B. Absorptance, Reflectance, and Transmittance with uncertainty bars for Back Surface of BreatheTex Material. 


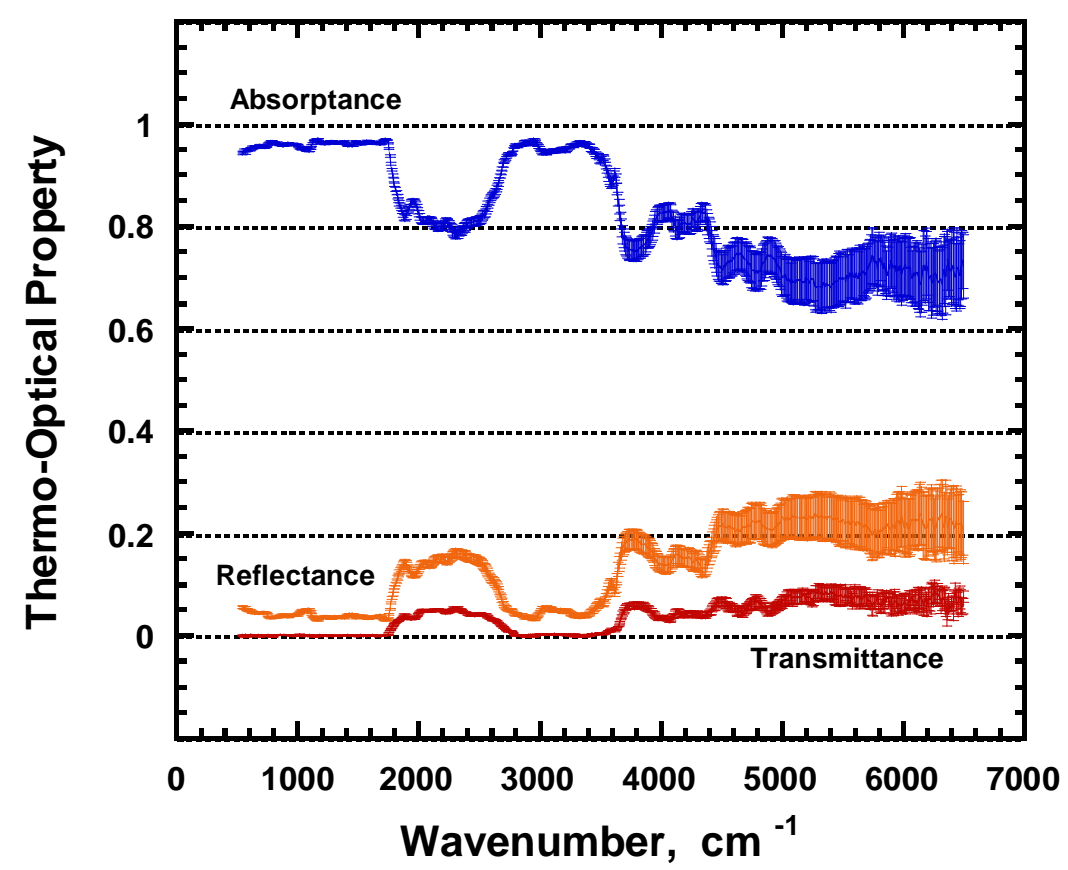

Figure 24B. Absorptance, Reflectance, and Transmittance with uncertainty bars for Front Surface of BreatheTex Plus Material.

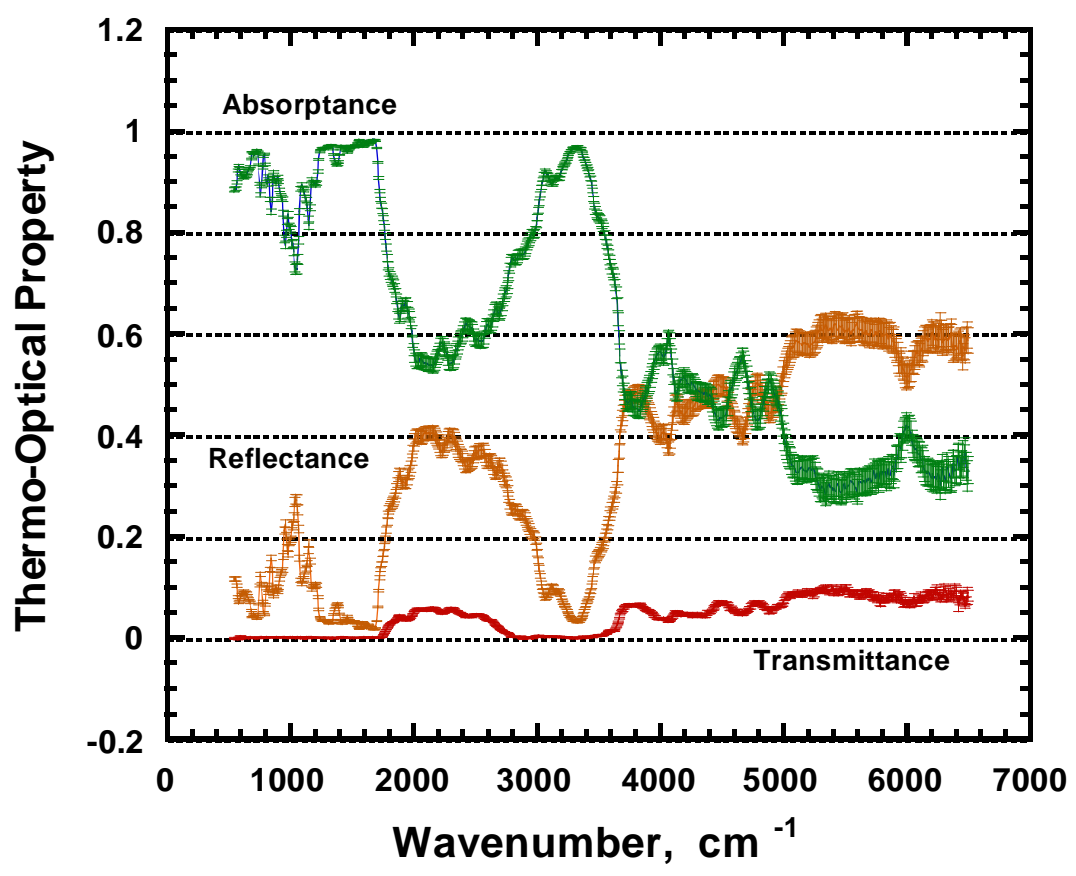

Figure 25B. Absorptance, Reflectance, and Transmittance with uncertainty bars for Back Surface of BreatheTex Plus Material. 


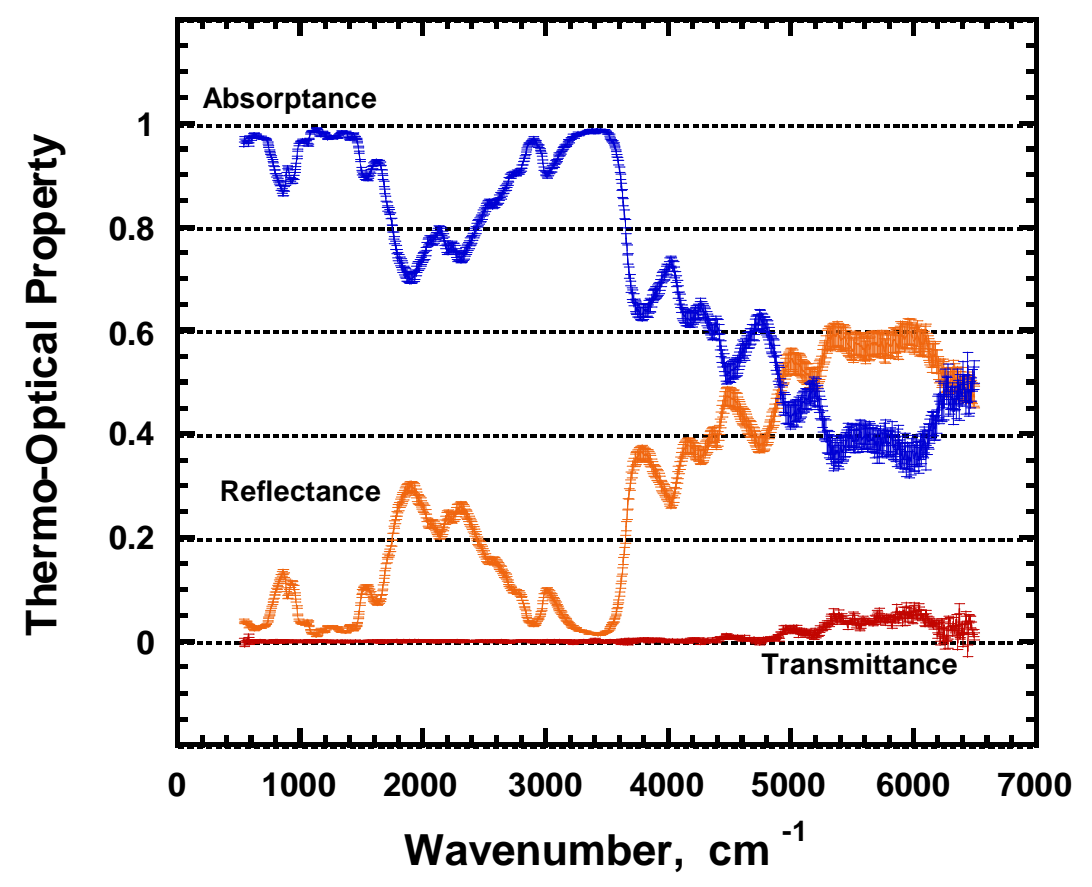

Figure 26B. Absorptance, Reflectance, and Transmittance with uncertainty bars for Cotton Duck Material.

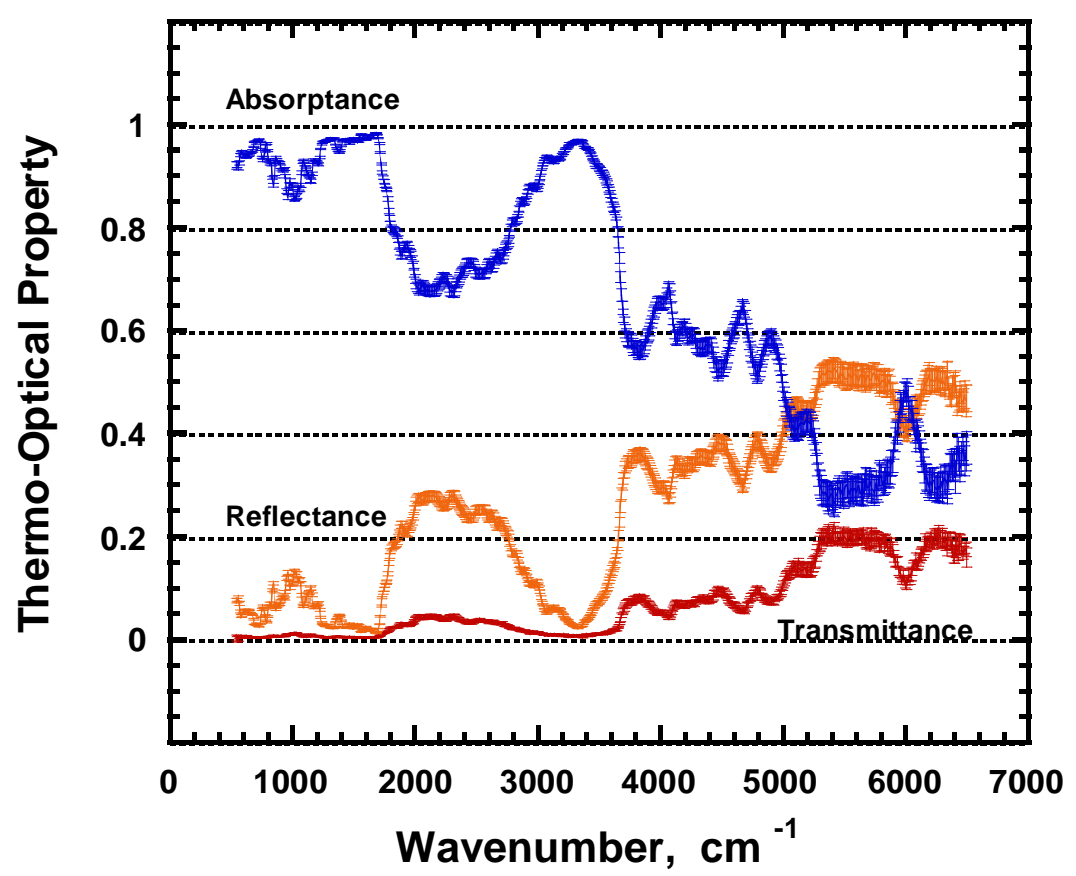

Figure 27B. Absorptance, Reflectance, and Transmittance with uncertainty bars for Nomex III Defender Material. 


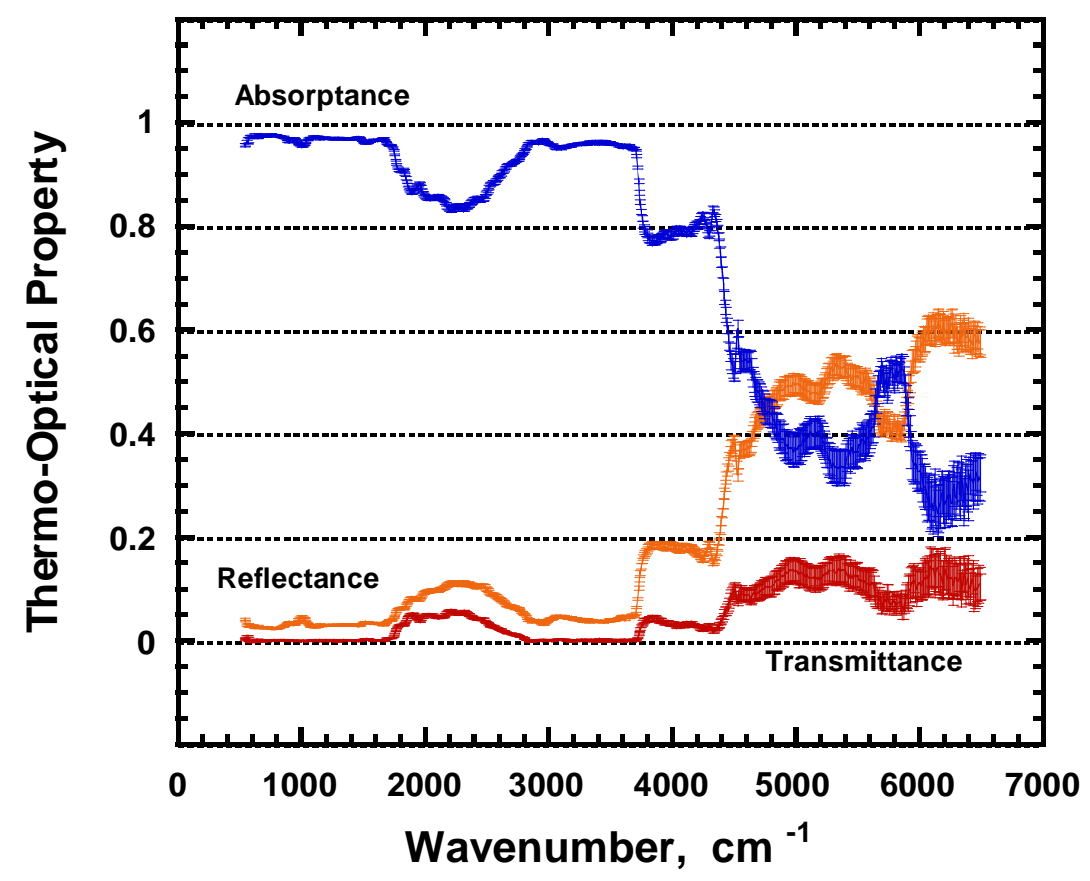

Figure 28B. Absorptance, Reflectance, and Transmittance with uncertainty bars for Front Surface of Neo-Guard Material.

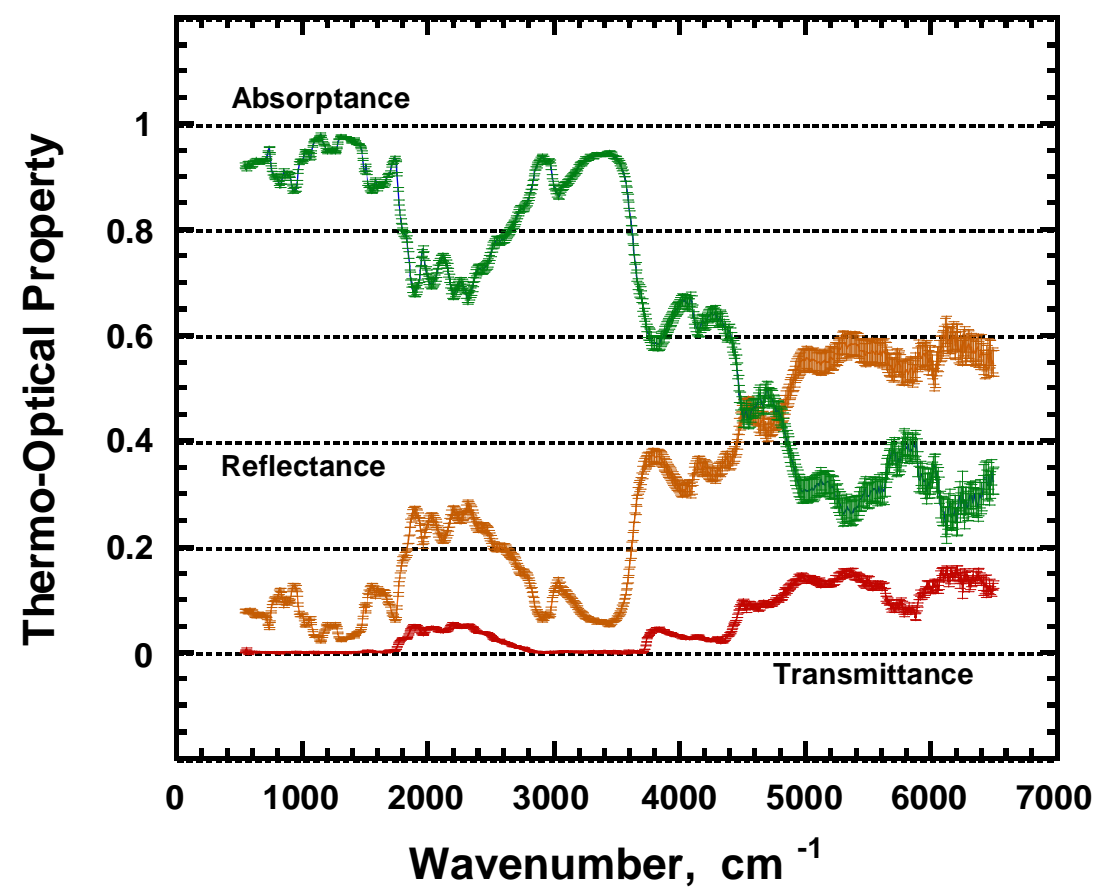

Figure 29B. Absorptance, Reflectance, and Transmittance with uncertainty bars for Back Surface of Neo-Guard Material. 


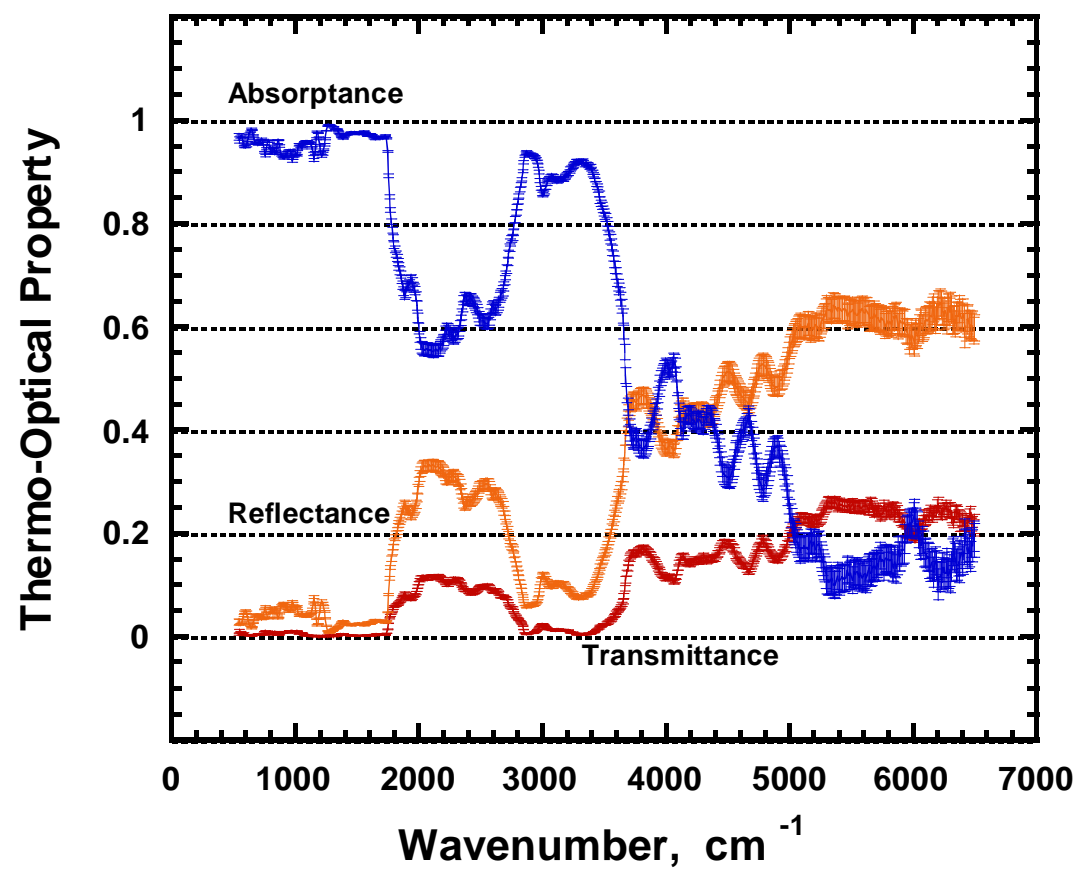

Figure 30B. Absorptance, Reflectance, and Transmittance with uncertainty bars for Front Surface of Nomex E89 Material.

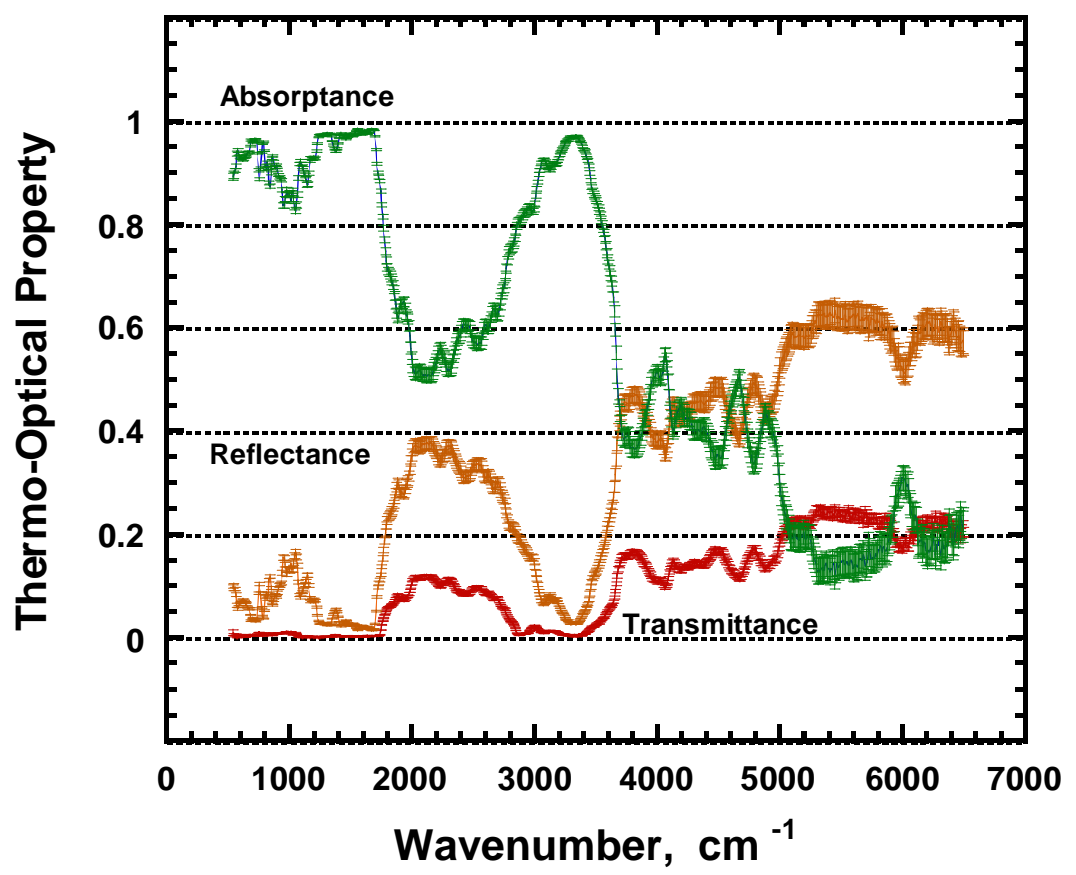

Figure 31B. Absorptance, Reflectance, and Transmittance with uncertainty bars for Back Surface of Nomex E89 Material. 


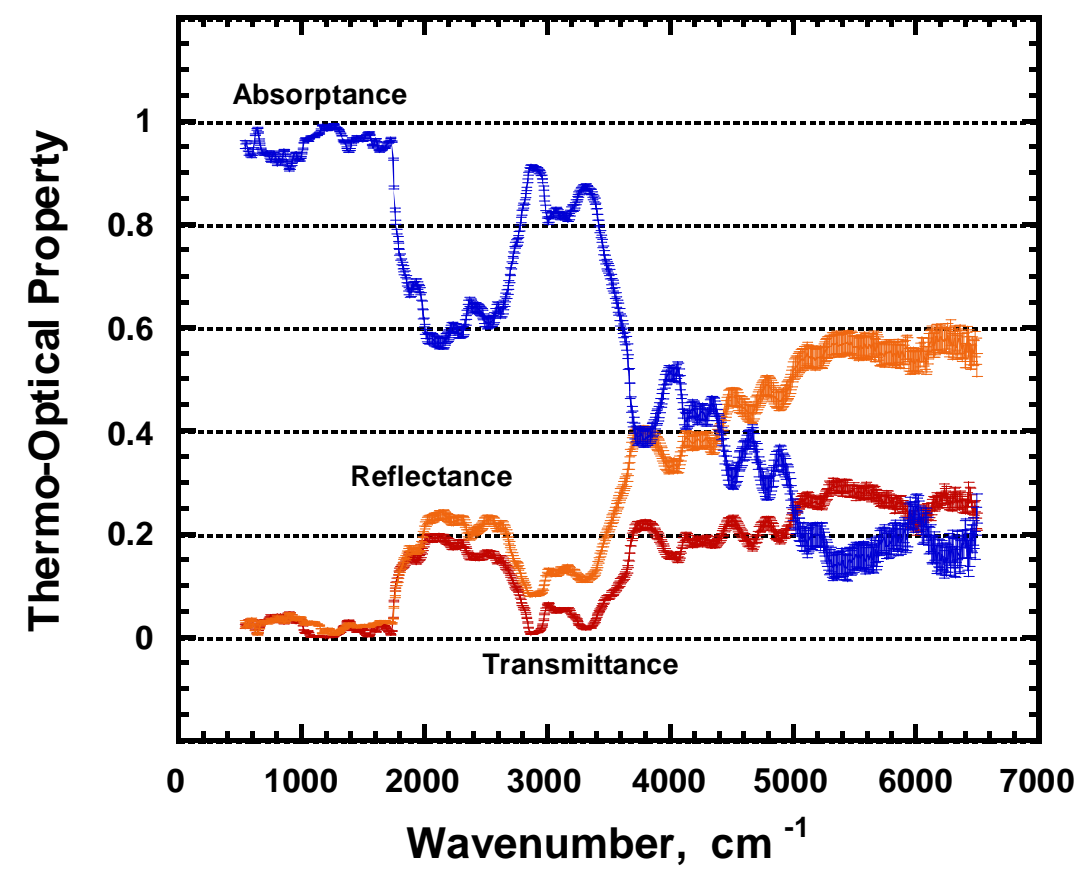

Figure 32B. Absorptance, Reflectance, and Transmittance with uncertainty bars for Front Surface of Nomex IIIA Material.

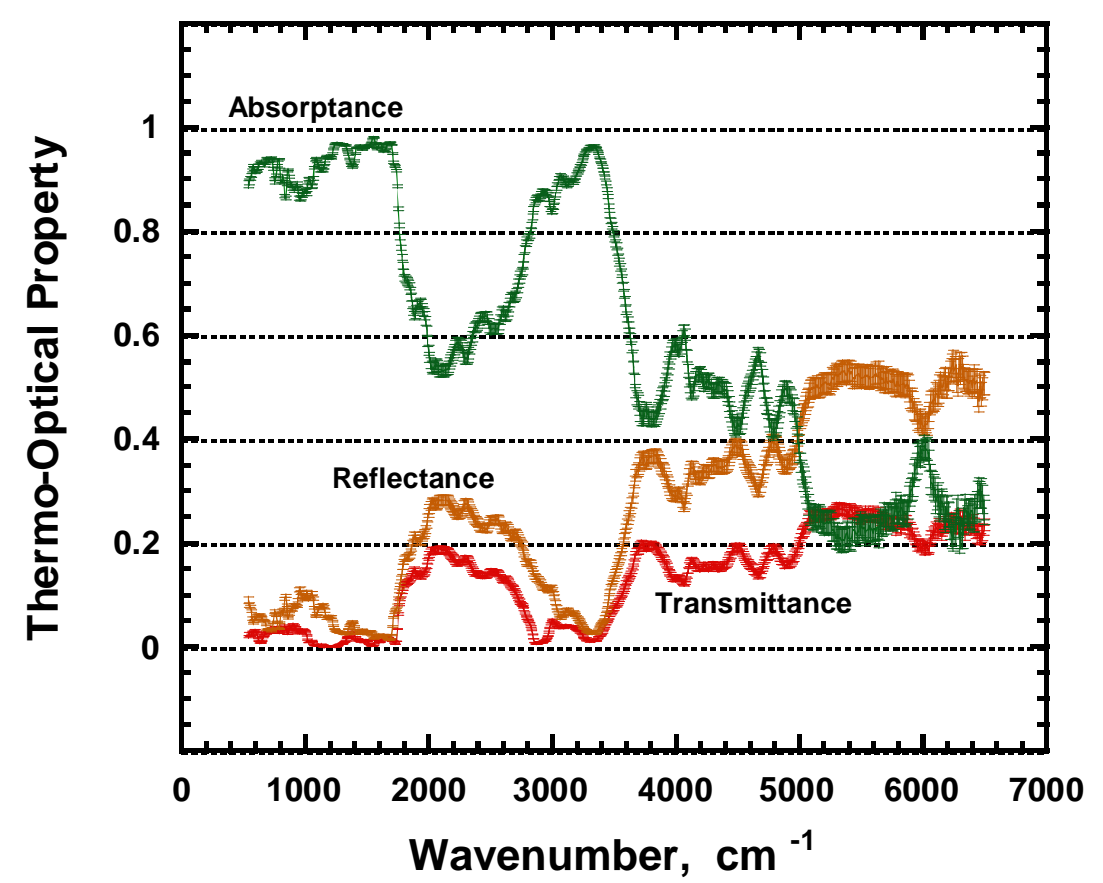

Figure 33B. Absorptance, Reflectance, and Transmittance with uncertainty bars for Back Surface of Nomex IIIA Material. 


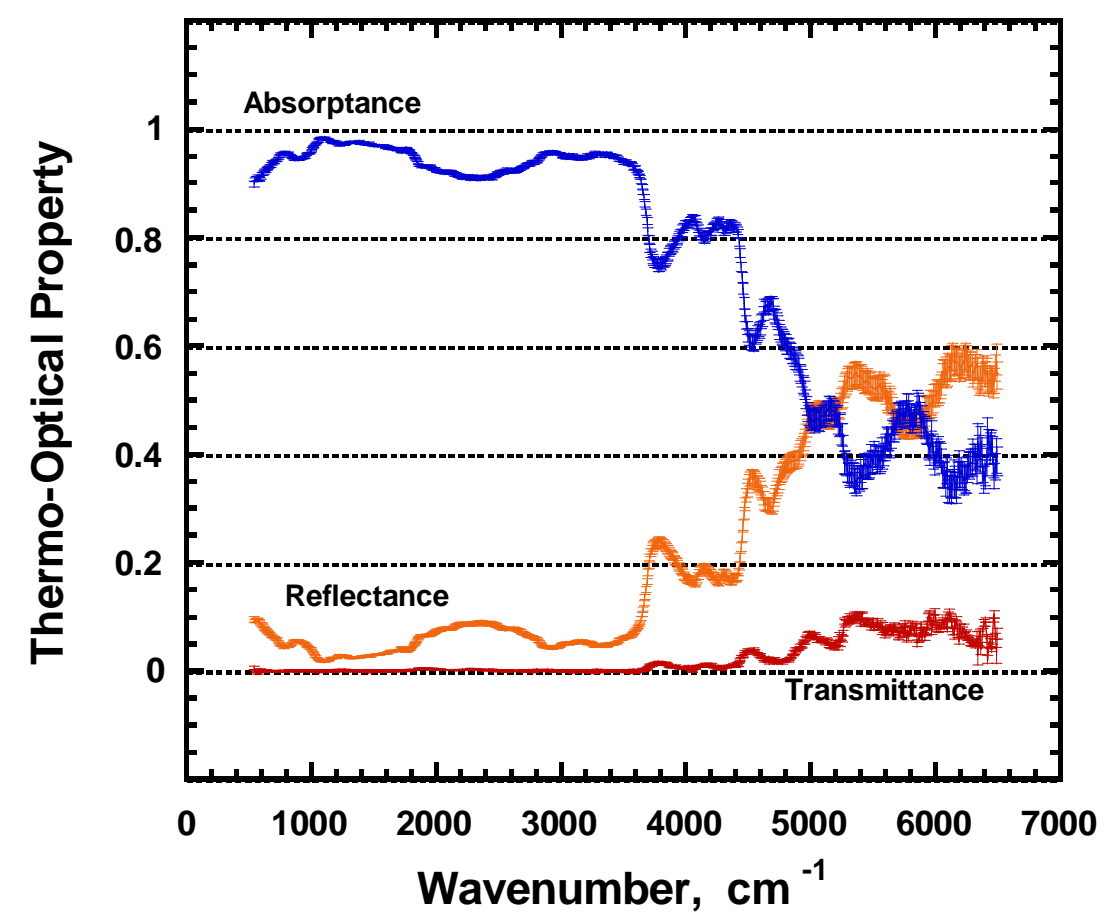

Figure 34B. Absorptance, Reflectance, and Transmittance with uncertainty bars for Front Surface of Scotchlite Orange Material.

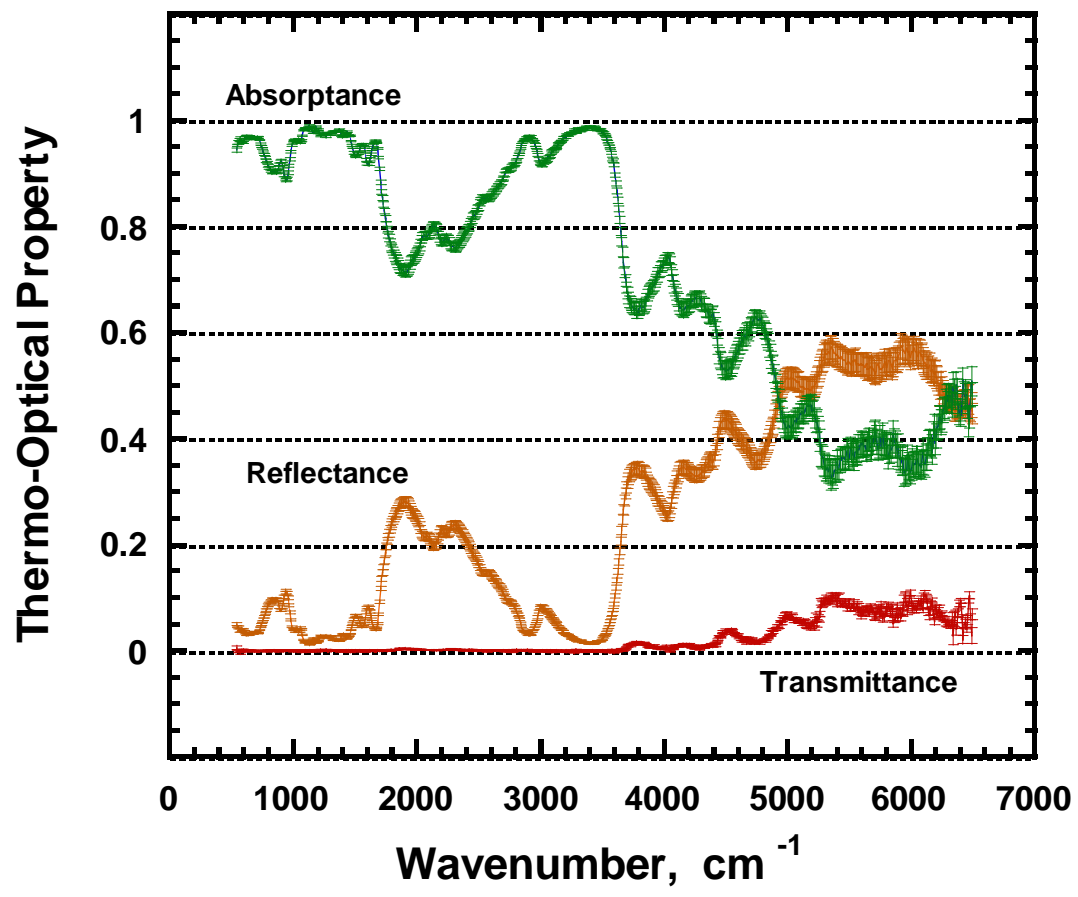

Figure 35B. Absorptance, Reflectance, and Transmittance with uncertainty bars for Back Surface of Scotchlite Orange Material. 


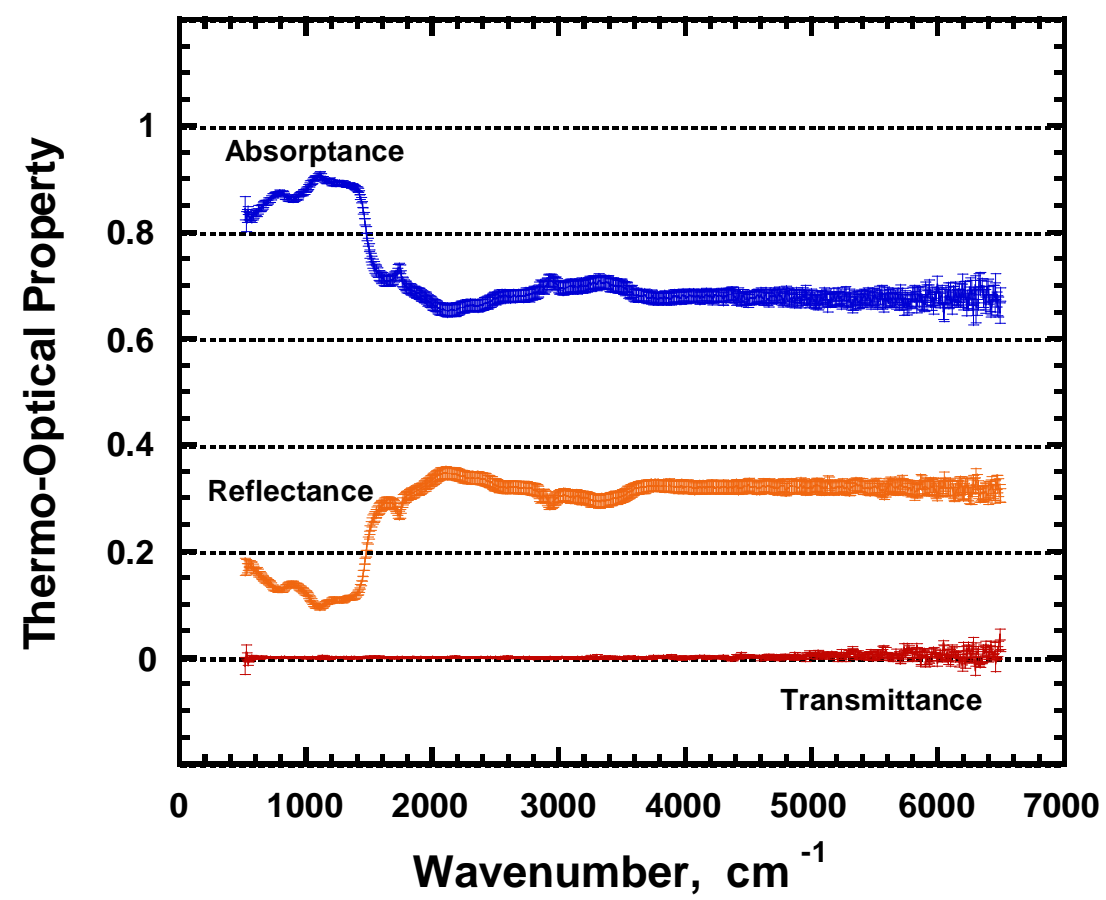

Figure 36B. Absorptance, Reflectance, and Transmittance with uncertainty bars for Front Surface of Scotchlite Silver Material.

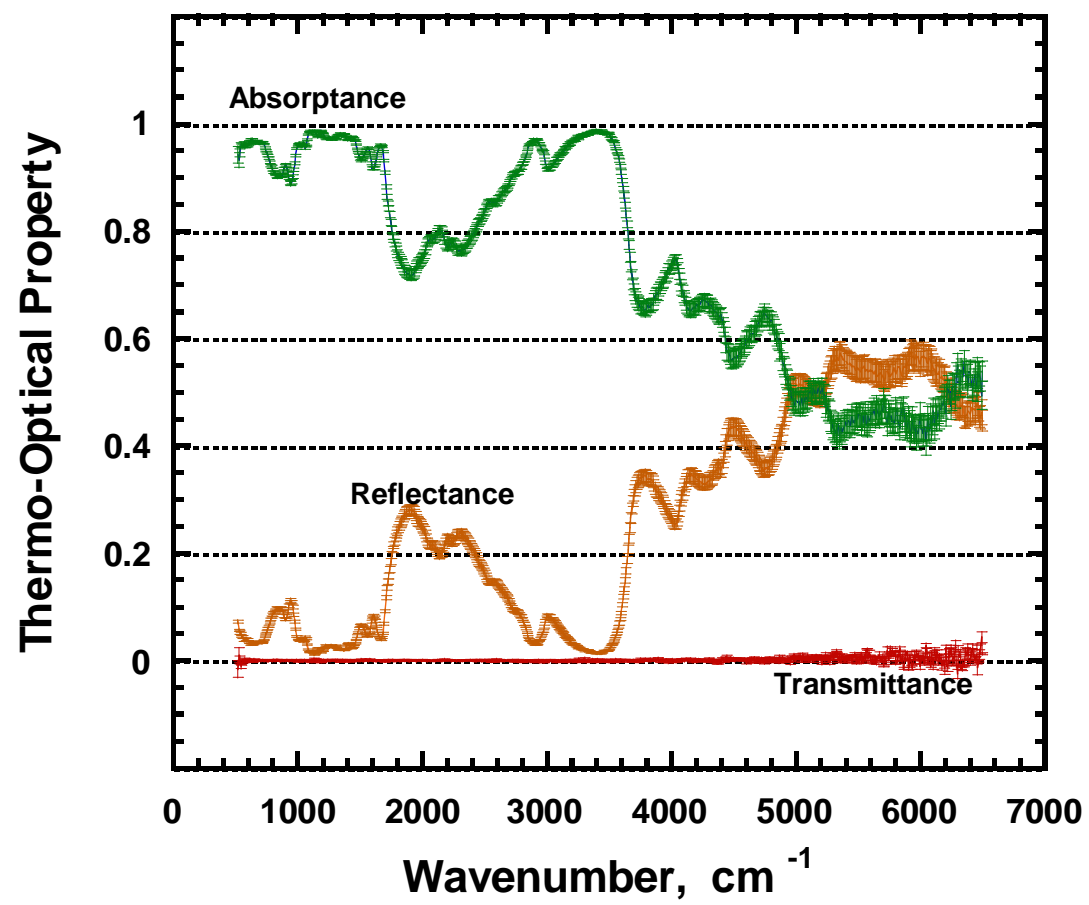

Figure 37B. Absorptance, Reflectance, and Transmittance with uncertainty bars for Back Surface of Scotchlite Silver Material. 


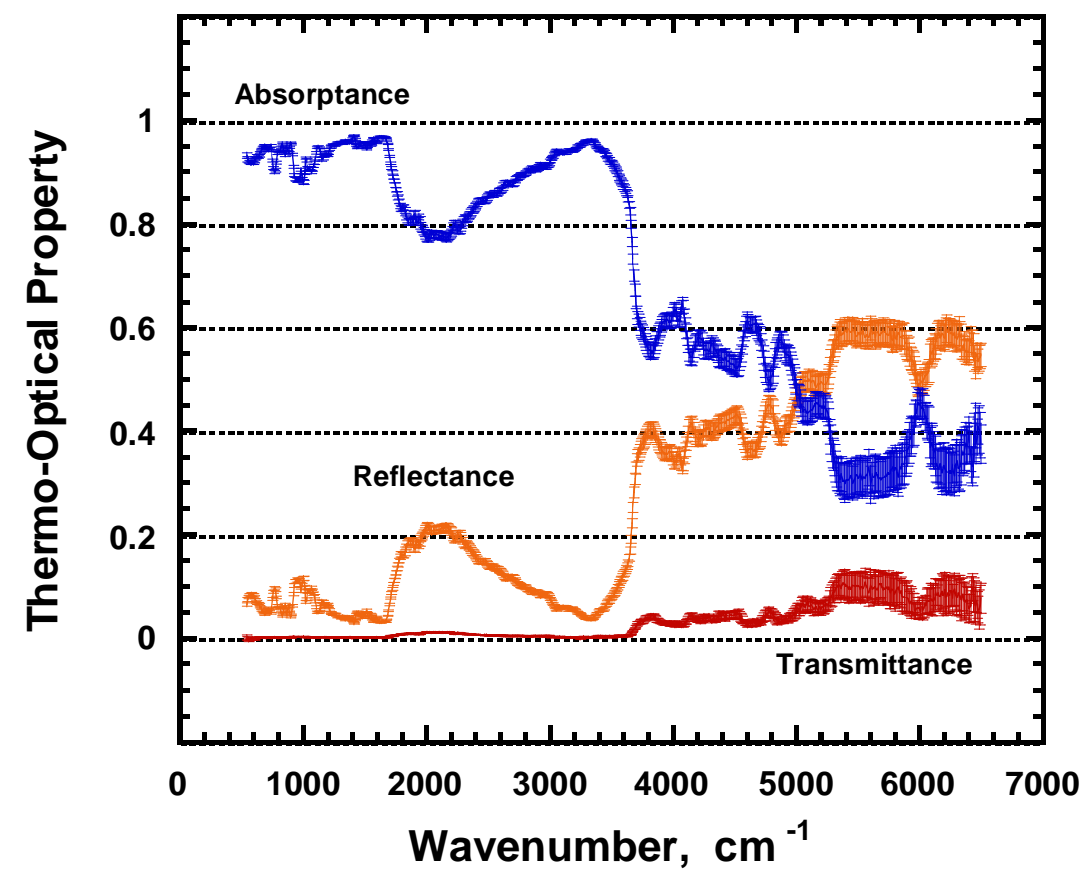

Figure 38B. Absorptance, Reflectance, and Transmittance with uncertainty bars for PBI Kevlar Kombat Material. 


\section{Appendix C}

\section{Integrated Values of Reflectance, Absorptance, and Transmittance}

Integrating the reflectance, absorptance, and transmittance over the wavenumber will make the data more useable to computer models. For absorptance and reflectance, the integration is weighted with the blackbody function at typical flame temperatures $(\sim 1400 \mathrm{~K})$ and for the emittance, the integration is weighted with the material temperature $(\sim 350 \mathrm{~K})$

The thermo-optical data (reflectance and transmittance) for each of the materials was measured at 773 different wavenumbers, ranging from $540.07 \mathrm{~cm}^{-1}$ to $6496.2 \mathrm{~cm}^{-1}$. The absorptance of the material at each of these wavenumbers was calculated from the identity $\boldsymbol{r}+\boldsymbol{t}+\boldsymbol{a}=1$, where $\boldsymbol{r}$ is the reflectance, $\boldsymbol{t}$ is the transmittance, and $\boldsymbol{a}$ is the absorptance.

To integrate the data, the wavenumbers (n) were first converted to wavelength $(\lambda)$

$$
\lambda=\frac{1}{100(n)} \quad \mathrm{n}[=] \mathrm{cm}^{-1} \quad \lambda[=] \mathrm{m}
$$

The interval between measurement points was defined as $\mathrm{d} \lambda$, and the average measured value of the thermo-optical property within this interval was considered to be the function $(f)$, where $f$ represents either the absorptance or the reflectance of the tested material.

The blackbody function, also known as Planck's Law, for total emissive power of an ideal radiator is given by ${ }^{1}$

$$
E_{b \lambda}(T)=\frac{C_{1}}{\lambda^{5}\left(\exp \left[\frac{C_{2}}{\lambda T}\right]-1\right)} \quad \frac{W}{m^{3}}
$$

where $C_{1}=3.7415 \times 10^{-16} \mathrm{~W} \mathrm{~m}^{2}$ and $C_{2}=1.4388 \times 10^{-2} \mathrm{~m} \mathrm{~K}$.

${ }^{1}$ Kreith, F. and Bohn, M. S., "Principles of Heat Transfer", Chapter 9, pp. 558. 
An estimate of the value of the spectrally, integrated thermo-optical properties, normalized by the blackbody function, is given by the ratio:

$$
\frac{\int_{\lambda_{1}}^{\lambda_{2}} f \cdot E_{b \lambda}(T) d \lambda}{\int_{\lambda_{1}}^{\lambda_{2}} E_{b \lambda}(T) d \lambda} \quad \text { [dimensionless] }
$$

where $\lambda_{1}$ and $\lambda_{2}$ are $540.07 \mathrm{~cm}^{-1}$ and $6496.2 \mathrm{~cm}^{-1}$, respectively. Using the RADCAL software ${ }^{2}$, the denominator in equation C-5 is estimated to be $69230 \mathrm{~W} \mathrm{~m}^{-2} \mathrm{sr}^{-1}$ for $\mathrm{T}=1400 \mathrm{~K}$, and $271.9 \mathrm{~W} \mathrm{~m}^{-2} \mathrm{sr}$ ${ }^{-1}$ for $\mathrm{T}=350 \mathrm{~K}$.

A summary of the weighted, integrated, normalized properties is shown in Table C-1.

\section{Uncertainty Analysis}

The uncertainty in the measured values is discussed in Appendix B. The estimated values of these uncertainties were weighted, integrated, and normalized in the same manner as the thermo-optical property measurements.

An additional uncertainty arises if the data were to be normalized to Planck's blackbody function over the entire spectrum ( for wavelengths $\lambda_{1}=0$ and $\lambda_{2}=4$ ). The data do not appear to be amenable to extrapolation beyond the spectral range in which they were measured. In the worst case, the thermooptical property values outside the measure range would drop to zero. To calculate the magnitude of the blackbody function outside the measured range ${ }^{3}$ in this case, the region from 0 to $\lambda_{1} T=0$ and from 0 to $\lambda_{2} \mathrm{~T}$ is determined,

$$
\frac{E_{b}\left(0-\lambda_{1} T\right)}{\sigma T^{4}}=\int_{0}^{\lambda_{1 \text { or } 2} T} \frac{E_{b \lambda}}{\sigma T^{4}} d(\lambda T)
$$

dimensionless

${ }^{2}$ Grosshandler, W.L., "RADCAL: A Narrow-Band Model for Radiation Calculations in a Combustion Environment", NIST Technical Note 1402, National Institute of Standards and Technology, 1993.

${ }^{3}$ Kreith, F. and Bohn, M.S., "Principles of Heat Transfer", Chapter 9, pp. 562. 
The magnitude of the fraction of the blackbody function lying in the region outside the measured range is

$$
F x\left(E_{b}, \text { outside - region }\right)=1-\int_{0}^{\lambda_{2} T} \frac{E_{b \lambda}}{\sigma T^{4}} d(\lambda T)-\int_{0}^{\lambda_{1} T} \frac{E_{b \lambda}}{\sigma T^{4}} d(\lambda T)
$$

This fraction amounts to 0.107 at $\mathrm{T}=1400 \mathrm{~K}$ and 0.225 at $\mathrm{T}=350 \mathrm{~K}$. The uncertainty associated with neglecting these portions of the spectrum has not been included in Table C-1. (Note that if the values for transmittance, reflectance, and absorptance are close to their averages in these spectral regions, the error introduced is small.) 
Table C-1 Weighted, integrated, normalized thermo-optical properties.

\begin{tabular}{|c|c|c|c|}
\hline \multicolumn{4}{|c|}{$\begin{array}{l}\text { Integrated Thermo-Optical Properties } \\
\text { (weighted and normalized by blackbody function at temperature indicated) }\end{array}$} \\
\hline \multirow[b]{2}{*}{ Material } & Reflectance & Absorptance & Emittance \\
\hline & $T=1400 \mathrm{~K}$ & $T=1400 \mathrm{~K}$ & $\mathrm{~T}=350 \mathrm{~K}$ \\
\hline Aralite (Front) & $0.236 \pm 0.00875$ & $0.643 \pm 0.00913$ & $0.714 \pm 0.00220$ \\
\hline Aralite (Back) & $0.288 \pm 0.0112$ & $0.591 \pm 0.0115$ & $0.688 \pm 0.00383$ \\
\hline Breathe-Tex (Front) & $0.437 \pm 0.0159$ & $0.439 \pm 0.0188$ & $0.672 \pm 0.00353$ \\
\hline Breathe-Tex (Back) & $0.304 \pm 0.0111$ & $0.571 \pm 0.0113$ & $0.690 \pm 0.00289$ \\
\hline Breathe-Tex Plus (Front) & $0.113 \pm 0.0140$ & $0.759 \pm 0.0146$ & $0.732 \pm 0.00156$ \\
\hline Breathe-Tex Plus (Back) & $0.294 \pm 0.0107$ & $0.575 \pm 0.0109$ & $0.679 \pm 0.00311$ \\
\hline Cotton Duck & $0.223 \pm 0.00861$ & $0.673 \pm 0.00843$ & $0.718 \pm 0.00204$ \\
\hline Neo-Guard (Front) & $0.159 \pm 0.00606$ & $0.707 \pm 0.00861$ & $0.742 \pm 0.00124$ \\
\hline Neo-Guard (Back) & $0.237 \pm 0.00873$ & $0.627 \pm 0.00897$ & $0.704 \pm 0.00229$ \\
\hline Nomex E89 (Front) & $0.268 \pm 0.00993$ & $0.545 \pm 0.0106$ & $0.719 \pm 0.00175$ \\
\hline Nomex E89 (Back) & $0.277 \pm 0.0101$ & $0.540 \pm 0.0107$ & $0.693 \pm 0.00256$ \\
\hline Nomex III & $0.215 \pm 0.00815$ & $0.637 \pm 0.00902$ & $0.708 \pm 0.00227$ \\
\hline Nomex IIIA (Front) & $0.239 \pm 0.00889$ & $0.537 \pm 0.0102$ & $0.715 \pm 0.00161$ \\
\hline Nomex IIIA (Back) & $0.221 \pm 0.00813$ & $0.570 \pm 0.00920$ & $0.693 \pm 0.00220$ \\
\hline PBI Kevlar & $0.219 \pm 0.00820$ & $0.661 \pm 0.00983$ & $0.713 \pm 0.00209$ \\
\hline Scotchlite Orange (Front) & $0.155 \pm 0.00593$ & $0.732 \pm 0.00612$ & $0.735 \pm 0.00140$ \\
\hline Scotchlite Orange(Back) & $0.209 \pm 0.00777$ & $0.678 \pm 0.00794$ & $0.721 \pm 0.00188$ \\
\hline Scotchlite Silver (Front) & $0.267 \pm 0.00974$ & $0.633 \pm 0.00986$ & $0.649 \pm 0.00414$ \\
\hline Scotchlite Silver (Back) & $0.209 \pm 0.0173$ & $0.691 \pm 0.0174$ & $0.722 \pm 0.00399$ \\
\hline
\end{tabular}

